\title{
Lithic Technology and Chronology of Initial Upper Paleolithic Assemblages at Tor Fawaz, Southern Jordan
}

\author{
Seiji Kadowaki ${ }^{1}$ (D) Toru Tamura ${ }^{2,9}$ (D) Risako Kida $^{3} \cdot$ Takayuki Omori $^{4}$. \\ Lisa A. Maher ${ }^{5}$ Marta Portillo ${ }^{6}$ Masato Hirose ${ }^{3} \cdot$ Eiki Suga $^{3} \cdot$ Sate Massadeh $^{7}$. \\ Donald O. Henry ${ }^{8}$
}

Accepted: 31 October 2021

(c) The Author(s) 2021

\begin{abstract}
The Initial Upper Paleolithic (IUP) is a key chrono-cultural concept in our understanding of the cultural and population dynamics at the transition from the Middle Paleolithic to Upper Paleolithic period. This paper presents technological and chronological analyses of lithic assemblages from a rockshelter site at Tor Fawaz in the Jebel Qalkha area, southern Jordan, to provide accurate dating and detailed recognition of the IUP variability in the Levant. We present integrated micromorphological, phytolith, and dung spherulite analyses to evaluate formation and postdepositional processes of archaeological remains through high-resolution micro-contextual studies. As a result, the Tor Fawaz assemblages show general similarity to those of Boker Tachtit Level 4, Tor Sadaf A-B, and Wadi Aghar C-D1 that represent the late phase of the IUP in the southern Levant. Based on the detailed recognition of site-formation processes, we suggest ca. 45-36 ka as the age of IUP occupations at Tor Fawaz. More specifically, the IUP occupations at Tor Fawaz and Wadi Aghar, a nearby IUP site in the same area, may represent slightly different phases that show a lithic technological trend paralleling the IUP sequence at Tor Sadaf in southern Jordan, and possibly post-date Boker Tachtit Level 4. We also discuss the issue of partial chronological overlap between the late IUP and the Ahmarian and also argue for the geographically different trends in cultural changes from the late IUP to the Ahmarian.
\end{abstract}

Keywords Initial Upper Paleolithic · Levant · Lithic technology · Chronology · Micromorphology $\cdot$ Dung and plant microfossils

\footnotetext{
This article is part of the Topical Collection on Across steppes and mountains: the Initial Upper Paleolithic in Eurasia

Guest Editors: Masami Izuho, Nicolas Zwyns and Steven Kuhn
}

Seiji Kadowaki

kadowaki@num.nagoya-u.ac.jp

Extended author information available on the last page of the article 


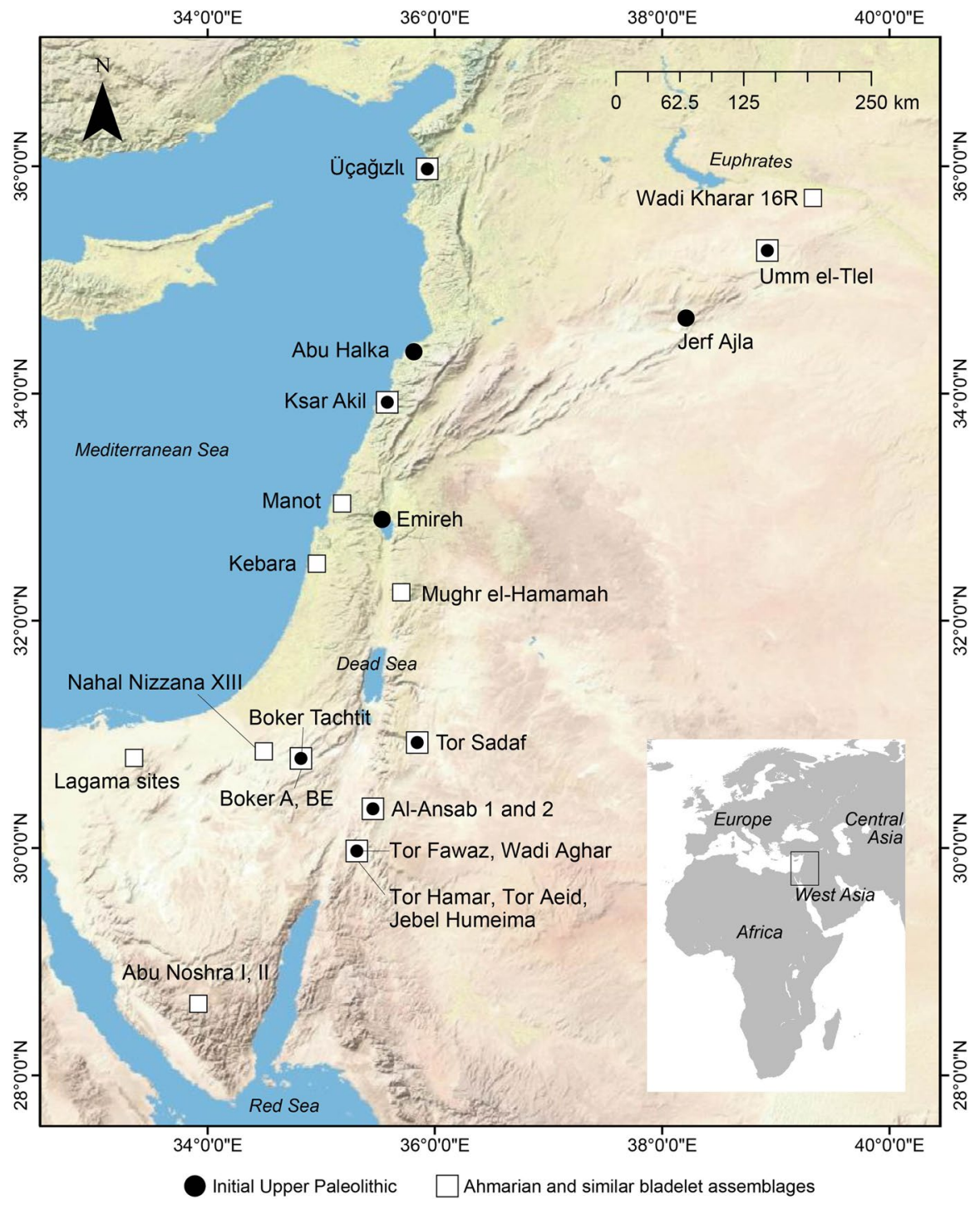

Fig. 1 Map of the Levant, showing the locations of Upper Paleolithic sites mentioned in the text

\section{Introduction}

\section{Initial Upper Paleolithic in the Levant}

The Initial Upper Paleolithic (IUP) was originally defined by Marks and Ferring (1988) to represent the latest phase of the Levantine Middle-Upper Paleolithic transition (thus, the earliest phase of the UP) that they proposed on the basis of the cultural stratigraphic sequence at Boker Tachtit in the Negev (Fig. 1). Specifically, the 
lithic assemblage from the uppermost level (Level 4) of the site was designated as the IUP. Currently, the term IUP is also applied to other assemblages (Bar-Yosef \& Belfer-Cohen, 2010a, 2010b; Kuhn, 2003; Meignen, 2012), including those that have been called UP Phase 1 (Neuville, 1951), Emiran (Garrod, 1951; Rose \& Marks, 2014; Shea, 2013), the MP-UP transition (Marks, 1983, 1993), the Bokerian (Leder, 2014, 2018), and the Paléolithique intermédiaire (Boëda, et al., 2015). Despite the varying nomenclature, the grouping of these lithic assemblages is broadly shared among the researchers. This study employs the term IUP in the broad sense.

The Levantine IUP lithics are broadly characterized by technomorphological elements of both the MP and the UP. Typologically, they are characterized by UP tool types, such as end scrapers and burins, and unique types, such as Emireh points and chamfered pieces. Blank forms are dominated by robust elongated pieces, i.e., blades and points that have broad, often faceted, striking platforms indicating hardhammer percussion (e.g., Kadowaki et al., 2019b; Kuhn et al., 2009; Marks \& Kaufman, 1983; Meignen, 2012; Ohnuma, 1988; Volkman, 1983).

The term IUP is currently used not only in the Levant but also in other regions, such as Central-Southeastern Europe and Central-North Asia to represent the earliest phase of the UP (Hublin, 2015; Kuhn \& Zwyns, 2014; Zwyns et al., 2019). One of the key issues in this continental-scale cultural phenomenon, broadly dated to ca. 50-40 ka, is its relationship to the concurrent human biogeographic phenomena that involved the geographic expansion of anatomically modern humans (AMHs) and the decline of archaic humans (e.g., Neanderthals and Denisovans) indicated by human fossil and genomic studies (Fu et al., 2014; Hublin et al., 2020).

Regarding this issue in the Levant, there are various explanations depending on how researchers evaluate the degree of cultural continuity and the roles of incoming AMHs in the cultural changes from the MP to the UP. One hypothesis regards the MP-UP cultural changes as the introduction of new cultural/behavioral patterns associated with incoming AMHs that replaced Neanderthals (Abadi et al., 2020; Bar-Yosef, 2007; Shea, 2007, 2008). Recently, some researchers have recognized both continuous and discontinuous cultural elements from the MP to the IUP and suggested autochthonous cultural development within indigenous populations with some influence of incoming groups (Abadi et al., 2020; Meignen, 2012, 2019; Rose $\&$ Marks, 2014). The latter views are congruent with an idea of coexistence of Neanderthals and AMHs in the Levant during the MP (Boaretto et al., 2021; Hovers, 2006; Hovers \& Belfer-Cohen, 2013) that lead to the formation of polymorphic populations through interaction and interbreeding (Green et al., 2010; Sánchez-Quinto et al., 2012; Fu et al., 2014; Reich, 2018; Dennell, 2020). The intensification of such social interactions, instead of a population turnover, has recently been proposed as a driver for the cultural changes from the MP to the UP (Goring-Morris \& BelferCohen, 2020; Greenbaum et al., 2019; Stutz, 2020).

Another issue regarding the IUP is its variability that does not easily allow us to treat the IUP simply as a short-term event marking the beginning of the UP. Instead, the IUP variability should be explained as manifestations of cultural phenomena taking place over millennia and wide geographic regions (Kuhn \& Zwyns, 2014; Marks \& Rose, 2012). In the case of the Levantine IUP, its geographic variability has been known for differential distributions of Emireh points and chamfered pieces 
(Garrod, 1951, 1955; Nishiaki, 2018). Diachronic changes in the IUP have also been recognized from stratigraphic records at several sites, such as Boker Tachtit (Marks \& Kaufman, 1983; Volkman, 1983), Tor Sadaf (Fox, 2003; Fox \& Coinman, 2004), Ksar Akil (Azoury, 1986; Ohnuma, 1988; Ohnuma \& Bergman, 1990), and Ücağızlı (Kuhn et al., 2009). More recently, several technological phases (Bokerian A, B, C, Jelf Ajlan, and Boker Tachtit 4) have been proposed by Leder $(2014,2016)$. He also examined the lithic variability of the IUP in relation to geographic locations, surrounding environment, on-site activities, and occupational intensity (Leder, 2018).

In order to contextualize the IUP in the cultural dynamics at the MP-UP transition, it is necessary to clarify its relationship with the late MP and the Ahmarian (Marks \& Rose, 2012). In general, most of IUP assemblages post-date the late MP and pre-date the Ahmarian. However, Boaretto et al (2021) have recently proposed that the earliest occupations at Boker Tachtit (i.e., Levels 1-3 and AH-B) and the earliest date from Wadi Aghar Layer D2, dated to ca. 50 ka (Kadowaki et al., 2019b), overlap with the reported ages of lateMP industries from regional sites (Tor Faraj and Far'ah II). From this, they suggest that late MP groups coexisted (and probably interacted) with IUP populations in the Negev ca. $50 \mathrm{ka}$ (Boaretto et al., 2021).

In addition, chrono-stratigraphic records at Kebara and Manot indicate the appearance of the Ahmarian at ca. 47-46 ka cal BP (Alex et al., 2017; Rebollo et al., 2011), preceding or overlapping the dates of the IUP occurrences at other sites, including Ksar Akil (Douka et al., 2012; Bosch et al., 2015a, 2015b), Ücağızlı (Kuhn et al., 2019), Umm el-Tlel (Boëda et al., 2015), and Wadi Aghar (Kadowaki et al., 2019b). The possible contemporaneity of the Ahmarian at Kebara/Manot and the IUP at other sites in the Levant could represent regional mosaic patterns of cultural developments that occurred at local scales (Stutz, 2020).

To provide new data relevant to the above issues, this paper presents chronological and lithic technological features of the IUP occupation at Tor Fawaz, southern Jordan. The previous studies of the site showed unique characteristics of the Upper Paleolithic assemblages (Coinman \& Henry, 1995; Kerry \& Henry, 2003), and the renewed investigation made a preliminary study of lithic assemblage and reported marine shells with interim radiocarbon dates (Kadowaki \& Henry, 2019; Kadowaki et al., 2019a). Here, we present more detailed descriptions of the lithic assemblages and present OSL and additional radiocarbon dates along with analyses of micromorphology, phytoliths, and dung spherulites to evaluate the formation and postdepositional processes through high-resolution micro-contextual studies.

\section{Research Background of the Site}

Tor Fawaz ( $29^{\circ} 56^{\prime} 49.44^{\prime \prime} \mathrm{N}, 35^{\circ} 20^{\prime} 9.03^{\prime \prime}$ E, $980 \mathrm{~m}$ a.s.l.) is one of several rockshelter sites in the Jebel Qalkha area, southwest Jordan (Figs. 1-3). The area (ca. $6 \mathrm{~km}^{2}$ ) is located at a northwestern corner of the Wadi Hisma basin, where extensive exposure of Paleozoic and Cretaceous sandstone beds are dissected by valleys flanked with many rockshelters (Rabb'a, 1987; Hassan, 1995). The investigation of Tor Fawaz was initiated by one of the authors (D.H.) as part of a long-term prehistoric project in which systematic surveys and excavations at numerous prehistoric 
sites were conducted in several study areas with different elevational, topographic, and biotic settings including the Mediterranean zone on the Ma'an Plateau, the Irano-Turanian steppe in the Judayid Basin, the Saharo-Arabian desert in the lowland of Wadi Hisma, and the Wadi Araba Rift Valley (Henry \& Beaver, 2014; Henry, 1994, 1995, 2003, 2017a, 2017b). The Jebel Qalkha area (ca. 1,000 m a.s.l.) corresponds to the lower piedmont zone and is physiographically transitional between the Irano-Turanian and the Saharo-Arabian zones. The current climate of the area is hyperarid, receiving less than $50 \mathrm{~mm}$ of annual rainfall. More detailed descriptions about the natural settings of the Jebel Qalkha are available in previous publications (Henry, 1995, 2003).

In the Jebel Qalkha area, fourteen Paleolithic sites have been investigated (Fig. 2), and a chrono-cultural scheme from the MP and UP to the Epipaleolithic periods has been suggested on the basis of technotypological studies of lithic assemblages along with radiometric dating and sedimentological correlations of cultural deposits (Henry, 1995, 1997, 2003). Since 2016, a renewed investigation has been conducted at MP and UP sites in an effort to refine the cultural-chronology and to increase human behavioral and paleoenvironmental records in the late Pleistocene (Kadowaki \& Henry, 2019). Recent results include chronological and lithic technological studies of an IUP occupation at a rockshelter site of Wadi Aghar (Kadowaki et al., 2019b). Here we present another occurrence of IUP occupation at nearby Tor Fawaz.

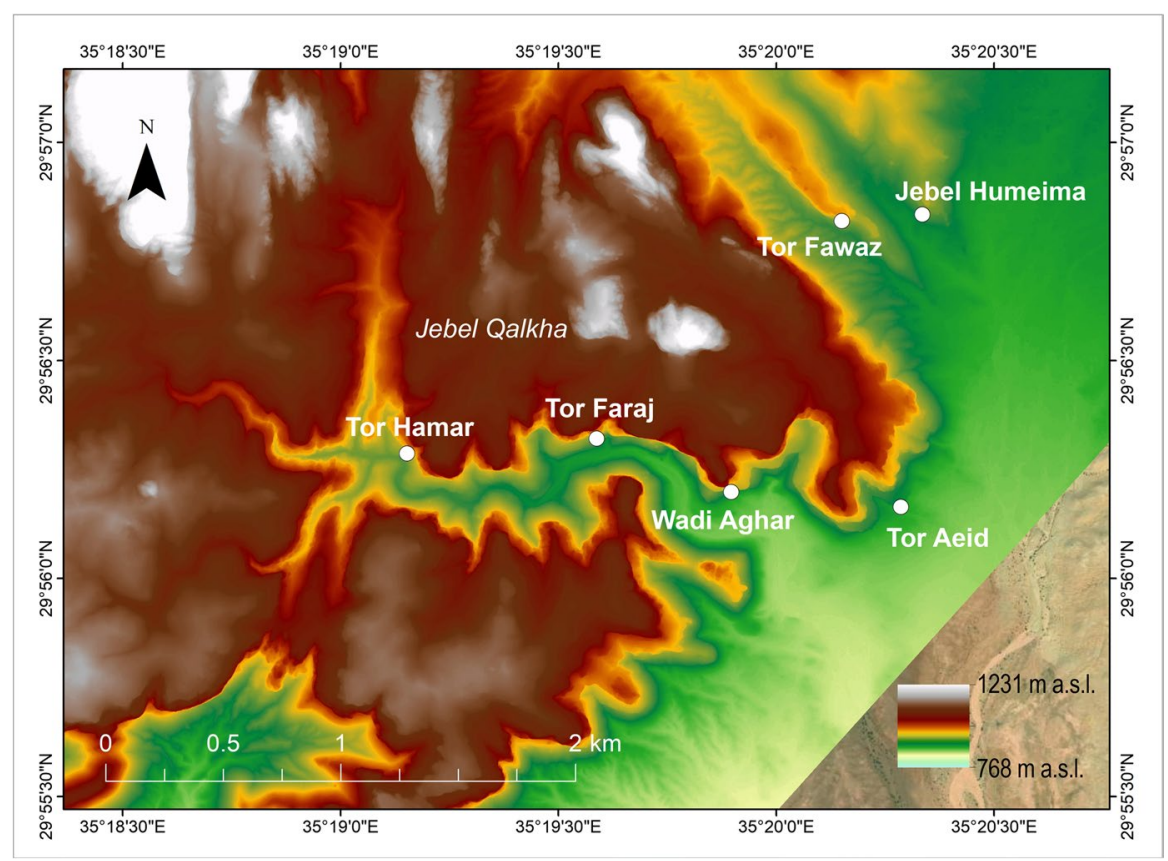

Fig. 2 Topographic map of the Jebel Qalkha area, showing the locations of Middle and Upper Paleolithic sites mentioned in the text. Late Middle Paleolithic (Tor Faraj), Initial Upper Paleolithic (Tor Fawaz and Wadi Aghar), and Ahmarian (Tor Hamar, Tor Aeid, and Jebel Humeima) 
In the initial excavation at Tor Fawaz in 1983 and 1984, five $1 \mathrm{~m} \times 1 \mathrm{~m}$ squares (Units 1-5 in Fig. 4) were opened. Units 1-4 were located outside the rockshelter on the slope, while Unit 5 was near the drip line. The excavation of Units 1-4 revealed shallow deposits (10-20 cm deep), and Unit 5 exposed a thicker deposit $(>70 \mathrm{~cm})$ of a compact light brown silt. From Units 1-5, Upper Paleolithic chipped stones $(n=3983)$ were recovered. The lithic assemblage was described as "non-Ahmarian" by Coinman and Henry (1995) due to the lack of diagnostic elements of either the Ahmarian or the Levantine Aurignacian, and they characterized it as "a blade technology that produced large, thick, bulky debitage and tools" (Coinman \& Henry, 1995: 194).

The following investigation in 1994 excavated a larger area $(3 \mathrm{~m} \times 4 \mathrm{~m})$ behind the drip-line (Figs. 4 and 5) where cultural deposits accumulated more, up to $1 \mathrm{~m}$ in thickness. The deposits were divided into five stratigraphic layers (A, B1, B2, C, and $\mathrm{D}$ from the top). Layer A is a surface deposit of loose, dark grey silt including many twigs, dung, ash, and charcoal of probably recent time periods. Layer B consists of silty deposits that grade in color from grey (B1) to tan (B2). The deposits of Layer $\mathrm{B}$ become progressively compacted with depth, underlain by Layer $\mathrm{C}$ that consists of very compact yellow silt. Yellow silt of Layer $\mathrm{C}$ is partly underlain by red sand (Layer D) resting on bedrock. This sedimentary succession matches that seen at the nearby UP site of Jebel Humeima and follows the areal stratigraphy recognized in other Jebel Qalkha sites in which the Q3 yellow silt is associated with UP horizons, whereas the Q4 red sand holds MP horizon (Henry, 1997; Kadowaki et al., 2019b).

Kerry and Henry (2003: 74) interpreted that Layers A and B represent different degrees of disturbance and reworking of Layer C because Upper Paleolithic artifacts $(n=1314)$ were recovered throughout Layers A-C. The study of the lithic assemblage from the 1994 trench in combination with the 1983/84 collection suggested unique techno-typological characteristics that do not fit a conventional scheme of UP traditions, i.e., the Levantine Aurignacian or the Early Ahmarian (Kerry \& Henry, 2003). A possible correlation of the Tor Fawaz assemblage to the IUP was mentioned by Belfer-Cohen and Goring-Morris (2003) and Goring-Morris and Belfer-Cohen (2018, 2020).

In 2016 and 2017, we conducted renewed fieldwork at Tor Fawaz to take samples for dating and to increase sample size of archaeological materials. Preliminary reports were published in Kadowaki and Henry (2019) and Kadowaki et al. (2019a), and here we show more detailed descriptions of the lithic assemblages and present new evidence from OSL/radiocarbon dates and micromorphological, phytolith and dung spherulites analyses, in order to make more thorough evaluations of the chrono-cultural characteristics of Tor Fawaz.

\section{Materials and methods}

\section{Excavation and Micromorphology Sampling}

In the 2017 season, we set up five $1 \mathrm{~m} \times 1 \mathrm{~m}$ squares (Units 6-10) to the north of Units $1-5$ that were excavated in the $1983 / 84$ season (Figs. 3 and 4 ). The area for 
Units 6-10 was selected because of the high density of lithic distributions on the surface. In addition, the area is located behind the drip line of the rockshelter and near the highest part of the slope. We expected that this location may have preserved primary deposits of archaeological remains near prehistoric activity areas. Units 6 and 10 were excavated to the depth of $30-45 \mathrm{~cm}$ below the surface (Fig. 6), while only surface finds were collected in Units 7-9.

The excavation was conducted by $5 \mathrm{~cm}$ arbitrary levels, and levels were grouped as layers according to changes in sedimentological characteristics, such as color, compactness, and grain size. Archaeological remains were collected by $5 \mathrm{~cm}$ level and by $50 \times 50 \mathrm{~cm}$ quadrat (e.g., 6a, 6b, 6c, 6d) forming a quarter of one square. All of the excavated sediments were dry-sieved with a mesh of $2 \mathrm{~mm}$. Finds from the excavation were predominantly chipped stone artifacts alongside several gastropod shells (Kadowaki et al., 2019a). The preservation of organic remains, such as bones and charcoal, was very poor, and these materials were difficult to find even under a microscope.

For micromorphological analyses, a large column of sediment (MM6) was collected from Layer C in the east section of the 1994 trench (Figs. 5, Online Resource Fig. 1). Another sediment block (MM12) was collected from the east section of Unit 6d covering Layers B and C (Figs. 6, Online Resource Fig. 2). The intact sediment blocks were each processed into six thin section slides by Nichika GeoScience Material Inc. in Kyoto Japan. Following standard thin section preparation techniques, each block was thoroughly air and oven dried, then impregnated with a clear epoxy polyester resin in a vacuum environment to remove air bubbles and,

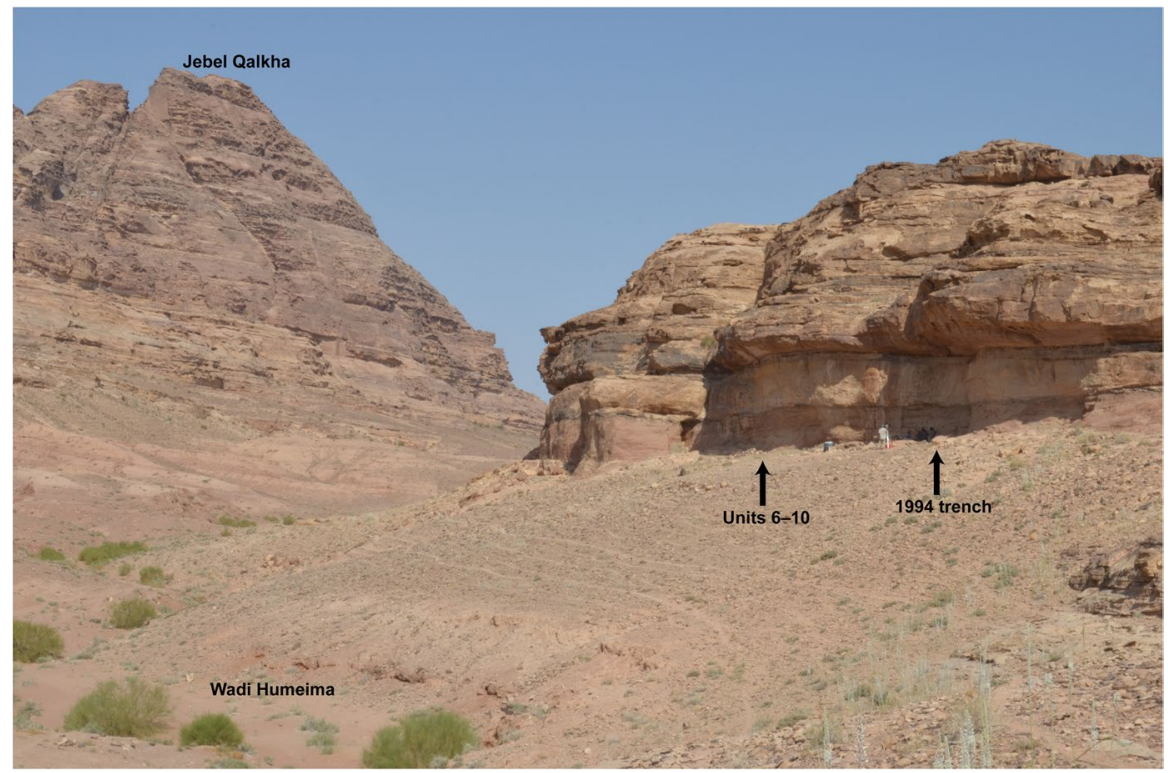

Fig. 3 Overview of Tor Fawaz, looking west towards Jebel Qalkha. Note excavation areas at the top of the slope near the shallow rockshelter 


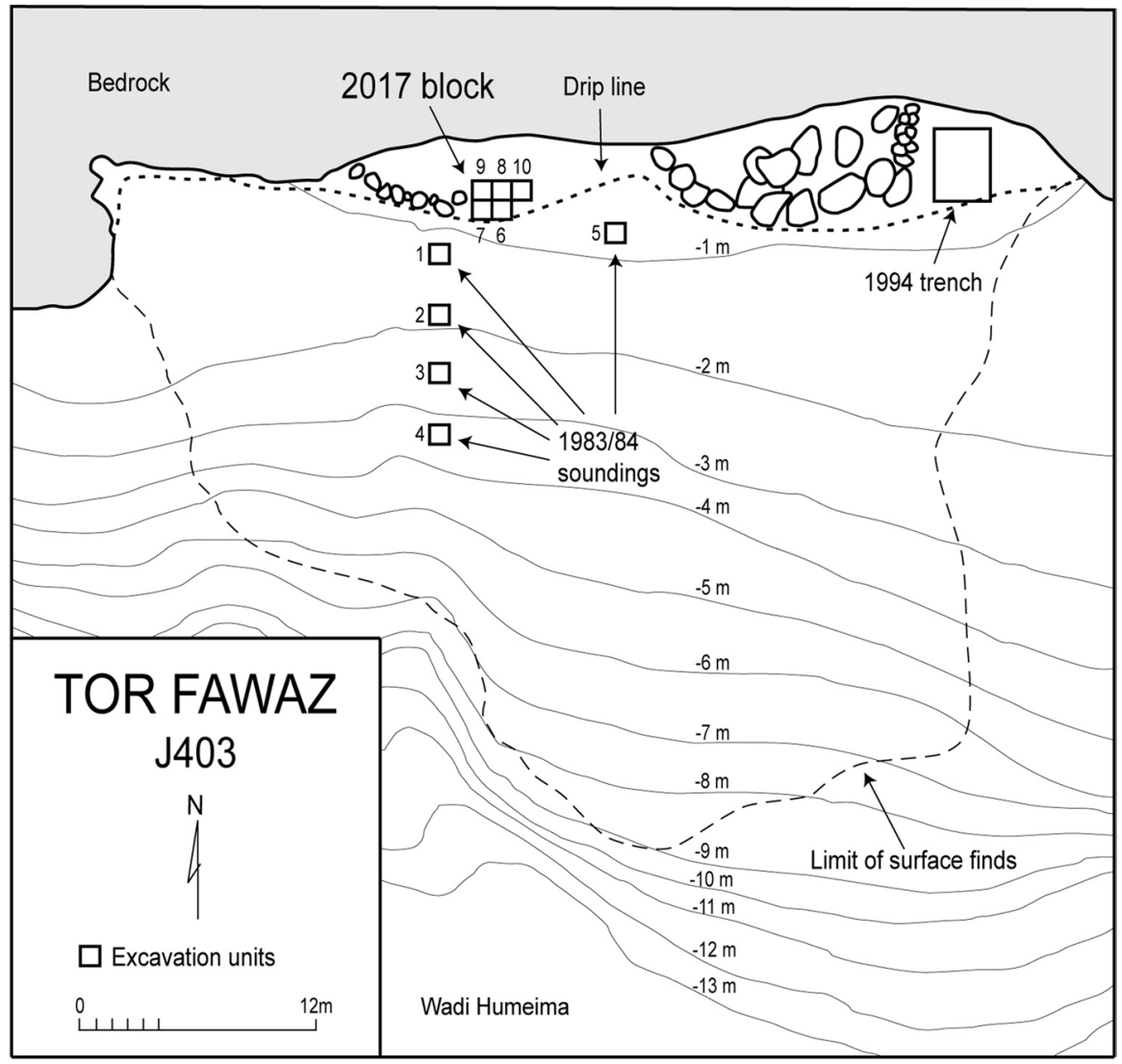

Fig. 4 Topographic map of Tor Fawaz, showing the location of excavated areas

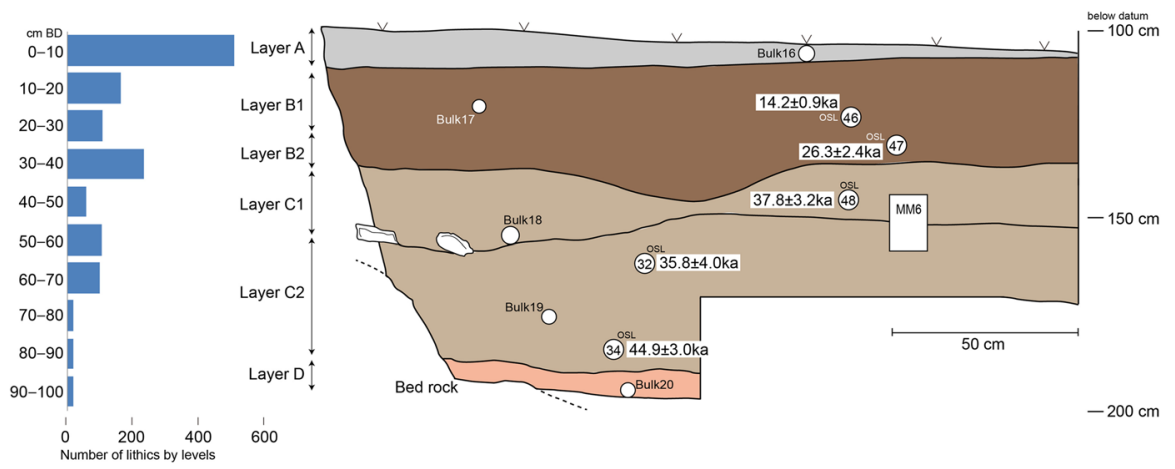

Fig. 5 East stratigraphic section of the 1994 trench at Tor Fawaz, also showing the vertical distribution of lithics and the location of sediment samples. A bar graph shows the number of lithics by 10-cm-thick arbitrary levels reported by Kerry and Henry (2003). Numbers in circles are the OSL sample \# associated with dates. Circles associated with Bulk 16-20 are spots of sediment samples for phytolith and fecal spherulite analyses. A rectangle labeled as MM 6 shows the location of a micromorphology sample 


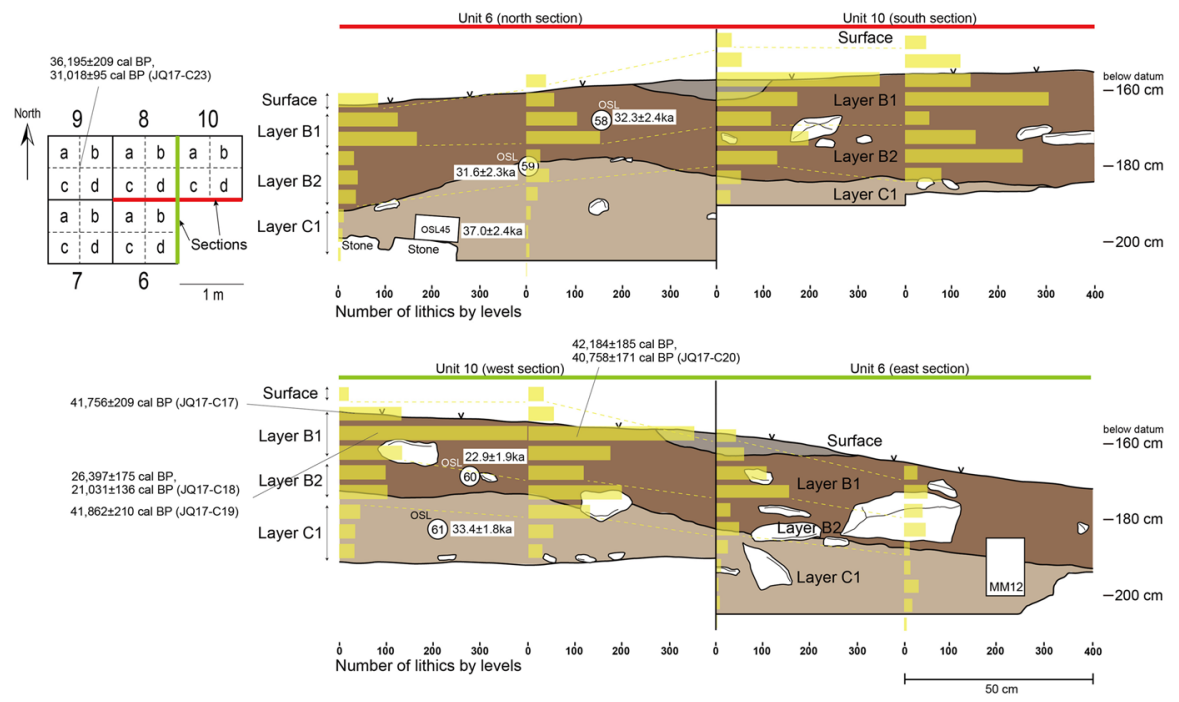

Fig. 6 Stratigraphic section of Units 6 and 10 at Tor Fawaz, showing the vertical distribution of lithics and the location of sediment samples and marine shells. Bar graph shows the number of lithics by 5-cm-thick arbitrary levels. Numbers in circles are the OSL sample \# associated with dates. A rectangle labeled as MM 12 shows the location of a micromorphology sample. The find spots of marine shells (JQ17-C17, C18, C19, C20, and C23) are indicated by their radiocarbon dates calibrated against the Marine20 curve in the OxCal v4.4.2 (Bronk Ramsey, 2009; Heaton et al., 2020)

once consolidated, prepared into thin section slides, each $30 \mu \mathrm{m}$ in thickness and $3 \times 5 \mathrm{~cm}$ in size.

\section{OSL Dating}

After the excavations of Units 6 and 10, sediment samples for OSL dating were taken by hammering light-tight plastic or metal tubes $15 \mathrm{~cm}$ long into the trench walls (Table 1). Five sediment samples for OSL dating were collected from the stratigraphic sections in Units 6 and 10 (Fig. 6). In addition, five more OSL samples were taken from the section in the 1994 trench (Fig. 5) that was reported by Kerry and Henry (2003). In total, four samples (OSL46, OSL47, OSL58, and OSL60) were taken from Layer B, while five samples (OSL32, OSL34, OSL45, OSL48, and OSL61) were collected from Layer C. Another sample (OSL59) was taken from the interface between Layer B and Layer C.

Sample preparation and luminescence measurement were done at the luminescence laboratory of the Geological Survey of Japan. Samples were prepared under subdued red light to avoid affecting the luminescence signals. Sediment within $20-25 \mathrm{~mm}$ of the ends of the tube was removed and used for measurements of water content and dosimetry. The remaining samples were processed for luminescence measurements. They were dried, sieved to extract grains of 62-90 $\mu \mathrm{m}$ diameter, and then treated with hydrochloric acid and hydrogen peroxide to remove carbonate 


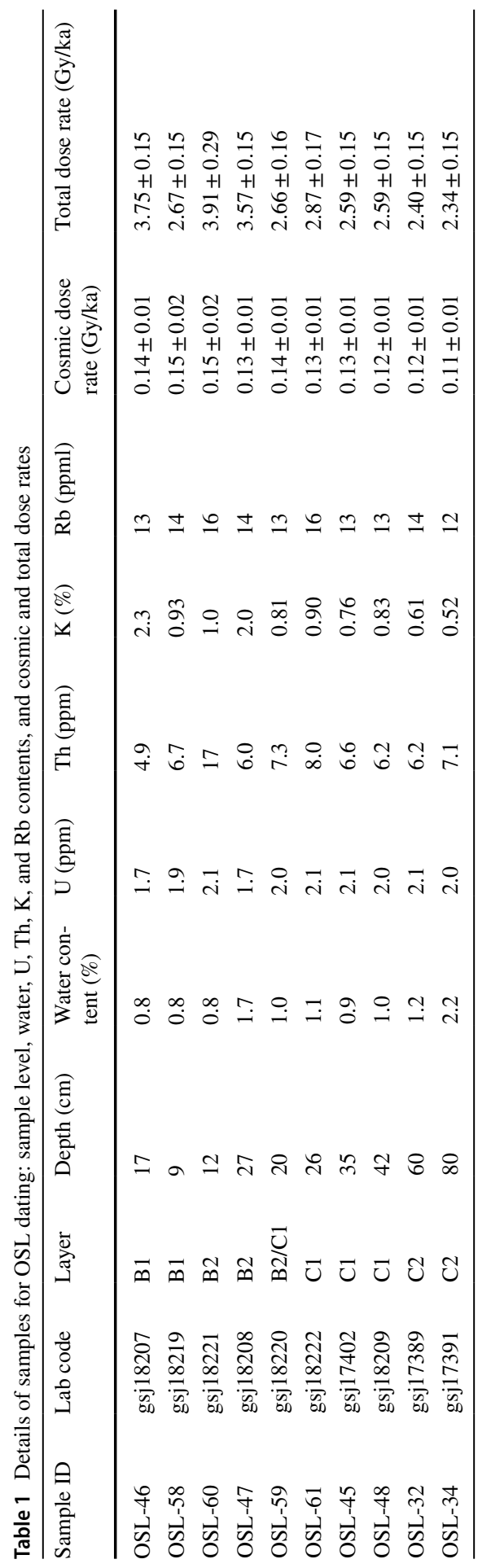


and organic matter. Quartz and K-feldspar grains were then separated using sodium polytungstate liquids of densities $2.70,2.58$, and $2.53 \mathrm{~g} / \mathrm{cm}^{3}$. The $2.53-58 \mathrm{~g} / \mathrm{cm}^{3}$ fraction was taken as K-feldspar. Quartz grains were purified by etching the fraction of $2.58-70 \mathrm{~g} / \mathrm{cm}^{3}$ in $40 \%$ hydrofluoric acid for $1 \mathrm{~h}$, followed by hydrochloric acid treatment for $1 \mathrm{~h}$. Grains were mounted on stainless steel disks to form small ( $2 \mathrm{~mm}$ in diameter) aliquots for luminescence measurements with a TL-DA-20 automated Ris $\varnothing$ TL/OSL reader equipped with blue and infrared (IR) LEDs centered on wavelengths of 470 and $970 \mathrm{~nm}$, respectively, for stimulation, and a ${ }^{90} \mathrm{Sr} /{ }^{90} \mathrm{Y}$ beta source for laboratory irradiation. For stimulation by blue and infrared LEDs, emitted luminescence through a Hoya U-340 filter, and a combination of Schott BG3 $(3 \mathrm{~mm}$ thick), BG39 (2 mm), and GG400 (3 mm) filters, respectively, was measured with a photomultiplier tube.

Preliminary measurements indicated that natural quartz OSL signals showed anomalous dependency on preheat temperature, characteristics unfavorable for dating. Therefore, only post-IR IR-stimulated luminescence (post-IR IRSL, referred to here as pIRIR) signals of K-feldspar grains were further investigated. Further details of the quartz OSL measurements are provided in Online Resource Text 1 and Online Resource Fig. 4.

The modified single-aliquot regenerative (SAR) dose protocols of pIRIR measured at $150{ }^{\circ} \mathrm{C}$ (Online Resource Table 1; Buylaert et al., 2009, 2012; Thomsen et al., 2008) after a prior IRSL at $50{ }^{\circ} \mathrm{C}$ (signal referred to as pIRIR ${ }_{50 / 150}$ ) was applied to the K-feldspar grains. This measurement temperature was selected after tests of preheat plateau and dose recovery carried out for sediments at the Wadi Aghar site, $1.2 \mathrm{~km}$ distant from the Tor Fawaz site. Bright pIRIR signals were observed for all samples (Online Resource Fig. 5). The luminescence signal was sampled every $0.1 \mathrm{~s}$ for $100 \mathrm{~s}$, and the intensity was derived from the integral of the first $2.0 \mathrm{~s}$ of signal after subtracting the average intensity during the last $20 \mathrm{~s}$ of signal. Preheat temperatures were set at $180{ }^{\circ} \mathrm{C}$ in all cases. Dose recovery was examined with bleaching experiments for sample gsj18208 (OSL-47) as follows. Six aliquots for each case were exposed to artificial sunlight for $4 \mathrm{~h}$ in a UVACUBE 400 chamber (Hönle) with a SOL 500 lamp module. After bleaching, three aliquots were dosed and then used for a dose recovery test; the remaining aliquots were used to estimate the residual dose. Dose recovery was assessed after subtracting the residual dose from the recovered dose, yielding an acceptable recovery ratio $0.95 \pm 0.03$.

$D_{e}$ were determined for eight replicates per sample with five regeneration points including $0 \mathrm{~Gy}$ and a replicate of the first regeneration point, which was used to check whether the sensitivity correction procedure was performing adequately. No aliquot showed a recycling ratio outside $1.0 \pm 0.1$. For age determinations, mean $D_{e}$ values were determined per sample by applying the Central Age Model of Galbraith et al. (1999) (Table 2). Fading tests were also carried out on aliquots measured for $D_{e}$ to determine fading rates (expressed as $\mathrm{g}_{2 \text { days }}-\mathrm{value}$ ) by following the method of Auclair et al. (2003). The environmental dose rate was determined using the DRAC of Durcan et al. (2015) based on the contributions of both natural radioisotopes and cosmic radiation (Table 1). Concentrations of $\mathrm{U}, \mathrm{Th}$, and $\mathrm{Rb}$ were measured by inductively coupled plasma mass spectrometry (ICP-MS), and concentration of $\mathrm{K}$ was by ICP atomic emission spectrometry (ICP-AES). These concentrations 
were then converted to dose rate according to the conversion factors of Adamiec and Aitken (1998). The attenuation factors used for beta and alpha rays were based on Mejdahl (1979) and Bell (1980), respectively. We used an a-value of $0.15 \pm 0.05$ (Balescu \& Lamothe, 1994). The internal K content of K-feldspar was assumed to be $12.5 \pm 0.5 \%$ (Huntley \& Baril, 1997). For water content, an error of $5 \%$ was applied to the measured value. As the excavation is located close to the rockshelter, cosmic dose rate is assumed to be $50 \%$ of the rate at an open-air site which is estimated based on Prescott and Hutton (1994) with the overburden of $1.8 \mathrm{~g} / \mathrm{cm}^{3}$. The mean $D_{e}$ values were divided by the environmental dose rate to obtain uncorrected ages. Fading corrections were performed for uncorrected ages based on Huntley and Lamothe (2001) and using the R Luminescence Package (Fuchs et al., 2015; Kreutzer et al., 2012). All dates are expressed relative to the present (Table 2).

\section{Radiocarbon Dating of Sea Shells}

Radiocarbon dating was conducted on five marine shells collected from Units 6, 9, and 10 (Fig. 6). They include three fragments of Pecten sp. (JQ17-C17, JQ17-C19, and JQ17-C20), one fragment of Conus sp. or Conomurex sp. (JQ17-C18), and one fragment of Naria sp. (JQ17-C23). Four of them (JQ17-C17, C18, C19, and C20) were found in the upper part of Layer B (Layer B1) in Unit 10 corresponding to the highest density of lithic distribution. The Naria sp. shell (JQ17-C23) was found on the surface in Unit 9 in association with abundant lithic artifacts $(n=554)$. Previously, we reported the taxonomic identification and preliminary radiocarbon dates of these shells (Kadowaki et al., 2019a). Here, we report the results of their re-dating.

The re-dating of three additional samples (JQ17-C18, JQ17-C20, and JQ17-C23) was conducted in Laboratory of Radiocarbon Dating at The University of Tokyo. Marine carbonates have contamination risks derived from recrystallisation or replacements in nature burial environments. Main polymorphs of original marine shells are magnesium enriched calcite or aragonite, but the secondary carbonate forms low magnesium calcite. Since the calcite reforming occurs with exogenous contamination and/or internally within shell carbonates, the degree of contamination cannot be evaluated quantitatively by only examining the calcite contents in the sample. However, observations of aragonite or calcite are helpful to choose appropriate pretreatment methods and to imply the quality of carbonate ${ }^{14} \mathrm{C}$ data. The calcite and aragonite in the samples were detected by X-ray diffraction, and the polymorphs composition was evaluated by the direct derivation method (Rigaku MiniFrex 600). After the sample surface was cleaned by acid etching with $\mathrm{HCl}$, if the sample mainly consisted of aragonite, the carbonate density separation method (CarDS; Douka et al., 2010) was performed to concentrate the sample originated carbonate, removing calcite residue. Finally, the pure $\mathrm{CO}_{2}$ extracted from the prepared sample was reduced to graphite for AMS ${ }^{14} \mathrm{C}$ dating. The ${ }^{14} \mathrm{C}$ measurements were performed by 0.5 MV 1.5 SDH-1 AMS system (NEC). The conversion of ${ }^{14} \mathrm{C}$ age into a calibration date was calculated by the OxCal 4.4 program (Bronk Ramsey, 2009) with the Marine 20 (Heaton et al., 2020) calibration curve. 


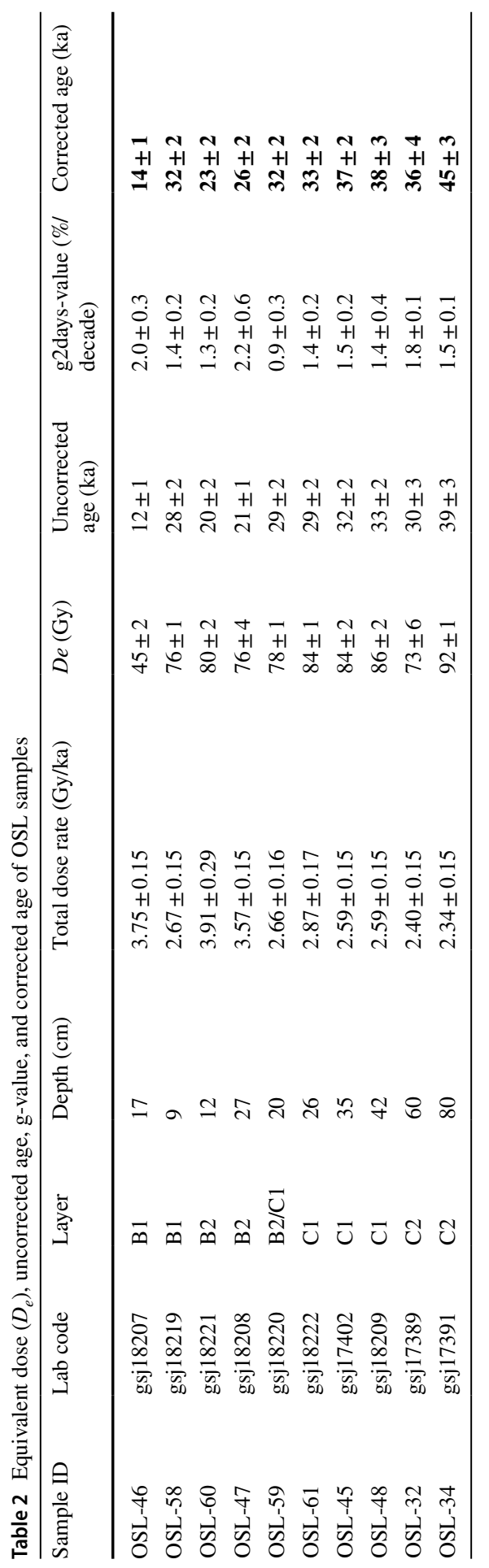




\section{Phytolith and Dung Spherulites Analyses}

Five sediment samples (Bulk 16-20) were taken from Layers A, B, C, and D exposed on the eastern section of the 1994 trench (Fig. 5). Phytoliths were extracted following the method of Katz et al. (2010). A weighed aliquot of $40 \mathrm{mg}$ of air-dried sediment was treated with $50 \mu \mathrm{l}$ of a volume solution of $6 \mathrm{~N} \mathrm{HCl}$. Phytoliths were concentrated using $450 \mu \mathrm{l} 2.4 \mathrm{~g} / \mathrm{ml}$ sodium polytungstate solution [Na6(H2W12O40)]. Microscope slides were mounted with $50 \mu \mathrm{l}$ of material. Phytoliths were examined at $200 \times$ and $400 \times$ magnification using a Leica DMEP optical microscope at the Department of Archaeology, University of Reading. Morphological identification was based on modern plant reference collections and standard literature (Albert et al., 2016; Brown, 1984; Mulholland \& Rapp, 1992; Piperno, 1988, 2006; Rosen, 1992; Twiss, 1992; Twiss et al., 1969). The terms used to describe phytolith morphologies follow the standards of the International Code for Phytolith Nomenclature 2.0. (Neumann et al., 2019).

The methods used for the calcitic dung spherulite analysis are similar to those proposed by Canti (1999). About $1 \mathrm{mg}$ of dried sediment was mounted on a microscope slide with Entellan New from Merck. Spherulites found in a known number of randomly chosen fields were counted at $400 \times$ magnification under the optical microscope with crossed polarized light (XPL). Both dung spherulite and phytolith assemblages were compared to modern reference ethnoarchaeological datasets of modern dung remains that have followed a similar quantitative approach (Tsartsidou et al., 2008; Portillo et al., 2012, 2014, 2017, 2021; Portillo and Matthews, 2020).

\section{Technotypological Analyses of Lithics}

We analyzed the lithic artifacts from Tor Fawaz according to their technomorphological classification, primarily following the scheme used in previous studies (Coinman \& Henry, 1995; Kerry \& Henry, 2003) so that the new samples can be compared. The general categories include tools, debitage, and debris. The tools principally consist of retouched tools; however, the categories of Levallois-like points and Umm el-Tlel points include both retouched and unretouched pieces.

We use the term "Levallois-like points" instead of "Levallois points" because they are likely sub-products of robust blade production from single platform cores as we discuss later (see the "Discussion" section). In other words, they are similar to points from Boker Tachtit Level 4 that were described as "pointed blades that morphologically parallel the elongated Levallois points" (Volkman, 1983).

Umm el-Tlel points are characterized by a series of small elongated scars, like bladelet scars, near the butt (Boëda et al., 2015). Multiple (up to five) elongated scars from the butt end of the points have also been reported from Boker Tachtit Levels 1-3 (Volkman, 1983).

This study has another point category "pointed flake," which is an unretouched blank form. It does not show characteristic dorsal scar patterns and has plain 
striking platforms. Thus, pointed flakes do not indicate standardized production methods, unlike Levallois-like points or Umm el-Tlel points.

All of other point types, such as el-Wad points and Ksar Akil points, are always retouched. According to the definition by Bergman (1981), both el-Wad points and Ksar Akil points are blades or bladelets pointed by abrupt or semi-abrupt retouch near the distal end, and the distinction between them is sometimes difficult, as discussed by Ohnuma (1988: 314-315). In this study, we differentiated between el-Wad points and Ksar Akil points on the basis of technomorphological features of blanks. More precisely, el-Wad points are made on bladelets with small butts (i.e., punctiform or linear platforms), while Ksar Akil points are made on blades with larger platforms.

The debris category consists of chips and chunks. Chips are flakes whose maximum length is smaller than $25 \mathrm{~mm}$, and chunks are fragmented pieces that do not clearly show ventral or dorsal surfaces. The debitage category consists of various unretouched pieces, such as flakes, blades, primary elements, core trimming elements (CTE), and cores. A blade is defined as a flake whose length is equal to or greater than twice its width. Usually, a blade also has parallel lateral sides and ridges. We employ a definition of bladelet by Tixier (1963) to be consistent with the previous study (Kerry \& Henry, 2003). A bladelet is a blade with a length $<50 \mathrm{~mm}$ and a width $<12 \mathrm{~mm}$. Primary elements are flakes or blades that have cortex covering more than $50 \%$ of their dorsal surfaces.

The identification of Levallois products is based on the Levallois flaking concept defined by Boëda (1994) and Eren and Lycett (2012). Although we identified a few Levallois-like points/blades/flakes by observing their lateral and distal convexities as well as the platforms that show large, often facetted platforms, the Levallois flaking is primarily defined by the volumetric concept and hierarchical exploitation of cores. As we describe in the "Result" section, we did not identify genuine Levallois cores or CTEs indicative of Levallois flaking, such as éclat debordant. Thus, we use the term "Levallois-like point/blade/flake."

CTEs are flakes or blades with distinctive morphologies, such as core tablets and crested pieces, which result from their detachment from specific parts of cores for the maintenance of core-surface morphology. Crested blades and core tablets follow the definitions by Inizan et al. (1999). In Tor Fawaz, we also found "half-crested blades" that have a ridge created by perpendicular flaking in only one direction (in contrast to two opposed directions in typical crested blades). We also include plunging flakes (or overshot flakes; Inizan et al., 1999) as CTEs although they may have been accidental results rather than intentional core-maintenance.

We conducted analyses by focusing on cores, CTEs, blank morphology, the production technology of blades/bladelets, and tool types. Cores and CTEs were analyzed by subdividing them according to their detailed technomorphological traits. Such traits for cores include the locations and the extent of the working surface that are related to the volumetric concepts in core exploitation.

We examined the morphological variations of blanks by focusing on the relative frequencies of several debitage categories including, flakes, blades, bladelets, Levallois-like flakes, Levallois-like blades, and convergent blanks that include Levalloislike points, Umm el-Tlel points, and pointed flakes. 
The production technology of blades/bladelets was analyzed by observing their several attributes, including (1) dorsal-distal shapes, (2) dorsal scar patterns, (3) platform types, (4) relative platform size, and (5) overhang removals. These attributes, except for the dorsal-distal shapes, have been reported in Kadowaki et al. (2021) in comparison with those of other sites in the Jebel Qalkha area, but here we re-examined the data by separating the assemblages according to the stratigraphy (Surface, Layer B1, Layer B2, and Layer C1) that pertains to the chronological discussion.

Dorsal-distal shapes are classified into four types, including convergent blanks, pointed blades, in-betweeners, and blunt blades, primarily following the scheme by Leder (2014). This attribute is a combination of dorsal shape and distal shape defined by Marks (1976). The first three types (i.e., convergent blanks, pointed blades, and in-betweeners) commonly show a tapering form. Among them, the convergent type has the greatest width at the proximal end and has converging lateral sides, thus resembling elongated Levallois points. In contrast, the pointed-blade type has parallel lateral sides with a pointed distal end. The in-betweener type has an intermediate morphology between the former two types. The blunt category includes blades with a blunt distal end. The dorsal scar patterns of blades/bladelets were classified into unidirectional, bidirectional, crossed, and centripetal.

Regarding the platform types, we followed a standard scheme by Inizan et al. (1999), but also included a category of 'partially faceted type' (Kadowaki, 2017) that has been defined by Ohnuma (1988) and Ohnuma and Bergman (2013). The partially faceted butt shows multiple facets, but it is distinguished from the multifaceted type by the location (sometimes concentration) of small facets at spots, where dorsal ridges meet the butt.

The relative platform size is defined as a ratio of the platform area (platform width $\mathrm{x}$ platform depth) to the cross-sectional area of the blank (width $\times$ thickness of the blank). The smaller the value is, the smaller the platform size is in comparison to the width and thickness of the blank. This measurement is similar to the ratio of platform width to width analyzed by Wiseman (1993).

Lastly, we examined the traces of overhang removals at the platform of blades/ bladelets. When the removal traces are present, they were divided into coarse flaking and fine flaking (or abrasion/grinding). The latter technique is known to have increased since the Ahmarian (Kuhn et al., 2009; Ohnuma, 1988).

For the above analyses of blades/bladelets, we used only complete pieces for the surface and Layer B assemblages while we also used broken pieces retaining the relevant attributes for the Layer $\mathrm{C}$ assemblage to increase the sample size.

To evaluate the patterns of the above quantitative data, we used Kruskal-Wallis test and Pearson's chi-square test according to the measurement scales.

\section{Results}

\section{Stratigraphy and the Distributions of Lithic Artifacts}

In the 2017 fieldwork, the deposits in Units 6 and 10 were excavated to the depth of $30-45 \mathrm{~cm}$ below the surface (Fig. 6). The upper deposits of ca. $30 \mathrm{~cm}$ thickness 
consisted of tan silt that resembled Layer B in the 1994 trench. The sediments became increasingly compact and lighter in color in the lower levels which were similar to yellowish silt of Layer C in the 1994 block. The deposits included sandstone rubble of various sizes (up to ca. $30 \mathrm{~cm}$ in the maximum length) throughout the excavated levels.

The archaeological finds from the deposits consisted mainly of lithic artifacts. We also collected lithic artifacts on the surface in Units 7-9. As shown in Fig. 6, lithic artifacts were most densely distributed in the upper part of Layer B (Layer B1). Although the density of lithic distribution generally decreased towards Layer C, it slightly increased in the lower part of Layer B (Layer B2). This distributional pattern partly differs from that in the 1994 trench (Fig. 5: Kerry \& Henry, 2003), where the greatest density appeared in Layer A. On the other hand, the lower part of layer B (Layer B2) commonly showed a slight increase in the density of lithic distribution.

In the re-examination of the stratigraphic section of the 1994 trench, we separated Layer $\mathrm{C}$ into the upper and lower parts (Layer $\mathrm{C} 1$ and Layer $\mathrm{C} 2$ ) because of greater compactness in Layer C2 (Fig. 5). The border between Layer C1 and Layer C2 also corresponds to a few flat-lying cobbles exposed on the section. According to this subdivision of Layer C in the 1994 trench, we correlated Layer C in Units 6 and 10 to Layer $\mathrm{C} 1$ because its proximity to Layer B2. This layer designation is consistent with OSL dates, as we describe later.

According to the above stratigraphy and lithic distributions, we defined lithic assemblages by the surface, Layer A, Layer B1, Layer B2, Layer C1, and Layer C2. Regarding the horizontal distributions of lithic artifacts, Table 3 shows the density of lithics (number $/ \mathrm{m}^{3}$ ) from the excavated units of the previous (Units $1-5$ and the 1994 trench) and renewed investigations (Units 6 and 10). The density of lithics is distinctively high in Unit 10, followed by Units 3, 2, 4, 6, 1, and 5 in the descending order. The lithic density is the lowest in the 1994 trench. Units 1-4 are located on the slope beneath the rockshelter and exposed only shallow deposits $(10-20 \mathrm{~cm})$ which are considered to represent displaced re-deposition (Kerry \& Henry, 2003). Units 6 and 10 are located within the rockshelter near the top of the slope. Given

Table 3 Density of lithic artifacts by excavation areas in Tor Fawaz

\begin{tabular}{|c|c|c|c|c|c|c|c|c|}
\hline \multirow{2}{*}{$\begin{array}{l}\text { Excavation season } \\
\text { Excavation area }\end{array}$} & \multirow{2}{*}{$\begin{array}{l}1994 \\
1994 \text { trench }\end{array}$} & \multicolumn{5}{|c|}{$1983 / 84$} & \multicolumn{2}{|l|}{2017} \\
\hline & & Unit 1 & Unit 2 & Unit 3 & Unit 4 & Unit 5 & Unit 6 & Unit 10 \\
\hline Tool & 113 & 42 & 70 & 74 & 48 & 99 & 39 & 121 \\
\hline Debitage & 369 & 219 & 408 & 413 & 282 & 337 & 641 & 1683 \\
\hline Debris & 832 & 222 & 460 & 622 & 298 & 389 & 858 & 2069 \\
\hline Total & 1314 & 483 & 938 & 1109 & 628 & 825 & 1538 & 3873 \\
\hline Volume $\left(\mathrm{m}^{3}\right)$ & $6.00^{\mathrm{a}}$ & 0.15 & 0.15 & 0.15 & 0.15 & 0.70 & 0.41 & 0.35 \\
\hline Number $/ \mathrm{m}^{3}$ & 219 & 3,220 & 6,253 & 7,393 & 4,187 & 1,179 & 3,708 & 11,123 \\
\hline
\end{tabular}

${ }^{a}$ Because the stratigraphic section in Kerry and Henry (2003) shows that only part of the 1994 trench $(3 \mathrm{~m} \times 4 \mathrm{~m}$ ) was excavated to the depth of $1 \mathrm{~m}$ below surface, the excavated volume was estimated to be a half of the cuboid trench $(3 \mathrm{~m} \times 4 \mathrm{~m} \times 1 \mathrm{~m})$ 
these locational contexts, the area around Units 6 and 10 is considered to represent the densest part of the lithic distributions at Tor Fawaz.

\section{OSL Dates}

Natural signals are well beneath the saturation level and $D_{e}$ was successfully obtained from the dose-response curve (Online Resource Fig. 5), ranging from 45 to 92 Gy (Table 2). Uncorrected pIRIR $_{50 / 150}$ ages range from $12 \pm 1$ to $39 \pm 3 \mathrm{ka}$. $\mathrm{g}_{2 \text { days }}$-values of individual samples are low and consistent (0.9-2.2\%/decade), yielding slightly higher corrected ages between $14 \pm 1$ and $45 \pm 3 \mathrm{ka}$. As shown in Table 2, corrected ages are consistent with the stratigraphic order from Layer B1 to Layer C2 with a single exception (OSL-58) in Layer B1. pIRIR signals are generally harder to bleach than quartz OSL and in some cases associated with a residual dose which leads to age overestimation. Our bleaching test for sample gsj18208 (OSL47 ) indicated a residual of $\sim 0.9$ Gy after 4-h exposure to artificial sunlight. Samples dated here are considered of aeolian origin and likely well-bleached before burial. Thus the potential residual dose for the samples should be equivalent to, or lower than, $0.9 \mathrm{~Gy}$; this leads to possible age overestimation of $<300$ years for the average dose rate of the site (c. $2.9 \mathrm{~Gy} / \mathrm{ka}$ ). Compared to the errors of individual age estimates, this possible age overestimation is negligible.

\section{Radiocarbon Dating of Sea Shells}

According to the carbonate component of modern references, the shells of Conus sp. or Conomurex sp. (JQ17-C18) and Naria sp. (JQ17-C23) consist mainly of aragonite, and the shells of Pecten sp. (JQ17-C20) are mainly calcite. The polymorphs component estimated by XRD generally agreed with the original components, indicating that the samples including JQ17-C20 had a low probability of heavy diagenetic changes, such as the exchanges of carbonate polymorphs over $10 \%$. CarDS was applied only to JQ17-C18 in which the calcite content was slightly recognized.

Table 4 shows the ${ }^{14} \mathrm{C}$ ages and calibrated dates, including the previous (Beta) and new results (TKA). The additional dates approximately supported the previous ones, but the age discrepancy appeared in each duplicate measurement. For example, the JQ17-C18 and JQ17-C23, which are mostly aragonite (99\%), were younger than the previous ages by more than 4800 years, and the JQ17-C20 sample, mostly calcite, was younger by 2500 years. Based on the results of the XRD analysis, the existence of exogenous contamination to explain the large offsets is not commensurate with the mass balance, at least in the additional analyses. Even if there is a laboratory offset, it is inconsistent with the fact that the relatively old JQ17-C20 sample, which can be easily affected by a laboratory offset, had a smaller age difference than the other two samples. In this way, it was difficult to specify the reasons for the age differences although they may have resulted from contamination influences or laboratory offset. Therefore, we accepted the previous and new data as the upper and lower limits, respectively. 


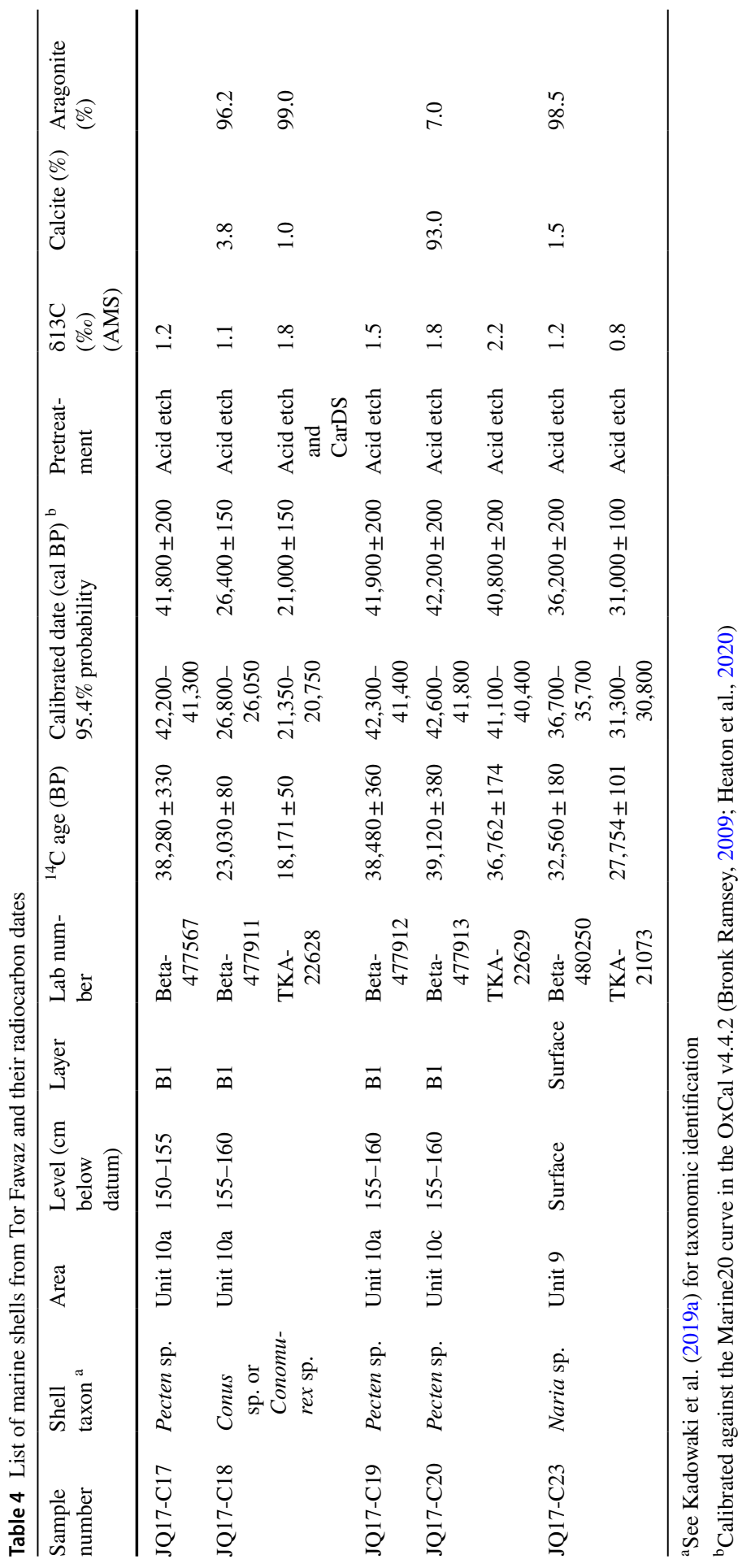




\section{Micromorphology}

Sediment block MM6 comes from the east section of the 1994 excavation trench, located at the eastern side near the mouth of the rockshelter (Fig. 5). The six slides cut from this block represent samples from the upper portion of Layer C, i.e., Layer C1 (slides 1-3) and lower portion of Layer C, i.e., Layer C2 (slides 4-6), and the transition between them (Online Resource Fig. 1). All of these sediments are primarily aeolian in origin, although there is also clear input from in situ disintegration of the local sandstone bedrock (as evidenced by 20\% sand-sized fragments of sandstone) and colluvial input. Abundant secondary carbonate impregnation and nodule formation indicate significant infiltration from water (likely a combination of seasonal rainwater and location of the trench at the dripline of the rockshelter). Mineralogically, the sediments are primarily composed of well-rounded and wellsorted medium to fine sand-sized quartz grains (30-40\%) derived from the local sandstone (Fig. 7). Sandstone fragments show iron-rich cementation of quartz sand and silt; the weathering of this sandstone and breakdown and ongoing weathering of the iron-enriched cement contributes to the reddish color of the groundmass. The quartz grains are generally embedded in the compact and dense groundmass to form a close porphyric c/f related distribution (Stoops, 2003) and intergrain microaggregate microstructure (Fig. 7).

Secondary pedogenic features are restricted in type to intrusive pedofeatures (Fig. 7c-h): (1) clay coatings around rock fragments (generally as pendants), quartz grains, and voids and (2) carbonate impregnation of the groundmass creating welldeveloped nodules and bridges between grains and clay aggregates and lining large planar voids and (3) calcite crystal growths and intergrowths in the groundmass. Typic and concentric nodules range from incipient to well-developed. In some cases, secondary calcite growth within the very fine silt and clay groundmass cemented the fine fraction to produce a consolidated, speckled birefringence. These types of pedofeatures are abundant and indicate persistent infiltration and movement of water through the sediment; occasional or seasonal inundation of the sediment with groundwater led to the formation of more invasive pedofeatures like nodule formation and crystal intergrowths.

Anthropogenic input is limited to small (fine sand to silt-sized) fragments and slivers of bone (5\%) and shell ( $<3 \%)$, and one flint flake from MM6-6 (Fig. 7a-b), and these components are more common in the Layer $\mathrm{C} 1$ slides than the Layer $\mathrm{C} 2$ slides. The bone is both burnt and unburnt (Fig. $7 \mathrm{~g}-\mathrm{h}$ ). Charcoal and ash were not identified in any of the MM6 slides. The bone fragments are embedded within the groundmass and, alongside the horizontal orientation of larger fragments (sandstone and flint), indicate that the depositional structure of the sediments in Layer C2 are largely intact with minimal reworking; the more random orientation and distribution of materials in Layer $\mathrm{C}$, and the presence of burnt bone with no evidence of charcoal or ash, suggests more extensive reworking. The boundary between Layer C1 and Layer C2 is unclear and gradual in thin section and based primarily on slightly higher quantities of microartifacts in Layer $\mathrm{C} 1$ and a greater degree of carbonate impregnation and carbonate formation in Layer $\mathrm{C} 2$. There are no obvious breaks in deposition and no visible erosional unconformities. 
Sediment block MM12 comes from the east section of Unit 6, located in the western portion of the rockshelter entrance, also near the dripline (Fig. 6). In general, the MM12 slides are more disaggregated and less dense than the samples from MM6 (Online Resource Fig. 2), where a spongy structure and macroscopic and microscopic laminations are visible in Layer B2 (lower part of Layer B). Slides MM12-1 to MM12-3 (top) are from Layer B2, while MM12-3 (lower) to MM12-6 are from Layer C1. Like MM6, these slides are all dominated by quartz sand and silt (30-40\%) and fragments of sandstone (5\%) embedded within a reddish-brown silty clay groundmass (Fig. 8). The distinction between Layers B2 and C1 are visible in the degree of carbonate impregnation, abundance of anthropogenic input, and overall microstructure; however, these differences are generally in magnitude or degree of expression of features, rather than in content. As with MM6, these slides represent largely aeolian processes with secondary carbonate formation related to water infiltration and subsurface movement.

The Layer B2 slides are composed of well-sorted and well-rounded (and extensively weathered) coarse silt and sands-sized grains of quartz and fragments of sandstone that exhibit a double-spaced porphyric coarse/fine related distribution and vughy to granular microstructure (Fig. 8). While there are no clear orientation and distribution patterns in the coarse components, including the anthropogenic materials, the abundance of calcium carbonate within the groundmass gives the fabric a speckled to crystallic birefringence. Anthropogenic input includes small shell fragments (sand-sized, 5\%), highly fragmented charcoal (5\%), fine slivers and fragments of bone (5\%; Fig. 8e-h), and very fine ash. However, there is no evidence of in situ combustion features. There is also 5\% amorphous organic tissue throughout these slides that may relate to the other clearly anthropogenic material. Like MM6, the highly fragmented and randomly distributed and oriented nature of the anthropogenic material embedded in the groundmass suggests it has been partially reworked or redeposited.

There are also differences in slides MM12-1, MM12-2, and MM12-3 (from Layer B2) as the sediments grade gradually into Layer C1. MM12-1 contains more anthropogenic material (especially shell, amorphous organic tissue, charcoal, and ash rhombs), extensive clay coatings around quartz grains (not around voids). MM12-2 exhibits a higher quartz silt content (and more extensive weathering of quartz grains) and more, larger sandstone fragments, a denser groundmass, and better-developed secondary carbonate features (layered nucleic nodule formation and coatings around voids). MM12-3 exhibits many large sandstone fragments, many with pendants of carbonate or clay coatings, and extensive carbonate impregnative pedofeatures. These differences correspond to macroscopic layering of the sediment in Layer B2 that may result from successive slopewash or colluvial events, each causing the reworking and fragmentation of microartifacts.

The Layer C1 slides are very similar to those from MM6; calcitic secondary pedofeatures (nodules, crystal growths, impregative features) are common and increase with depth from MM12-4 to MM12-6 (Fig. 8a-d). These slides, however, have no charcoal or ash, no flint microflakes, and only the rare occurrence $(3 \%)$ of very small fragments of bone. Taken together with the MM6 slides, Layer $\mathrm{C} 1$ represents continuous, ongoing aeolian activity-both erosion 
and deposition-such that the accumulation of sand is persistent but slow. The highly variable degree of weathering of quartz sand and silt derives from the combination of erosion of local sandstone and input from windblown sediment. Water movement through the rockshelter, especially at its entrance, and likely episodic during the rainy seasons (and perhaps also sometimes inundating), has kept vegetation growth at a minimum (voids related to plant root casts are rare), but secondary calcite features are very common. The rate of deposition increased during the accumulation of Layer B2, formed by a combination or alternation of aeolian processes and colluviation, and the comparative decrease in the expression of secondary carbonate features suggests less water input. There is little difference in the content of anthropogenic material between Layers B2 and C1, with the exception of ash and charcoal being more prominent in Layer B2. Given the proximity $(0-30 \mathrm{~cm})$ of Layer B to the ground surface, recent use of the rockshelter may have also contributed to less compact, more disaggregated and spongy Layer B. The range of OSL dates are consistent with long-term, continuous but slow accumulation of these deposits over time, producing a wide range of dates for the sediments in Layers C and B and consistent with the repeated deposition and reworking of the deposits over an extended period of time.

\section{Phytolith and Dung Spherulite}

Phytoliths were noted in all samples (15,000-270,000 phytoliths/g sediment, Table 5), whereas dung spherulites were only noted in the upper layers (Layer A and Layer B1). The richest sample by far corresponds to the topsoil (Layer A) including animal dung (sample 16; 0.8 million spherulites/g sediment; Table 5), which showed also high phytolith concentrations, mainly produced by dicotyledonous leaves (Fig. 9a; Table 6). This is noteworthy given that dicotyledonous plants are minor producers of phytoliths. These microfossil associations are suggested to derive from herbivorous fecal matter showing a diet that is either based on or includes a component of dicotyledonous leaves (García-Suárez et al., 2021a, 2021b; Macphail et al., 1997; Portillo et al., 2019, 2020; Rasmussen, 1993). Both microfossil abundances decrease dramatically in Layer B1 (sample 17; below 30,000/g sediment; Table 5), where associations suggest a similar composition also dominated by dicotyledonous phytoliths (Table 6), that may relate to animal dung, likely infiltration from Layer A, as noted by the excavators in the field.

Lastly, sediments from Layer C1 (sample 18) and Layer C2 (19) yielded 16 phytoliths in total, whereas only 4 phytoliths were noted in sample 20 from Layer D and whereas dung spherulites were completely absent in these layers (Table 5). These assemblages are dominated by wood/ bark, as well as the leaves and culms of monocotyledonous plants, which are not diagnostic of any particular grass subfamily (Table 6). These plant materials possibly relate to anthropogenic remains; however, the general low microfossil amounts along with phytoliths weathering limit what can be said of these occupations. 


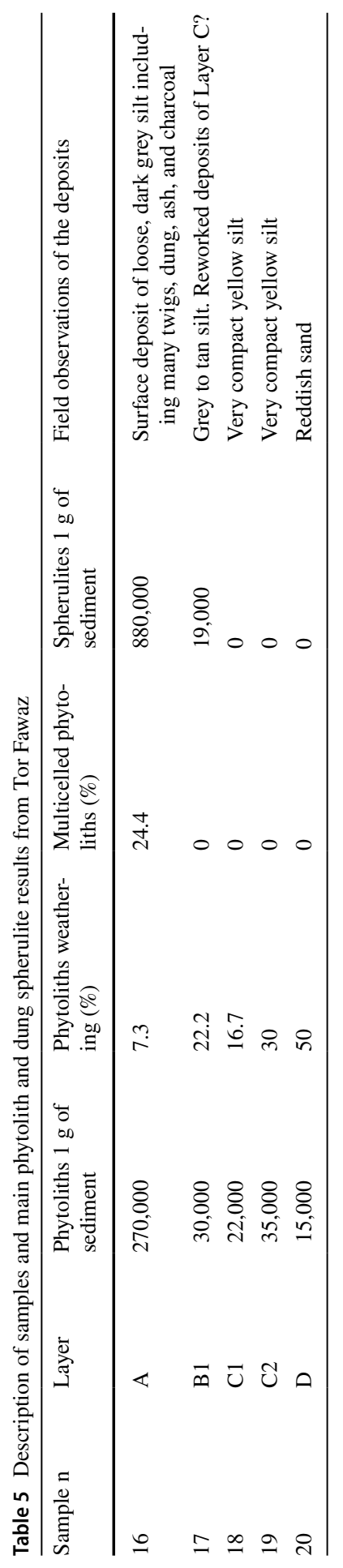



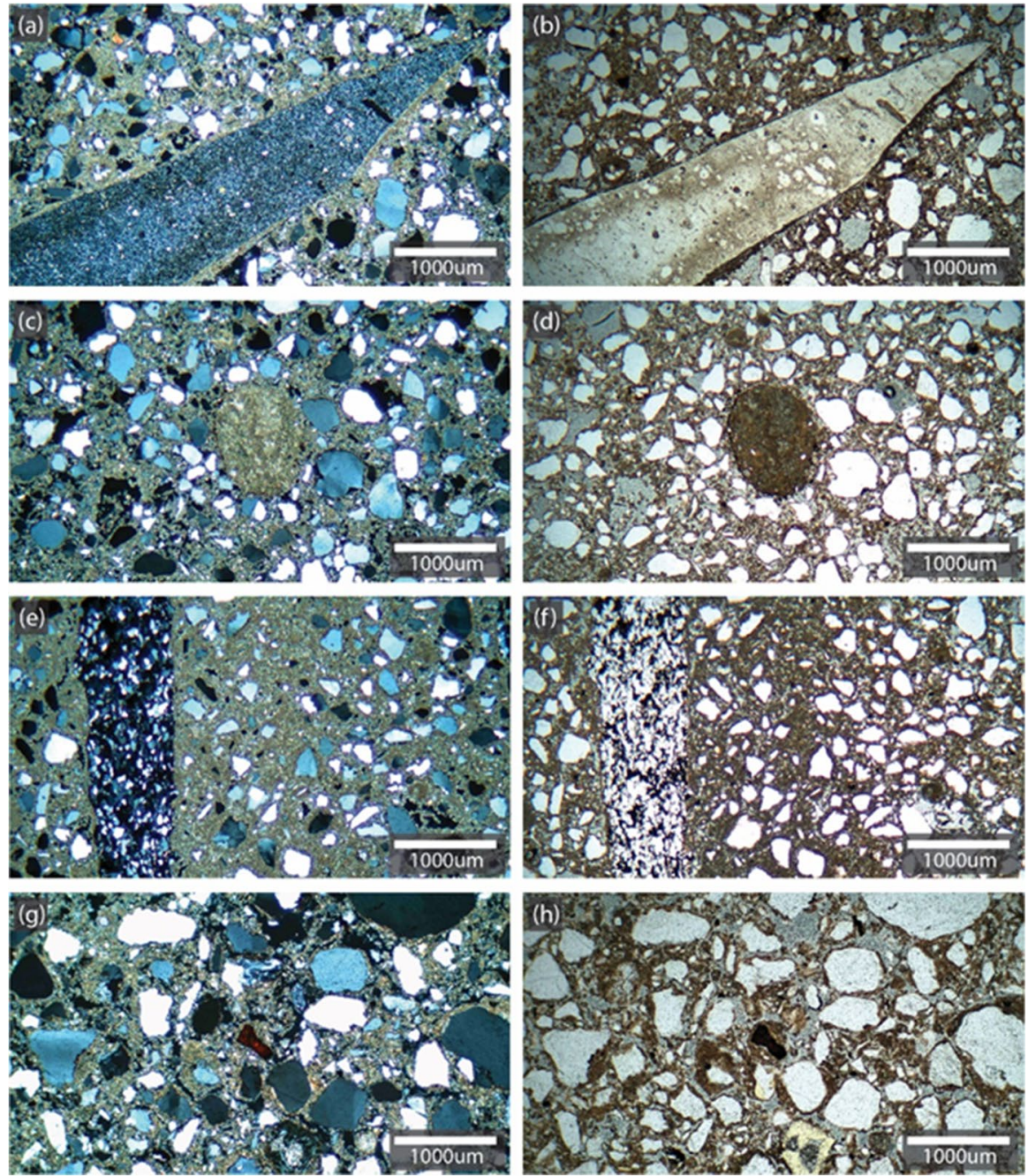

Fig. 7 Digital photomicrographs of MM6: a-b a microflake of chert with carbonate coating within a carbonate impregnated sandy (quartz) clay groundmass from MM6-6 at $3 \times$ magnification, XPL and PPL, respectively. c-d Well-developed typic carbonate nodule within a carbonate impregnated sandy (quartz) clay groundmass from MM6-5 at 3×magnification, XPL and PPL, respectively. e-f A fragment of sandstone (left) within a heavily carbonate concreted fine sandy clay groundmass from MM6-5 at $3 \times$ magnification, XPL and PPL, respectively. $\mathbf{g}-\mathbf{h}$ A small fragment of burnt bone (center) and unburnt bone (lower center, yellow in PPL) within a sandy clay groundmass from MM6-3 at $3 \times$ magnification, XPL and PPL, respectively. Note in the PPL image (h) that the well-developed matrix pedofeatures, creating small carbonate aggregates and bridges between quartz grains

\section{Technomorphological Characteristics of Lithics}

Table 7 shows technomorphological inventories of chipped stone artifacts from the previous and renewed excavations. The following presents the results of the analyses 

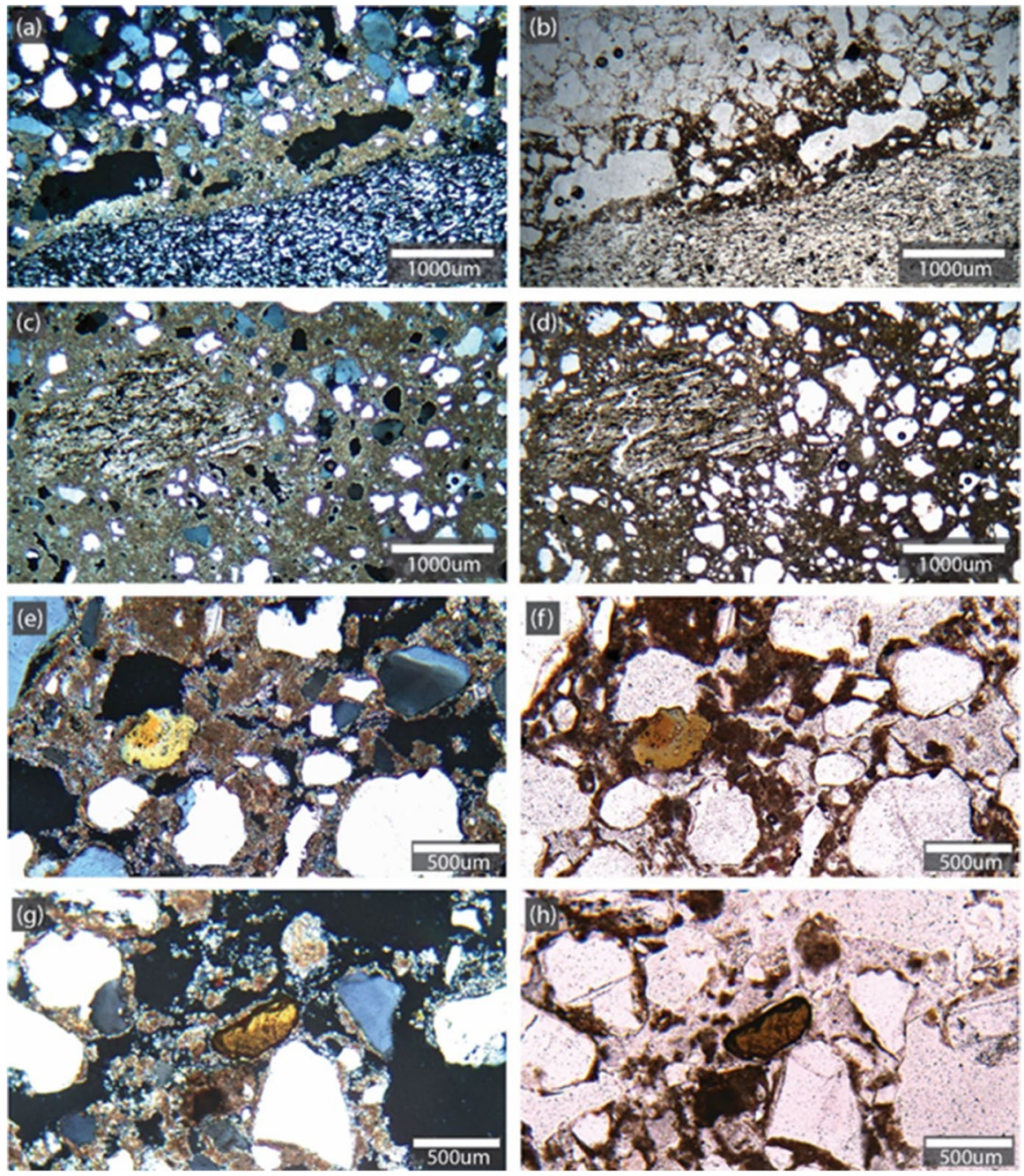

Fig. 8 Digital photomicrographs of MM12: a-b carbonate coatings around void spaces adjacent to a sandstone fragment (bottom) within a sandy (quartz) clay groundmass from MM12-4 at $3 \times$ magnification, XPL and PPL, respectively. c-d Well-developed carbonate crystal intergrowth (left) within a carbonate impregnated sandy (quartz) clay groundmass from MM12-5 at $3 \times$ magnification, XPL and PPL, respectively. e-f A partially burnt bone fragment (left center) within a heavily carbonate concreted fine sandy clay groundmass from MM12-2 at 4.5 × magnification, XPL and PPL, respectively. Note the welldeveloped carbonate aggregates and bridges between quartz grains. $\mathbf{g}-\mathbf{h}$ A small fragment of burnt bone (center) within a sandy clay groundmass from MM12-2 at $4.5 \times$ magnification, XPL and PPL, respectively

focusing on cores, core trimming elements, blank morphology, blades/bladelets, and tool types. 

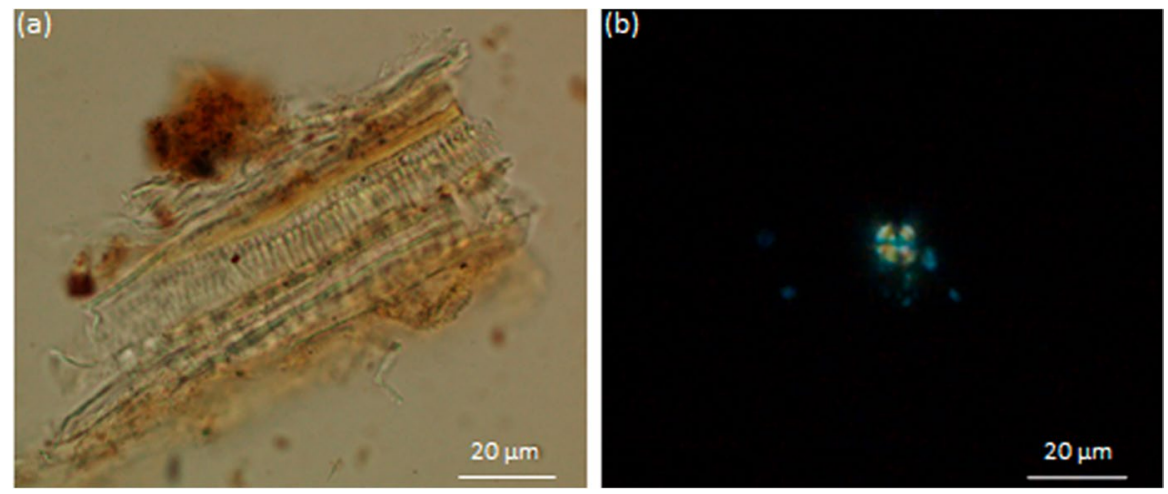

Fig. 9 Photomicrographs of microfossils identified in Tor Fawaz (sample 16). a tracheary phytolith from dicotyledonous leaves; $\mathbf{b}$ dung spherulite under crossed polarized light (XPL)

Table 6 Main phytolith morphotypes obtained from the samples with indication of plants or parts to which they are attributed based on modern reference studies (Albert \& Weiner, 2001; Albert et al., 2008, 2016; Tsartsidou et al., 2008; Portillo et al., 2014)

\begin{tabular}{lllllll}
\hline Phytolith morphotype & Attribution & \multicolumn{2}{l}{ Sample $\mathrm{n}$} & & \\
\cline { 5 - 7 } & & 16 & 17 & 18 & 19 & 20 \\
\hline Acute bulbosus (hair cell/base) & Monocot/dicot leaves & 7 & 1 & 1 & 0 & 0 \\
Bulliform flabellate & Grass leaves & 4 & 1 & 0 & 0 & 1 \\
Cylindroid & Monocot/dicot & 6 & 0 & 0 & 0 & 0 \\
Ellipsoid smooth/rugose surface & Wood/bark dicot & 2 & 0 & 0 & 0 & 0 \\
Multicelled elongate psilate & Grass leaves & 17 & 0 & 0 & 0 & 0 \\
Multicelled polyhedral & Dicot leaves & 2 & 0 & 0 & 0 & 0 \\
Parallelepiped blocky & Wood/bark dicot & 0 & 0 & 1 & 0 & 0 \\
Parallelepiped elongate/velloate & Monocot/dicot & 7 & 0 & 0 & 1 & 0 \\
Parallelepiped thin psilate & Grass leaves & 7 & 0 & 0 & 3 & 0 \\
Parallelepiped thin rugose & Wood/bark dicot & 7 & 5 & 1 & 3 & 1 \\
Platelet & Dicot leaves & 5 & 0 & 2 & 0 & 0 \\
Spheroid psilate/ornate & Monocot/dicot & 9 & 0 & 0 & 0 & 0 \\
Tracheary & Dicot leaves & 6 & 0 & 0 & 0 & 0 \\
\hline
\end{tabular}

\section{Cores and Core Trimming Elements}

Table 8 shows technotypological classification of cores from Units 6-10. The cores are dominated by several types of along-axis cores for which we follow the definition by Leder $(2014,2016)$. Along-axis cores assume a flat overall shape consisting of two convex surfaces (i.e., flat-faced cores). Only one surface is used for the detachment of blanks, while the other is used for striking platforms, thus resembling the Levallois concept (Boëda, 1994). Along-axis cores are characterized by the dominant use of axial flaking, i.e., unidirectional or bidirectional 


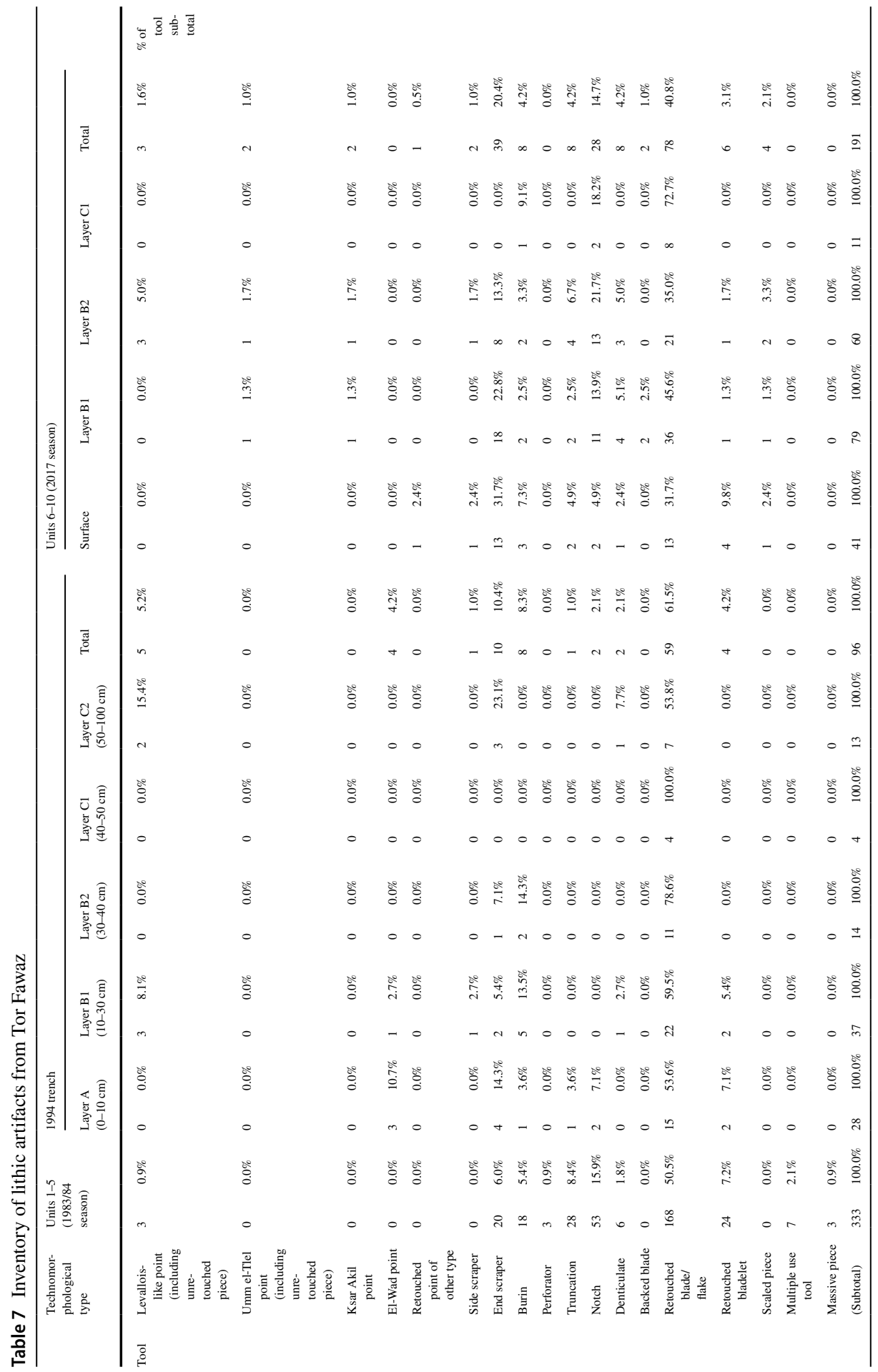




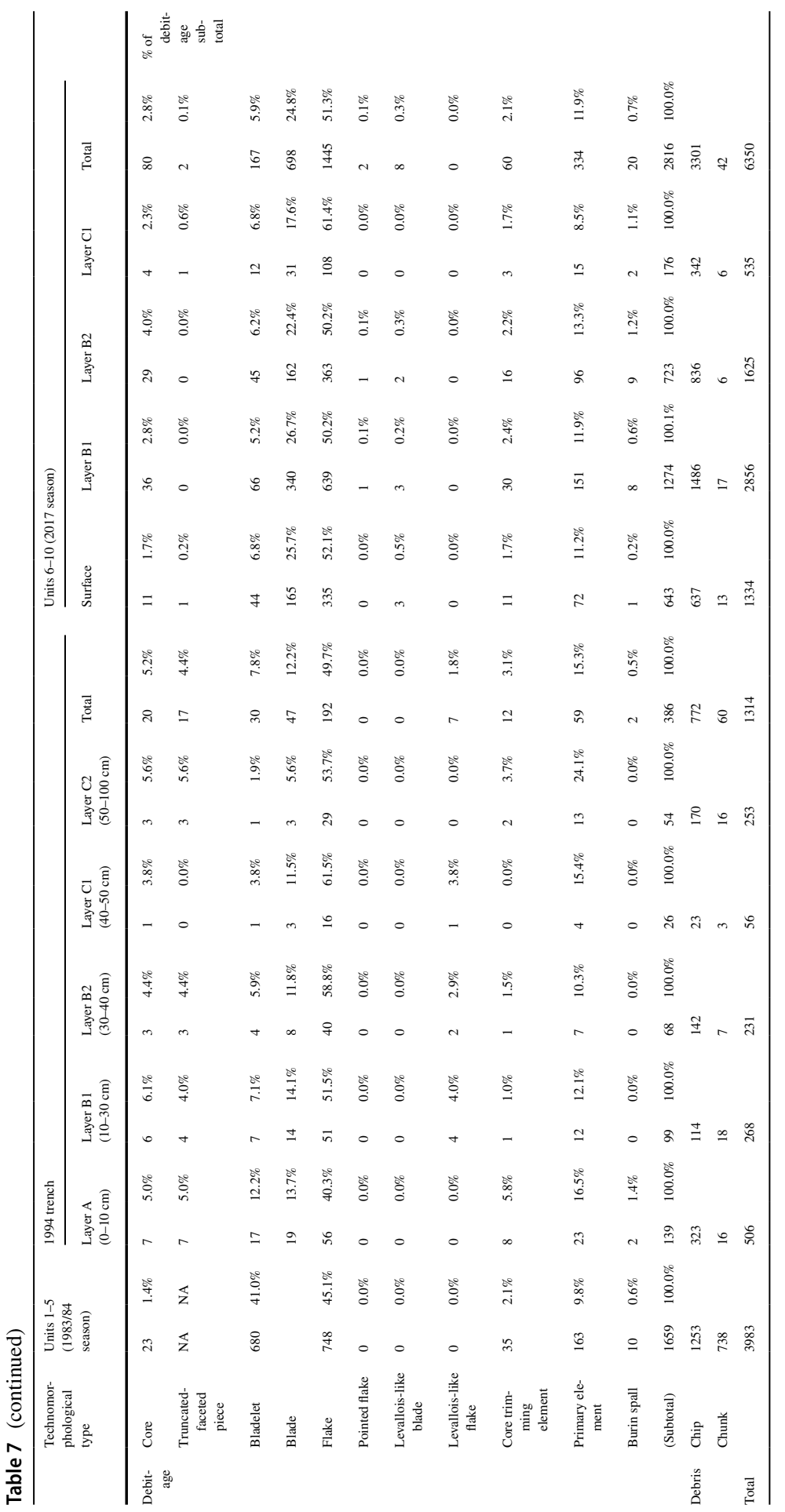


flaking (thus, along axis), for producing elongated blanks as well as for maintaining the convex working surface. However, it is difficult to distinguish between predetermined blanks from predetermining blanks, unlike Levallois methods.

In the along-axis cores from Tor Fawaz (Fig. 10a-h), parallel sided types (Type 1 according to Leder, 2014) are dominant, and unipolar and bipolar types occur in similar frequencies. Along-axis cores with convergent forms are less common and show unipolar flaking scars, including both preferential (Type 2B) and recurrent (Type 3) methods.

Volumetric cores differ from along-axis cores in the overall shape, assuming prismatic or pyramidal forms. In volumetric cores, a working surface extends around a wide periphery of the striking platform (i.e., cylindrical and conical cores) or is located at a narrow front of the core (i.e., narrow-fronted cores). In the Tor Fawaz assemblages, we classified eight cores as volumetric types including parallel or convergent lateral forms (Fig. 10i-j). There is one volumetric core with a narrow working surface, assuming a carinated form. All of the volumetric cores show unidirectional flaking scars. In addition, all volumetric cores appear to be made on blocks, while $26 \%$ of the along-axis cores $(n=48)$ are made on thick flakes.

Eight cores are made on flakes with less modification, thus largely retaining original morphology of the flakes. In such cores-on-flakes, we identified three types. The burin-core type (Fig. 10k-1) has lateral sides exploited for the detachment of narrow blanks, assuming a burin-like morphology (Zwyns et al., 2012). This type of core technology is part of "bladelet-core-on-flakes" defined by Leder $(2014,2018)$ and occurs at several Levantine IUP sites including Boker Tachtit (especially Level 2), where multifaceted burins and nucleiform burins are reported (Demidenko et al., 2020; Marks \& Kaufman, 1983). Another type of cores-on-flakes is the truncatedand-faceted type (also called Nahr Ibrahim cores). This type is usually made on flakes rather than blades, and their dorsal or ventral surfaces are exploited for the production of flakes (Henry, 2003; Hovers, 2009; Nishiaki, 1985; Solecki \& Solecki, 1970). They are included as cores in this study because the final removal scars extend large portions of the exploited convex surface, resembling the Levallois concept. The third type is represented by a scraper-like core. The thickness of the flake is exploited for flake production by using the ventral surface as a striking platform.

Table 8 also shows forms of flaking scars on the working surface of the cores. The majority of the along-axis cores, volumetric cores, and burin-cores show blade/ bladelet scars along with flake scars. Point scars occur on three along-axis cores. Exhausted and expedient cores are dominated by flake scars.

The four assemblages (surface, Layer B1, Layer B2, and Layer C1) are commonly characterized by the dominance of along-axis cores, particularly their single platform types. The absence of volumetric cores in Layer $\mathrm{Cl}$ is likely due to the small sample size. There is no statistical difference in the relative frequencies of alongaxis cores, volumetric cores, and cores-on-flakes between Layer B1 and Layer B2 that have larger sample size ( $p$ value of chi-square test $=0.68$ ).

CTEs are dominated by crested/half-crested blades and core tablets in the assemblages from surface, Layer B1, Layer B2, and Layer C1 (Fig. 11a-d; Table 9). On the other hand, Layer B2 is characterized by a higher frequency of plunging blades/ 


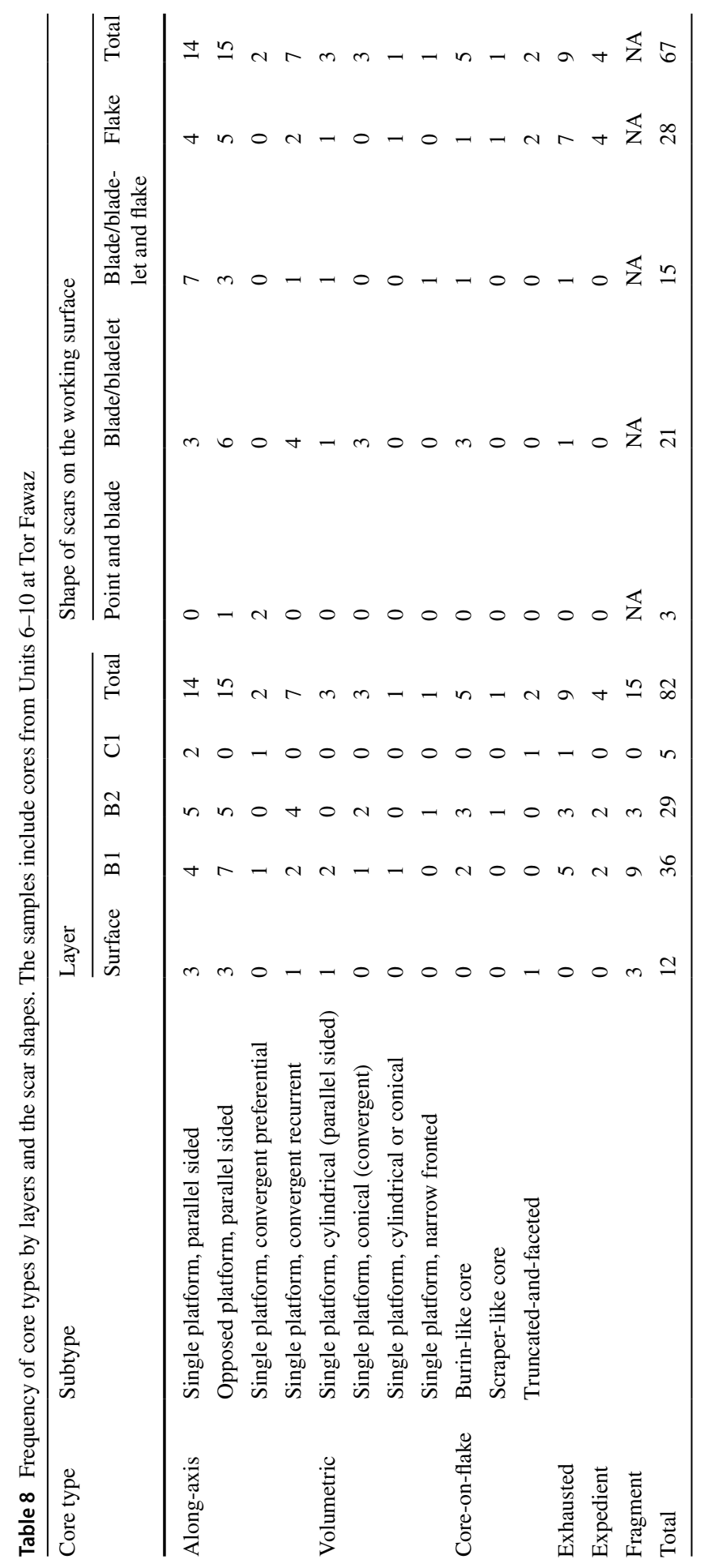



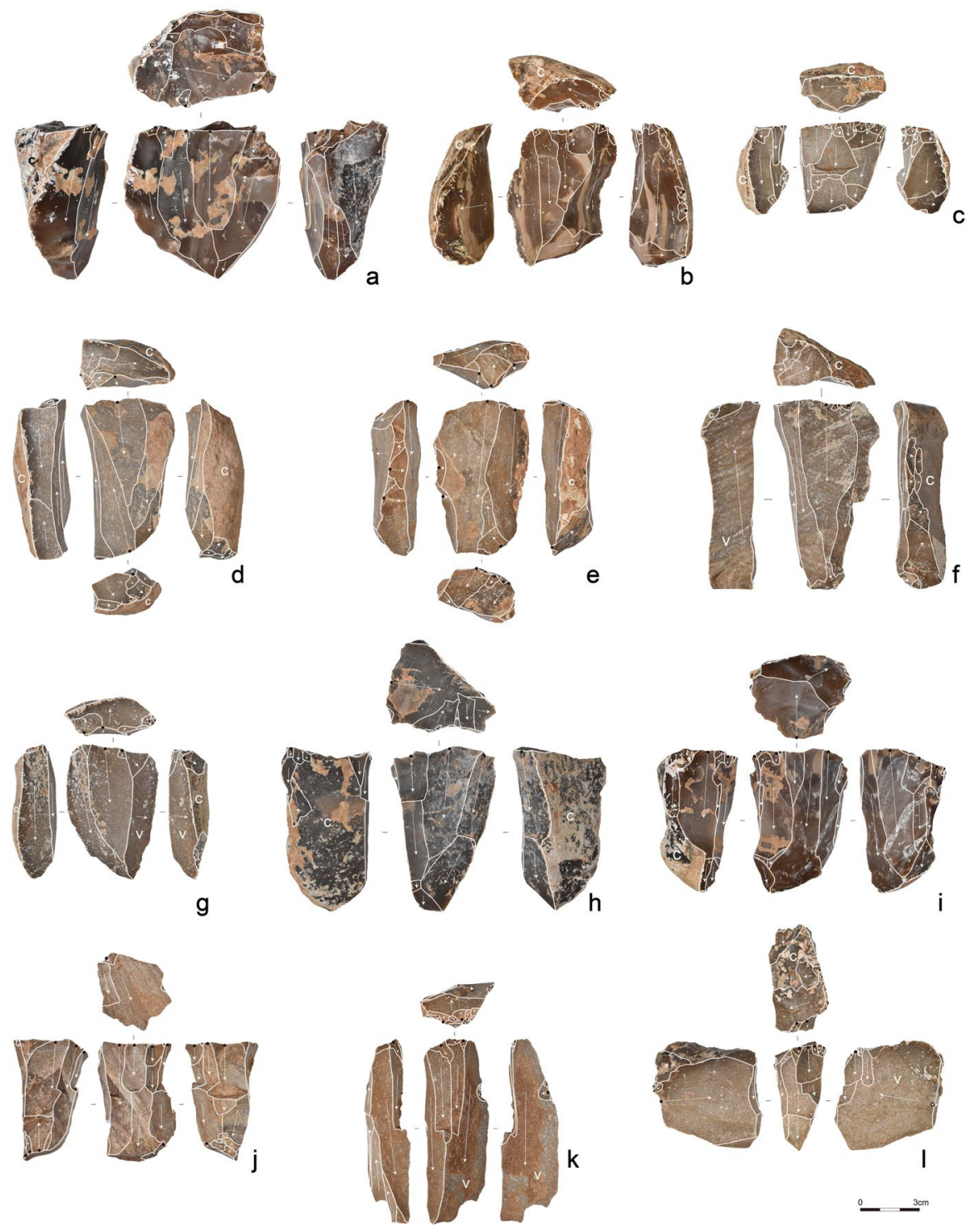

Fig. 10 Cores from Units 6-10 at Tor Fawaz. a-c Along-axis, single platform, parallel sided, d and e along-axis, opposed platform, parallel sided, $\mathbf{f}$ and $\mathbf{g}$ along-axis, single platform, convergent preferential for point, $\mathbf{h}$ along-axis, single platform, convergent recurrent for blades, $\mathbf{i}$ volumetric, single platform, conical, $\mathbf{j}$ volumetric, single platform, cylindrical, $\mathbf{k}$ and $\mathbf{l}$ burin-like cores on flakes. (a, d, e, f, h, i, j, $\mathbf{k}, \mathbf{l})$ from Layer B; (b, c, $\mathbf{g}$ ) from Layer C. Arrows on flaking scars (outlined) show flaking directions. Abbreviations: $\mathrm{C}=$ cortex; $\mathrm{V}=$ ventral surface of a flake used as a blank for core

flakes. Although the sample size of Layer $\mathrm{C} 1$ is small, it is similar to other assemblages in the occurrences of half-crested blades and a core tablet. There was no CTEs indicative of Levallois flaking, such as éclat debordant in any assemblage. 
Fig. 11 Core trimming elements and blades/bladelets from Units 6-10 at Tor Fawaz. a Core tablet, b-d v crested blades, e bladelet with a plain platform with coarse overhang removal, $\mathbf{f}$ bladelet with a plain platform without overhang removal, $\mathbf{g}$ Levallois blade with a faceted platform and a blunt distal end, $\mathbf{h}$ blade with a faceted platform and a pointed distal end, $\mathbf{i}$ Blade with a partially faceted platform and a lateral-distal shape of the in-betweener type, $\mathbf{j}$ Levallois-like blade with a faceted platform and a convergent lateral-distal form. Arrows on flaking scars (outlined) show flaking directions. Abbreviations: $\mathrm{C}=\mathrm{cortex}$

\section{Blank Morphology}

Table 10 shows frequencies of several technomorphological groups of main blanks (unretouched and not including CTEs, primary elements, and spalls) excavated from the 1994 trench and Units 6-10. Flakes are the most dominant morphology (60-83\%), and blades/bladelets (Fig. 11e-j) account for about 20-40\% except for Layer C2 (11\%) in the 1994 trench.

Also notable is the occurrences of pointed blanks, including Levallois-like points (Fig. 13a-c), Umm el-Tlel points (Fig. 13d-e), and pointed flakes (Fig. 13h-j). Their frequency is low $(n=12)$, but they were found in Layer B1, Layer B2, and Layer C2. In addition, Levallois-like flakes and Levallois-like blades occur in the assemblages from surface, Layer B1, Layer B2, and Layer C1.

There is no statistically significant difference ( $p$ value of chi-square test $=0.14$ ) in the frequencies of blank types among Layer B1, Layer B2, and Layer C1 that have larger sample size.

\section{Blades/Bladelets}

The ratios of bladelets to blades range between 0.19 and 0.89 (Table 10). The lowest value $(0.19)$ is based on the largest number of blades/bladelets $(n=409)$ of the Layer B1 assemblage in the Units 6-10. The ratio slightly increases in the underlying layers, i.e., Layer B2 (0.28) and Layer C1 (0.39) in the same units. Similar ratios are observable in Layer C1 (0.33) and Layer C2 (0.33) in the 1994 units. On the other hand, the highest ratio occurs in Layer A (0.89), followed by Layers B1 and B2 (both 0.5 ) in the 1994 trench.

Regarding the dorsal-distal shapes (Table 11), about a half of the blades/bladelets $(49 \%)$ are tapering towards the distal end, including three sub-types, i.e., the convergent (Fig. 11j), the in-betweener (Fig. 11i), and the pointed form (Fig. 11h). Among the three sub-types, the pointed type was observed most frequently, followed by the in-betweener. The convergent type, which has the maximum width at the proximal end, is few $(n=4)$. This pattern does not differ significantly among the assemblages from the surface, Layer B1, Layer B2, and Layer C1 ( $p$ value of chisquare test $=0.38$ ).

As shown in Table 12, the dorsal scar directions of blades/bladelets are dominated by the unidirectional scars, followed by the bidirectional and then the crossed pattern. This generally applies to the assemblages from the surface, Layer B1, Layer B2, and Layer C1. However, the percentage of the unidirectional scars gradually decreases from Layer $\mathrm{C} 1$ towards the surface, while the bidirectional 

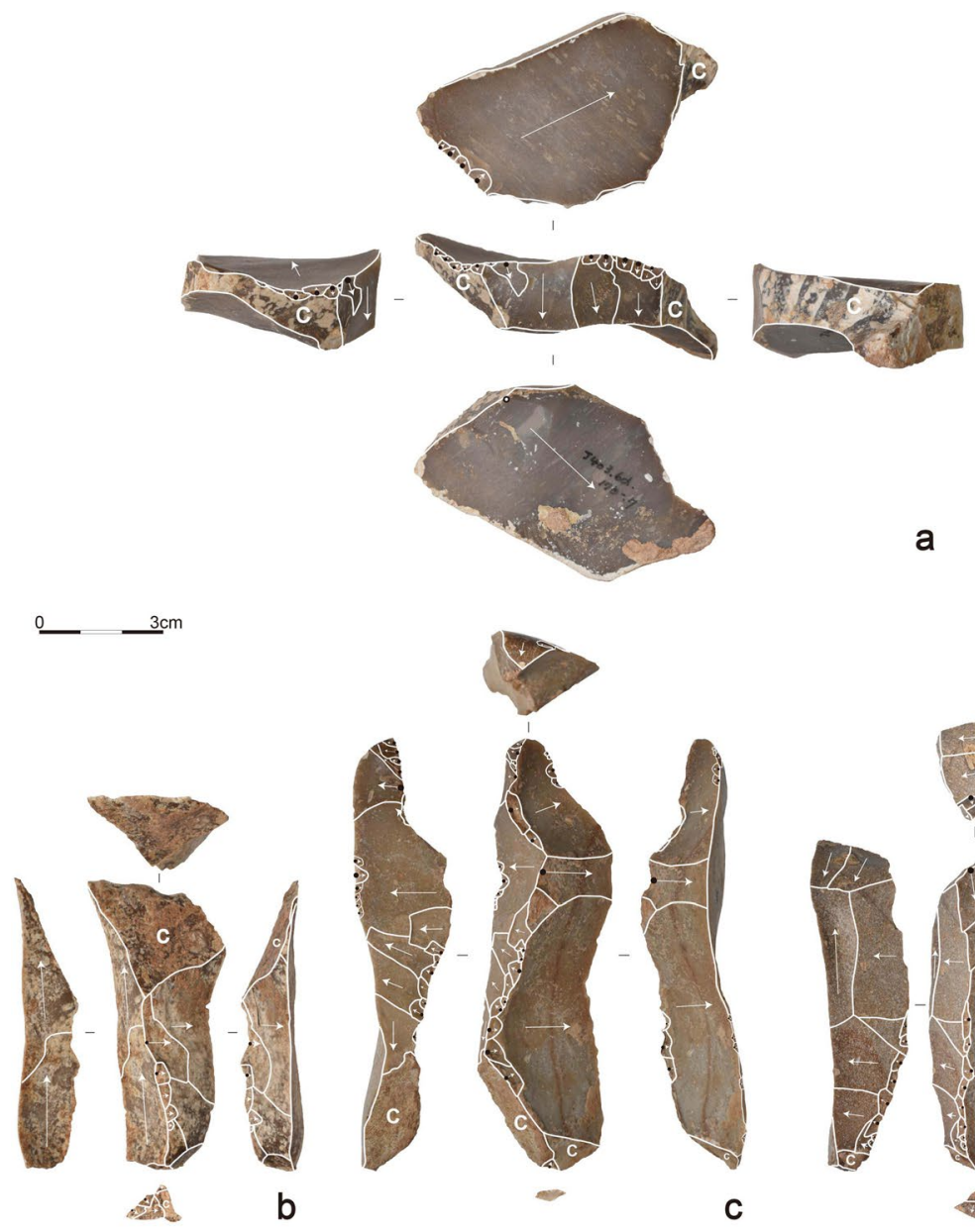

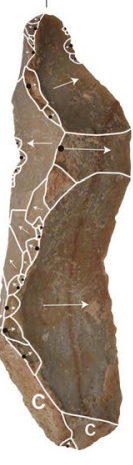

$-$

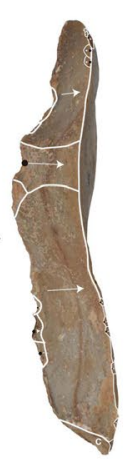

C

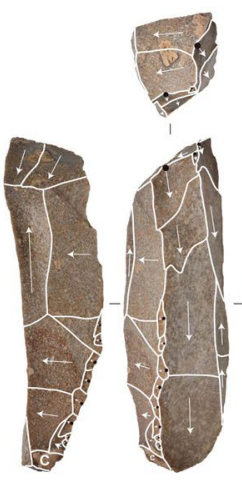

Sision

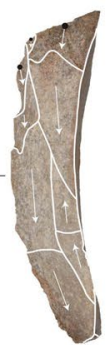

d

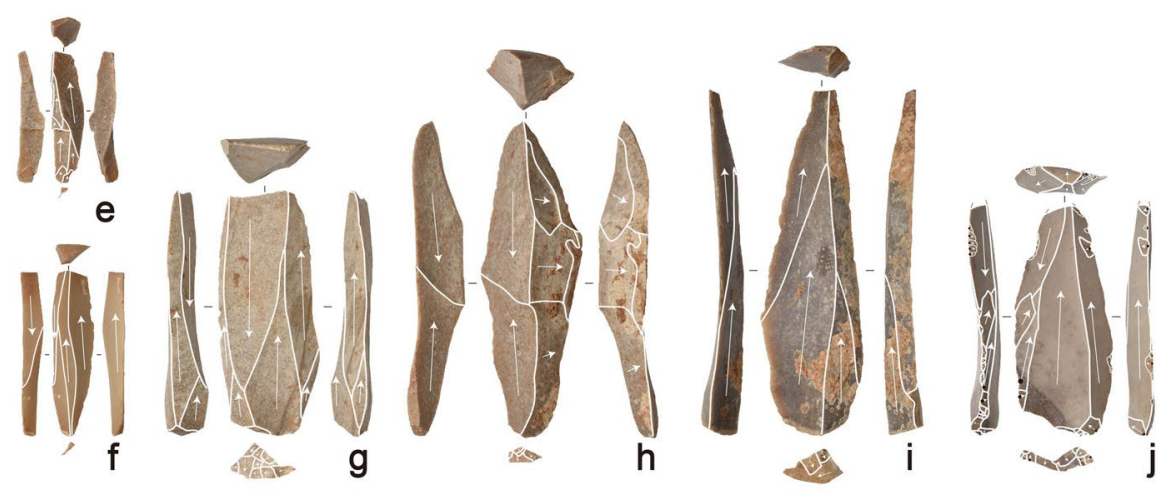


Table 9 Frequency of core trimming elements from Units 6-10 at Tor Fawaz

\begin{tabular}{lllllll}
\hline Types & Surface & Layer B1 & Layer B2 & Layer C1 & Total & \\
\hline Crested blade & 1 & 9 & 4 & 0 & 14 & $23 \%$ \\
Half-crested blade & 6 & 12 & 1 & 2 & 21 & $35 \%$ \\
Core tablet & 2 & 7 & 4 & 1 & 14 & $23 \%$ \\
Plunging blade/flake & 1 & 2 & 6 & 0 & 9 & $15 \%$ \\
Core edge piece & 1 & 0 & 1 & 0 & 2 & $3 \%$ \\
Total & 11 & 30 & 16 & 3 & 60 & $100 \%$ \\
\hline
\end{tabular}

pattern increases. Such differences are statistically significant ( $p$ value of chi-square test $<0.01$ ).

The plain platform occurs most frequently in blades/bladelets, followed by the faceted and partially faceted platforms (Table 13). The "chapeau de gendarme" platform is very rare, and the linear and punctiform platforms are almost completely absent. This pattern does not differ significantly among the assemblages from the surface, Layer B1, layer B2, and Layer C1 ( $p$ value of chi-square test $=0.40$ ). The blades/bladelets from the surface, Layer B1, Layer B2, and Layer C1 are also similar to each other in the relative size of the platform ( $p$ value of Kruskal-Wallis test $=0.31)$ (Fig. 12).

As shown in Table 14, the overhang removal is not observable in more than half of the blades/bladelets. When the overhang is removed, it is done by coarse flaking mostly. The fine flaking/abrasion is almost completely absent. This pattern does not differ significantly among the assemblages from the surface, Layer B1, Layer B2, and Layer C1 ( $p$ value of chi-square test $=0.82$ ).

\section{Tool Types}

As shown in Table 7, retouched blades/flakes, which are morphologically unstandardized, constitute the dominant tool type (32-79\%) in all the assemblages (Fig. 13). The occurrences of end scrapers (Fig. 13k-n) and burins (Fig. 13o-s) also generally characterize the assemblages from Tor Fawaz. The absence of end scraper from Layer $\mathrm{C} 1$ is likely due to the small sample size, rather than a chronological trend, as the underlying Layer $\mathrm{C} 2$ includes end scrapers. In contrast, side scrapers are absent or very few $(0-1 \%)$ in all the assemblages.

A few Levallois-like points were found in Layer B1, Layer B2, and Layer C2 (Fig. 13a-b). In addition, Layer B1 and Layer B2 included a single piece of Umm el-Tlel point respectively (Fig. 13d-e). They are characterized by a series of small elongated scars, like bladelet scars, near the butt (Boëda et al., 2015). One of them has marginal retouch near the tip and on the left lateral edge (Fig. 13d). Layer B1 and B2 also yielded a single piece of Ksar Akil point, respectively (Fig. 13f-g). These Ksar Akil points are made on pointed blades (not bladelets). One lateral edge near the tip is marginally retouched to enhance the acuteness 


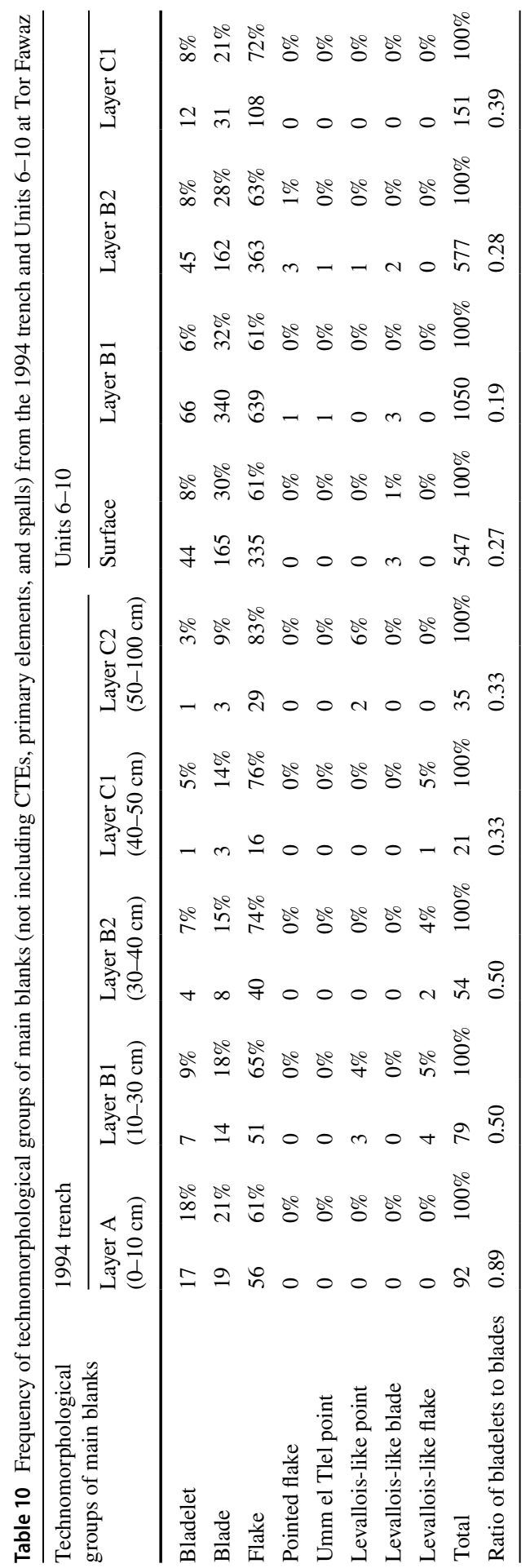


Table 11 Dorsal-distal shapes of blades/bladelets from Units 6-10 at Tor Fawaz

\begin{tabular}{|c|c|c|c|c|c|c|c|c|c|c|c|}
\hline \multirow[b]{2}{*}{ Tapering } & \multirow{2}{*}{$\begin{array}{l}\text { Sub-types } \\
\text { Convergent }\end{array}$} & \multicolumn{2}{|c|}{ Surface } & \multicolumn{2}{|c|}{ Layer B1 } & \multicolumn{2}{|c|}{ Layer B2 } & \multicolumn{2}{|c|}{ Layer C1 } & \multicolumn{2}{|c|}{ Total } \\
\hline & & 2 & $9 \%$ & 1 & $1 \%$ & 1 & $2 \%$ & 0 & $0 \%$ & 4 & $3 \%$ \\
\hline & In-betweener & 2 & $9 \%$ & 12 & $16 \%$ & 4 & $10 \%$ & 2 & $22 \%$ & 20 & $14 \%$ \\
\hline & Pointed & 4 & $18 \%$ & 30 & $39 \%$ & 13 & $32 \%$ & 3 & $33 \%$ & 50 & $34 \%$ \\
\hline Blunt & & 14 & $64 \%$ & 34 & $44 \%$ & 23 & $56 \%$ & 4 & $44 \%$ & 75 & $51 \%$ \\
\hline Total & & 22 & $100 \%$ & 77 & $100 \%$ & 41 & $100 \%$ & 9 & $100 \%$ & 149 & $101 \%$ \\
\hline
\end{tabular}

Table 12 Frequency of dorsal scar patterns of blades/bladelets from Units 6-10 at Tor Fawaz

\begin{tabular}{lllllllll}
\hline Dorsal scar pattern & Surface & Layer B1 & Layer B2 & $\begin{array}{l}\text { Layer } \\
\text { C1 }\end{array}$ \\
\hline Unidirectional & 13 & $59 \%$ & 50 & $66 \%$ & 30 & $71 \%$ & 33 & $89 \%$ \\
Bidirectional & 7 & $32 \%$ & 15 & $20 \%$ & 5 & $12 \%$ & 3 & $8 \%$ \\
Crossed & 2 & $9 \%$ & 7 & $9 \%$ & 7 & $17 \%$ & 1 & $3 \%$ \\
Centripetal & 0 & $0 \%$ & 3 & $4 \%$ & 0 & $0 \%$ & 0 & $0 \%$ \\
Cortex & 0 & $0 \%$ & 1 & $1 \%$ & 0 & $0 \%$ & 0 & $0 \%$ \\
Total & 22 & $100 \%$ & 76 & $100 \%$ & 42 & $100 \%$ & 37 & $100 \%$ \\
\hline
\end{tabular}

Table 13 Frequency of platform types of blades/bladelets from Units 6-10 at Tor Fawaz

\begin{tabular}{|c|c|c|c|c|c|c|c|c|}
\hline \multirow{2}{*}{$\begin{array}{l}\text { Platform types } \\
\text { Linear }\end{array}$} & \multicolumn{2}{|c|}{ Surface } & \multicolumn{2}{|c|}{ Layer B1 } & \multicolumn{2}{|c|}{ Layer B2 } & \multicolumn{2}{|c|}{ Layer C1 } \\
\hline & 0 & $0 \%$ & 0 & $0 \%$ & 0 & $0 \%$ & 1 & $6 \%$ \\
\hline Plain & 9 & $41 \%$ & 40 & $53 \%$ & 24 & $57 \%$ & 9 & $56 \%$ \\
\hline Dihedral & 1 & $5 \%$ & 0 & $0 \%$ & 0 & $0 \%$ & 1 & $6 \%$ \\
\hline Partially faceted & 2 & $9 \%$ & 8 & $11 \%$ & 2 & $5 \%$ & 1 & $6 \%$ \\
\hline Faceted & 8 & $36 \%$ & 21 & $28 \%$ & 12 & $29 \%$ & 3 & $19 \%$ \\
\hline Chapeau de gendarme & 0 & $0 \%$ & 1 & $1 \%$ & 0 & $0 \%$ & 0 & $0 \%$ \\
\hline Cortical & 0 & $0 \%$ & 0 & $0 \%$ & 1 & $2 \%$ & 0 & $0 \%$ \\
\hline Shattered & 2 & $9 \%$ & 6 & $8 \%$ & 3 & $7 \%$ & 1 & $6 \%$ \\
\hline Total & 22 & $100 \%$ & 76 & $100 \%$ & 42 & $100 \%$ & 16 & $100 \%$ \\
\hline
\end{tabular}

of the tip. Four el-Wad points were recovered in Layer A $(n=3)$ and Layer B1 $(n=1)$ in the 1994 trench (Kerry \& Henry, 2003).

Regarding the morphology of blanks of tool types, Table 15 shows that more than half of the retouched tools are made on blades (53\%), followed by flakes (34\%). The use of points, bladelets, and CTEs are infrequent (2-4\%). Given the predominance of flakes in debitage (Table 10), the greater percentage of blades in retouched tools indicates the selective use of blades with retouch. 


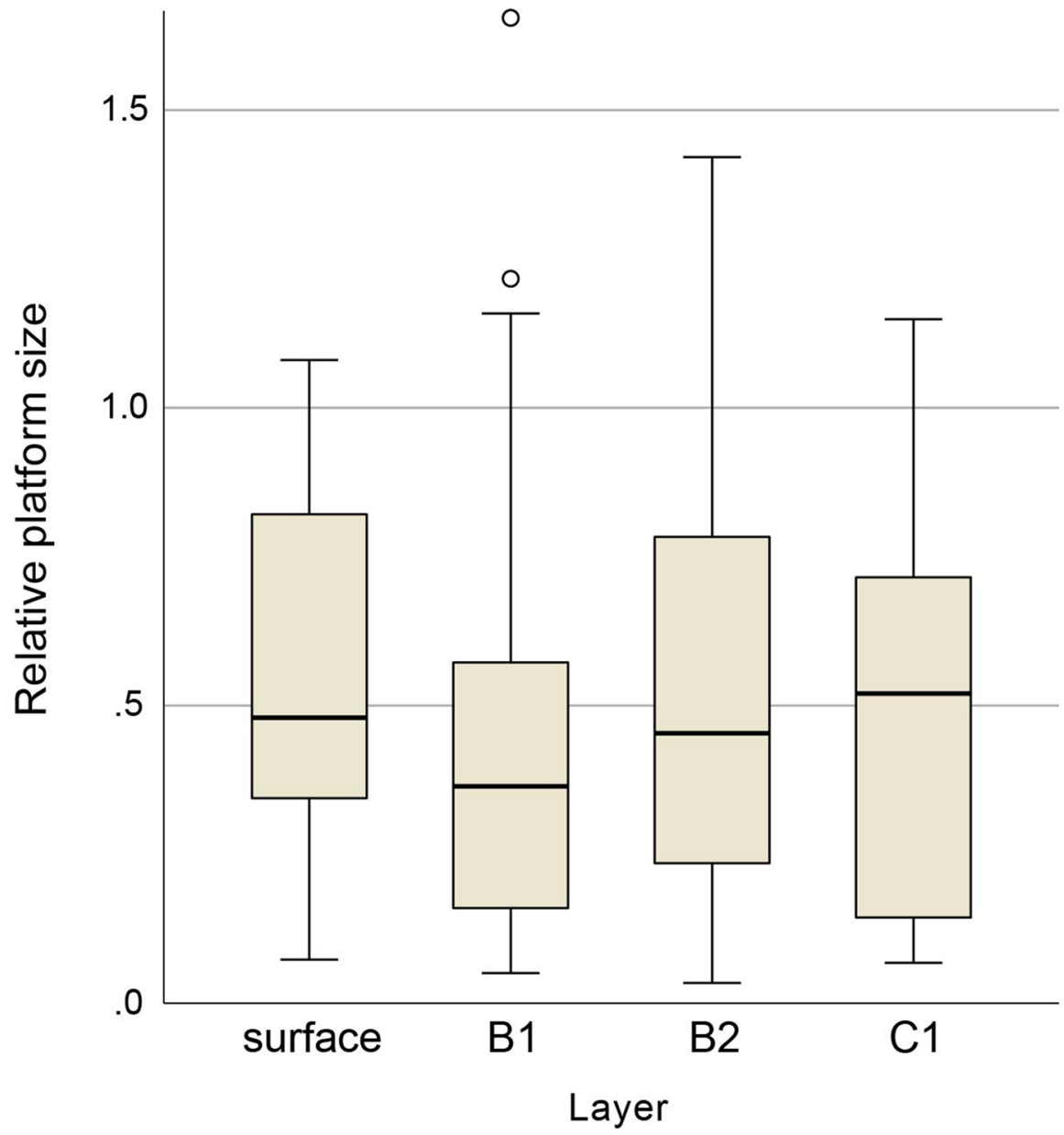

Fig. 12 Relative platform size (see text for the definition) of blades/bladelets from the surface $(n=20)$, Layer B1 $(n=70)$, Layer B2 $(n=39)$, and Layer C1 $(n=15)$ in Units 6-10 at Tor Fawaz

Table 14 Frequency of overhang removals of blades/bladelets from Units 6-10 at Tor Fawaz

\begin{tabular}{lllllllll}
\hline Overhang removal types & \multicolumn{2}{l}{ Surface } & \multicolumn{2}{l}{ Layer B1 } & \multicolumn{2}{l}{ Layer B2 } & \multicolumn{2}{l}{ Layer C1 } \\
\hline Fine flaking & 0 & $0 \%$ & 2 & $3 \%$ & 0 & $0 \%$ & 0 & $0 \%$ \\
Coarse flaking & 11 & $50 \%$ & 31 & $42 \%$ & 16 & $39 \%$ & 7 & $44 \%$ \\
None & 11 & $50 \%$ & 40 & $55 \%$ & 25 & $61 \%$ & 9 & $56 \%$ \\
Total & 22 & $100 \%$ & 73 & $100 \%$ & 41 & $100 \%$ & 16 & $100 \%$ \\
\hline
\end{tabular}



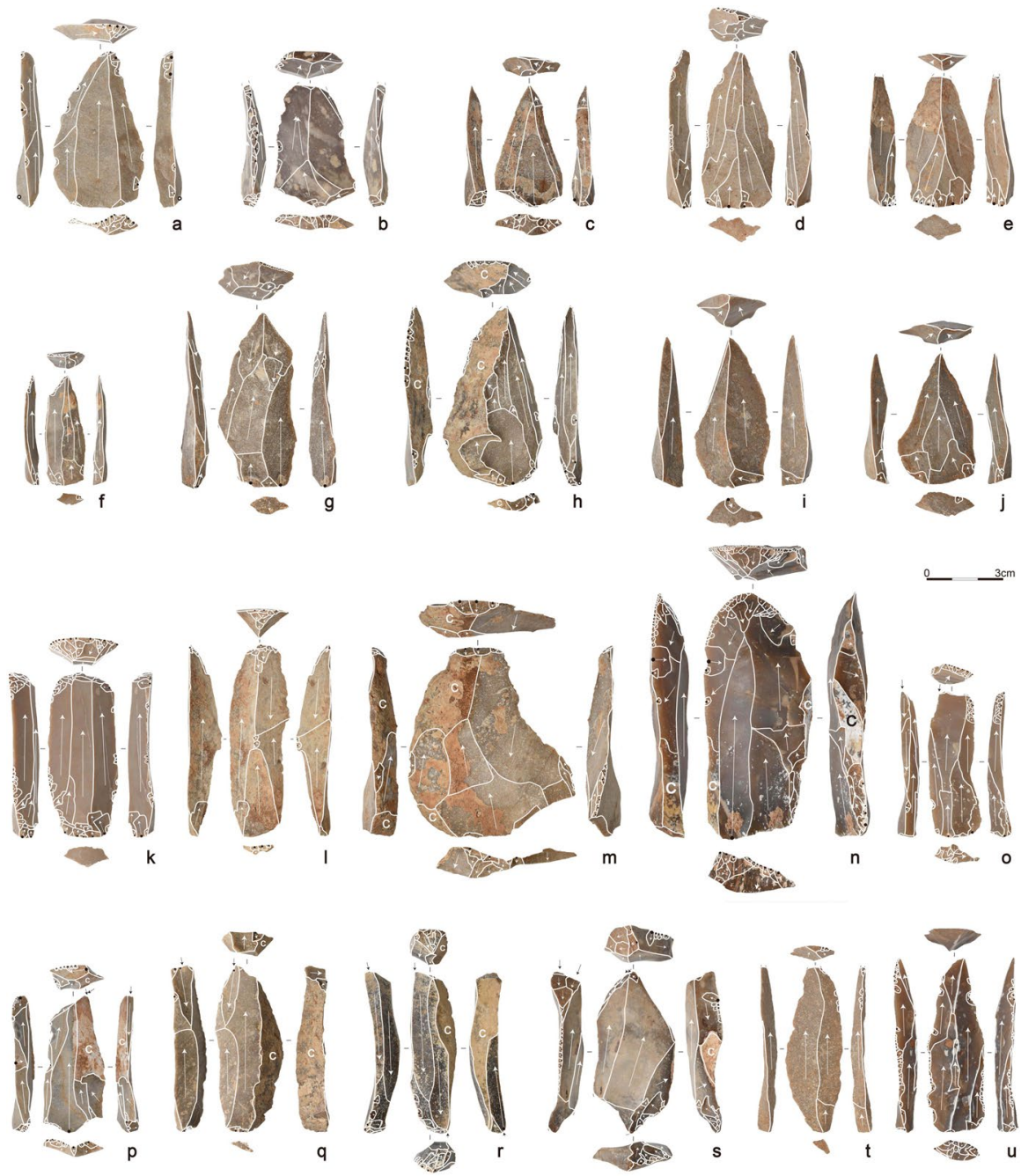

Fig. 13 Retouched tools, including unretouched points, at Tor Fawaz. a-b Retouched Levallois-like points, $\mathbf{c}$ unretouched Levallois-like point, d retouched Umm el-Tlel point, e unretouched Umm el-Tlel point, $\mathbf{f}$ and $\mathbf{g}$ Ksar Akil points, $\mathbf{h}$ retouched point on a pointed flake, $\mathbf{i}-\mathbf{j}$ unretouched pointed flakes, $\mathbf{k}-\mathbf{n}$ end scrapers, $\mathbf{o}$ and $\mathbf{r}$ burin on truncation, $\mathbf{p}$ dihedral burin, $\mathbf{q}$ and $\mathbf{s}$ angle burins, $\mathbf{t}-\mathbf{u}$ retouched blades. All the pieces are from Units 6-10, except for (r) from the 1994 trench. Arrows on flaking scars (outlined) show flaking directions. Abbreviations: $\mathrm{C}=$ cortex

\section{Discussion}

\section{Technomorphological Characteristics of the Tor Fawaz lithic Assemblages}

The new lithic assemblages from Units 6-10 $(n=6350)$ are larger than those of previous collections from Units $1-5(n=3983)$ and the 1994 trench $(n=1314)$, thus 
Table 15 Frequencies of tool types in Units 6-10 by their blank morphologies

\begin{tabular}{llllllll}
\hline & Point & Blade & Bladelet & Flake & CTE & Unidentifiable & Total \\
\hline $\begin{array}{l}\text { Levallois point (including unretouched } \\
\text { piece) }\end{array}$ & 3 & 0 & 0 & 0 & 0 & 0 & 3 \\
$\begin{array}{l}\text { Umm el-Tlel point (including unre- } \\
\text { touched piece) }\end{array}$ & 2 & 0 & 0 & 0 & 0 & 0 & 2 \\
Ksar Akil point & 0 & 2 & 0 & 0 & 0 & 0 & 2 \\
Retouched point of other type & 1 & 0 & 0 & 0 & 0 & 0 & 1 \\
Side scraper & 0 & 0 & 0 & 2 & 0 & 0 & 2 \\
End scraper & 1 & 24 & 0 & 4 & 2 & 8 & 39 \\
Burin & 0 & 5 & 0 & 2 & 1 & 0 & 8 \\
Perforator & 0 & 0 & 0 & 0 & 0 & 0 & 0 \\
Truncation & 0 & 7 & 1 & 0 & 0 & 0 & 8 \\
Notch & 0 & 12 & 0 & 16 & 0 & 0 & 28 \\
Denticulate & 0 & 5 & 0 & 3 & 0 & 0 & 8 \\
Backed blade & 0 & 2 & 0 & 0 & 0 & 0 & 2 \\
Retouched piece & 0 & 41 & 0 & 37 & 0 & 0 & 78 \\
Retouched bladelet & 0 & 0 & 6 & 0 & 0 & 0 & 6 \\
Scaled piece & 0 & 3 & 0 & 1 & 0 & 0 & 4 \\
Total & 7 & 101 & 7 & 65 & 3 & 8 & 191 \\
& $4 \%$ & $53 \%$ & $4 \%$ & $34 \%$ & $2 \%$ & $4 \%$ & $100 \%$ \\
\hline
\end{tabular}

doubling the sample size in total (Table 7: $n=11,647$ ). In addition, Units 6-10 were probably closer to prehistoric activity areas given their locations within the rockshelter around the highest part of the slope as well as high densities of lithic distributions on the surface and in the deposits (Fig. 4; Table 3). The depositional contexts of lithics in Units 6-10 were generally similar to those in the 1994 trench, but Layer A was not recognized in Units 6-10 where the greatest density of lithic artifacts was in Layer B1 that was exposed on the surface.

All the lithic assemblages at Tor Fawaz are commonly characterized by the occurrences of Upper Paleolithic tool types, such as end scrapers and burins, that are often made on blades (Tables 7 and 15). Tools made on bladelets, such as retouched bladelets and el-Wad points, are few. Bladelets are also a minor component in unretouched blanks that are dominated by flakes followed by blades (Table 10).

Thus, the previous and new assemblages at Tor Fawaz consistently indicate "a blade technology that produced large, thick, bulky debitage and tools," as originally pointed out by Coinman and Henry (1995: 194). The robustness of blades/bladelets is associated with their platform traits that are large and often faceted (including dihedral, faceted, partially faceted, and chapeau de gendarme types: Table 13). In addition, overhang removals are absent or conducted by coarse flaking (Table 14). While robust blanks with large, faceted platforms are the general characteristics of Levallois products, the Tor Fawaz assemblages do not include Levallois cores but are characterized by the frequent occurrences of along-axis cores and volumetric cores with blade scars (Table 8), a finding consistent with the presence of a few 
Levallois-like points, blades, and flakes (Tables 7 and 10). Moreover, the CTEs are characterized by crested blades and core tables with no element indicative of Levallois methods, such as éclat debordant (Table 9).

Among the Levallois-like products, only one of them shows double patination that indicates cultural recycling of the Middle Paleolithic artifacts (Kerry \& Henry, 2003). Another possibility is the post-depositional mixing of the Middle Paleolithic artifacts from the underlying layer (e.g., Layer D in the 1994 trench). However, as already pointed out by Kerry and Henry (2003), the Levallois blanks "do not seem to correlate with any stratigraphic trends," occurring both in Layers B and C. The same result was obtained in the new assemblages from Units 6-10 (Tables 7 and 10).

Consequently, the above techno-typological characteristics at Tor Fawaz are generally in line with IUP lithic technology. We suggest that the few occurrences of Levallois-like points/blades/flakes are part of the inherent characteristics of the Tor Fawaz lithic technology affiliated with the IUP. They are not likely main products of genuine Levallois methods but more likely sub-products of sequential blade production, either from along-axis cores or volumetric cores. Given the dominance of unidirectional dorsal scar patterns (Table 12), the blade production at Tor Fawaz is similar to those at Boker Tachtit Level 4 (Marks \& Kaufman, 1983; Volkman, 1983), Tor Sadaf A and B (Fox, 2003; Coinman and Fox, 2004), and Wadi Aghar C-D1 (Kadowaki et al., 2019b) in the southern Levant and Ksar Akil XXIII-XXI (Ohnuma, 1988) and Ücağılı I-F (Kuhn et al., 2009) in the northern Levant. Although Boker Tachtit Level 4 is characterized by the absence of crested blades (Volkman, 1983), the other IUP assemblages mentioned above include crested debitage like Tor Fawaz.

The distinction of along-axis cores from Levallois cores is sometimes difficult and can vary depending on researchers. For example, Levallois point cores have been recognized in the assemblages from Boker Tachtit Levels 1-3 by original investigators (Marks \& Kaufman, 1983; Marks \& Rose, 2012; Volkman, 1983), while the cores from these levels are classified as along-axis cores by Leder (2018). The latter position represents one of several opinions that regard the point production technology at Boker Tachtit Levels 1-3 different from the Levallois technology by recognizing some elements of the Upper Paleolithic volumetric flaking strategy (Bar-Yosef, 2000; Belfer-Cohen \& Goring-Morris, 2014; Kuhn, 2003; Meignen, 2012).

In the case of Tor Fawaz, along-axis cores, which dominate the core assemblage, should not be classified as "Levallois cores" because the dominance of "Levallois cores" would be inconsistent with the few occurrences of morphologically Levallois blanks (Table 7). In fact, cores and core reduction technology at Boker Tachtit Level 4, Tor Sadaf A/B, and Wadi Aghar C-D1 (that resemble the Tor Fawaz assemblages) are recognized as non-Levallois by original investigators of the sites (Marks, 1983; Volkman, 1983; Coinman and Fox, 2004; Kadowaki et al., 2019b).

On the other hand, the term "Levallois" is used for some cores and blanks in the reports of Ksar Akil XXIII-XXI (Ohnuma, 1988) and Ücağızlı I-F (Kuhn et al., 2009). However, Ohnuma (1988: 285) recognizes "a broad technological similarity" between Ksar Akil XXIII-XXI and Boker Tachtit Level 4, and Kuhn (2003) 
suggests that "IUP blank production technology already represents a significant departure from Levallois sensu stricto".

The IUP affiliation of the Tor Fawaz assemblages is also supported by the recovery of two Umm el-Tlel points and two Ksar Akil points from Layers B1 and B2 (Fig. 13). The former type has been known from the IUP contexts at Umm el Tle and Jerf Ajla (Boëda et al., 2015; Richter et al., 2001), while the latter is known from the IUP and the Ahmarian contexts at Ksar Akil (Bergman, 1981; Ohnuma, 1988). On the other hand, it is notable that no Emireh point or chamfered piece is included in the Tor Fawaz assemblages, like Boker Tachtit Level 4, Tor Sadaf A/B, and Wadi Aghar C-D1 in the southern Levant.

The IUP affiliation of the Tor Fawaz assemblages can also be shown by three key attributes of blades/bladelets, i.e., the relative frequencies of (1) unidirectional dorsal scar pattern, (2) pointed distal forms, and (3) faceted platforms including dihedral, multiple faceted, and partially faceted types. Figure 14 compares the Tor Fawaz assemblages from Units 6-10 with Boker Tachtit Levels 1-4 (Marks \& Kaufman, 1983), Ksar Akil XXV-XVI (Ohnuma, 1988), Boker A (Jones et al., 1983), and Wadi Aghar B-D1 (Kadowaki et al., 2019b). Layers B2 and C1 at Tor Fawaz are

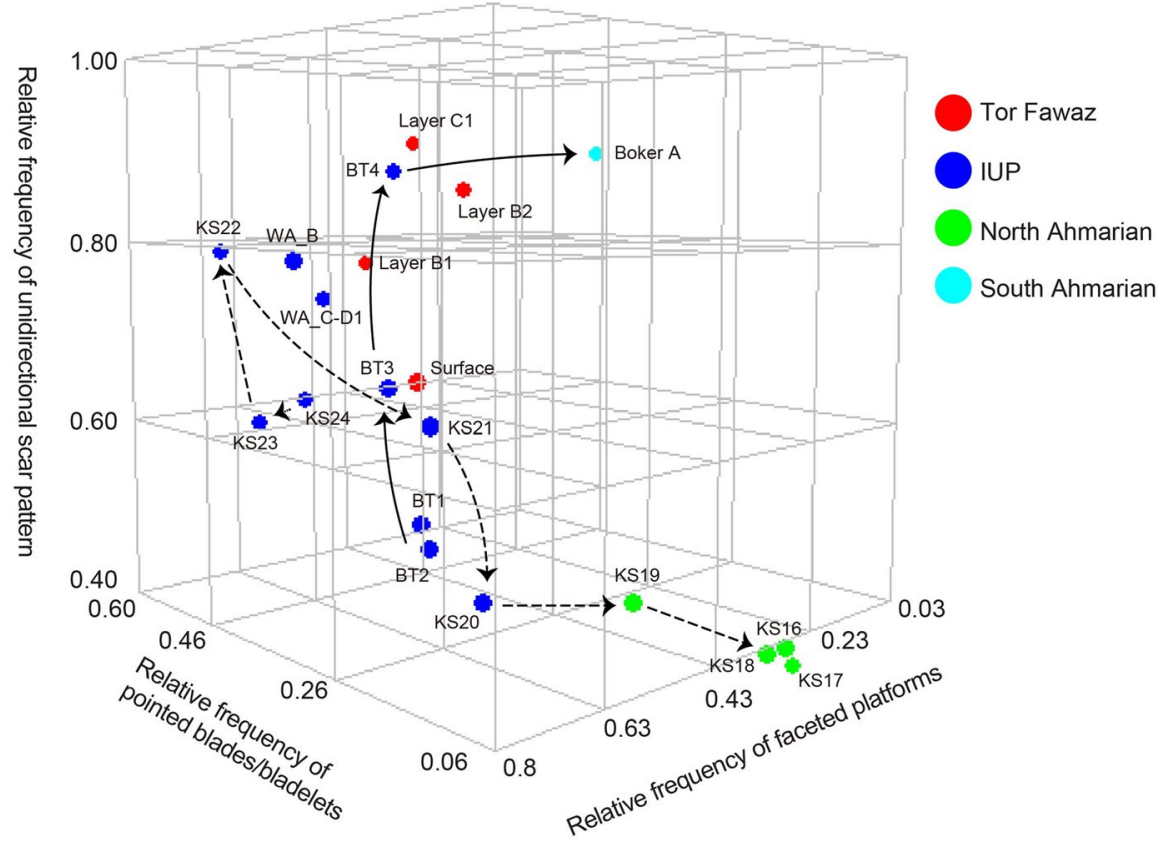

Fig. 14 Three-dimensional scatterplot of relative frequencies of unidirectional scar patterns on blades/ bladelets, pointed blades/bladelets, and faceted platforms (including multiple, dihedral, and partially faceted types) at Tor Fawaz in comparison with the IUP and Ahmarian assemblages. Abbreviations: BT =Boker Tachtit; KS=Ksar Akil; WA_B=Wadi Aghar Layer B; WA_C-D1; Wadi Aghar Layer C-D1. Chronological orders of the assemblages are indicated by arrows (solid lines for Boker Tachtit, dashed lines for Ksar Akil). See Kadowaki et al., 2019b2019b: SOM Tables S11-S13) for data sources of Ksar Akil, Boker Tachtit, Boker A, and Wadi Aghar. Data of Tor Fawaz are from Units 6-10 
plotted near Boker Tachtit Level 4. More specifically, Layers B2 and C1 are located slightly towards Boker A (Ahmarian) because of the decrease in the frequency of faceted platforms. Tor Fawaz Layer B1 is plotted near the Wadi Aghar assemblages, and the surface collection is near Boker Tachtit Level 3 and Ksar Akil XXI. The shift from Layers B2-C1 to Layer B1/Surface is caused by the decrease in the unidirectional scar pattern and the concomitant increase in the bidirectional scar pattern (Table 12). This technological trend is apparently opposite to that at Boker Tachtit Levels 3-4 and similar to Ksar Akil XXII-XXI; however, it has to be considered with caution because of the surface collection that additionally suffers from small sample size. In addition, Layer B1 in Units 6-10 is directly exposed on the surface and is likely to have been reworked, as we discuss in the next section.

Although all the Tor Fawaz assemblages generally show the IUP techno-typological features, as described above, we note some mixtures of later UP artifacts. Firstly, four el-Wad points have been found in the 1994 trench (Kerry \& Henry, 2003). Three of them were found near the surface (Layer A), and another one was from the upper part of Layer B (Layer B1). Secondly, the Layer A assemblage shows a distinctively greater percentage of bladelets $(18 \%)$ in blanks and a greater ratio of bladelets to blades (0.89) in comparison with the other assemblages (Table 10). However, bladelets are still minor components in the Layer A and Layer B1 assemblages. Based on these observations, we suggest some mixtures of later UP artifacts in Layer A that also infiltrated to Layer B1 in the 1994 trench. The mixed bladelet artifacts are most likely from the Ahmarian that is known at other sites in the Jebel Qalkha area, such as Jebel Humeima, Tor Aeid, and Tor Hamar (Coinman \& Henry, 1995; Kerry, 1997; Williams, 1997). In contrast, we did not detect clear signatures of later lithic artifacts in Units 6-10 even in the collection from the surface where Layer B1 deposits are directly exposed.

\section{Depositional Processes and Chronology of the Tor Fawaz Assemblages}

Despite the IUP affiliation of most lithic artifacts at Tor Fawaz, the associated OSL and radiocarbon dates are widely distributed from 45 ka to 14 ka (Fig. 15). A major reason for this discrepancy is most likely the redeposition of the lithic artifacts, as exemplified by their distributions on surface and in Layer A that includes twigs and animal dung from recent use of the rockshelter as an animal pen. Thus, we discuss here the depositional processes according to the stratigraphy at Tor Fawaz by considering the results of the multiple analyses presented in this study (Table 16).

\section{Layer A}

Layer A was detected only in the 1994 trench, and it has the greatest density of lithic artifacts in this area (Fig. 5) consisting mostly of IUP lithic artifacts with some mixtures of Ahmarian artifacts. The high density and the mixture of IUP and Ahmarian artifacts are likely to have resulted from the deflation of pre-existing deposits (Layer B1 and an overlying Ahmarian deposits). The recent use of 


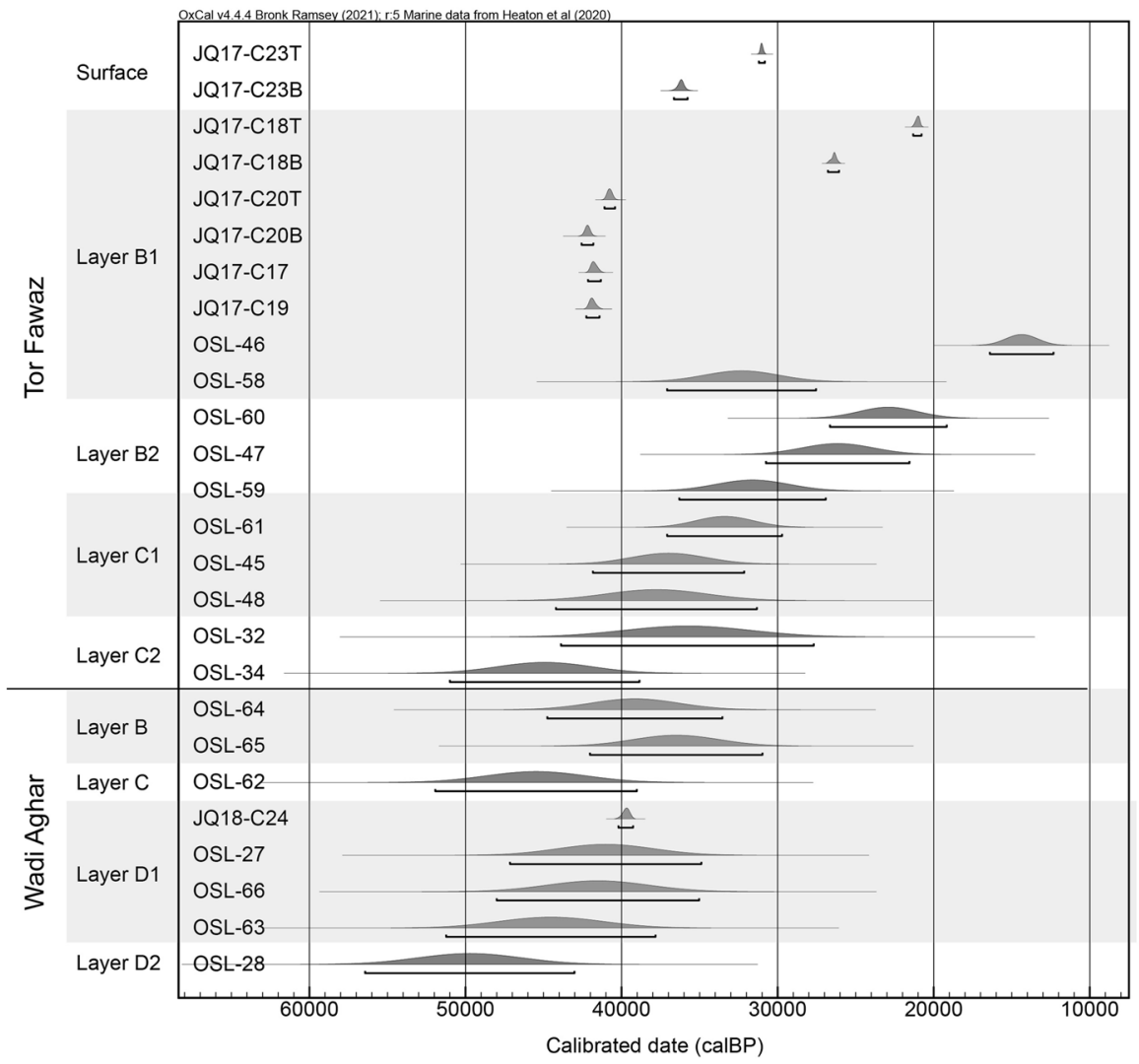

Fig. 15 Probability distributions of OSL and radiocarbon dates according to the stratigraphy at Tor Fawaz and Wadi Aghar. All the radiocarbon dates are from marine shells (a series of JQ17 and JQ18 numbers) and have been calibrated against the Marine20 curve in the OxCal v4.4.2 (Bronk Ramsey, 2009; Heaton et al., 2020)

the rockshelter as an animal pen resulted in the deposition of animal dung, twigs, and ash.

\section{Layer B1}

The lithic artifacts from Layer B1 also showed IUP techno-typological characteristics. However, a single el-Wad point was included in Layer B1 of the 1994 trench, indicating the infiltration of Ahmarian artifacts from Layer A. The mixture of Layer A deposits in Layer B1 was also indicated by the results of phytoliths and dung spherulite analyses (Table 16). These analyses were conducted specifically to examine whether modern animal dung in Layer A was mixed in the underlying layers. As a result, a sample from Layer B1 (No. 17) contained a combination of dung spherulites and phytoliths of dicotyledonous leaves, indicating some mixture with Layer A. 


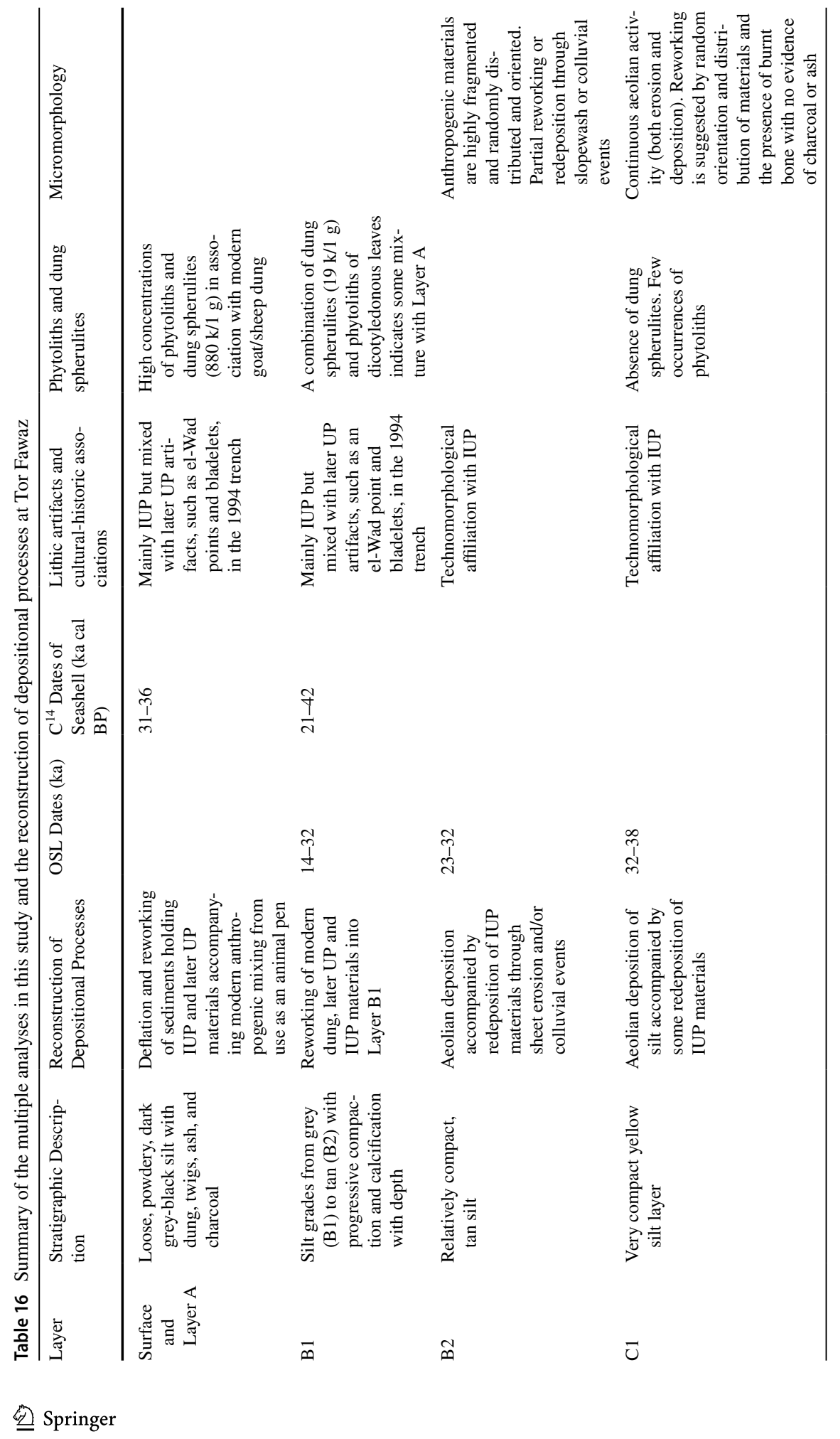




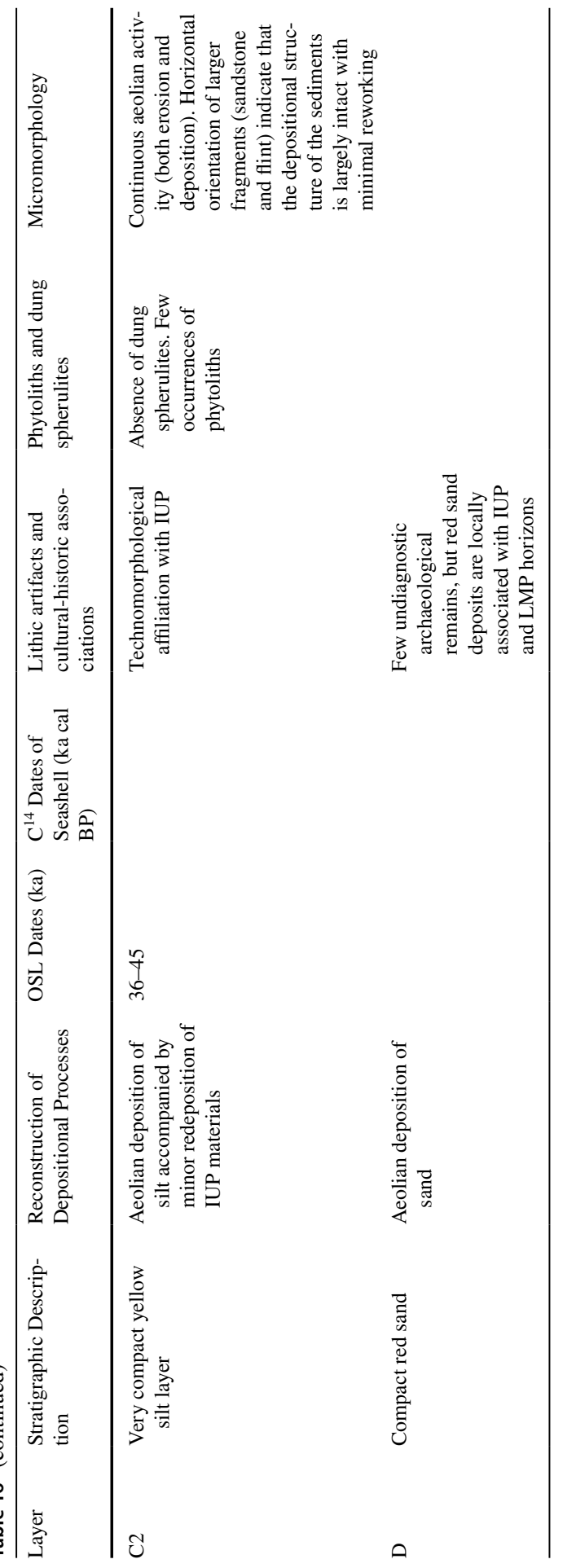




\section{Layer B2}

Layer B2 corresponds to the second highest density of lithic distributions (Fig. 5 and 6), and the Layer B2 assemblages show IUP techno-typological characteristics with no apparent mixture of later materials. Although Layer B2 was not analyzed for dung spherulites/phytoliths, the mixture of modern animal dung from Layer A is expected be minimum, if present, considering the significant drop of the dung spherulite density from Layer A $(880,000 / 1 \mathrm{~g})$ to Layer B1 $(19,000 / 1 \mathrm{~g})$ and its complete absence in the underlying Layer $\mathrm{C} 1$.

\section{Layers C1 and C2}

The density of lithic artifacts decreases in Layer C1, but the Layer C1 assemblage also shows IUP techno-typological characteristics, particularly in blade production technology (Fig. 14), as presented above. Layer C2 was detected only in the 1994 trench, and the Layer C2 assemblage is even smaller than Layer C1 However, the Layer C2 assemblage is characterized by the occurrence of end scrapers and a few Levallois-like blanks with no Levallois core (Table 7). Thus, we suggest it also affiliated with the IUP. The absence of later lithic artifacts in Layer C is consistent with the complete absence of dung spherulite (from surface deposits) in the Layer $\mathrm{C} 1 / \mathrm{C} 2$ samples (Table 5).

\section{Layer D}

Layer D, consisting of red sand, was only partially reached near the bedrock in the 1994 trench. The small extent of exposure yielded too few lithic artifacts to conduct techno-typological analysis. Like Layer C, no intrusion of dung spherulite from the surface was detected.

\section{Chronology of the IUP Assemblages at Tor Fawaz}

Based on the above discussion of depositional processes, we suggest that the OSL dates of Layer C2 (ca. 45-36 ka) as reliable chronological estimates for the IUP occupations at Tor Fawaz. This age partially overlaps with the OSL dates in Layer $\mathrm{C} 1$ and the radiocarbon dates of the marine shells associated with IUP artifacts. The younger OSL dates from Layers A-B2 likely represent the timing of redeposition. One marine shell (JQ17-C18), dated to ca. 26-21 ka cal BP, from Layer B1 probably originated from Ahmarian occupations that also left some lithic artifacts.

\section{Spatio-temporal Distributions and Variations of the IUP in the Levant}

The dates of Tor Fawaz and Wadi Aghar have greater overlap with those of the IUP layers at Ksar Akil and Ücağılı. The latter two sites' radiocarbon dates are distributed in the span between 46-41 ka cal BP. For example, the end of Ksar Akil Level XXI is estimated to 41.6-40.9 ka cal BP by Douka et al. (2013), and the start of 
Ksar Akil Level XXII is estimated to 44.9-43.6 ka cal BP by Bosch et al., (2015a, 2015b). Layers G-I at Ücağızlı are estimated to have formed between about 41.4-35 ka BP (ca. 45-40 ka cal BP) (Kuhn et al., 2009), which is similar to an estimate of 45-43 ka cal BP as a start date of Layers F-I by Douka (2013).

In southern Jordan, there are two more IUP sites, i.e., Tor Sadaf and Al-Ansab 2. The Tor Sadaf A and B assemblages are similar to each other in the production of elongated, convergent points with large striking platforms ("elongated Levallois-like points") from single platform cores, but Tor Sadaf B (later) can be distinguished from Tor Sadaf A (earlier) by some technological aspects, such as the decline of platform faceting and the increase in core tablets (Fox, 2003; Coinman and Fox, 2004). The lithics from Al-Ansab 2 also consist of robust blades and single platform blade cores (Richter et al., 2015) and more specifically characterized by the dominance of volumetric cores and the decline of convergent blanks according to Leder (2018). Although no radiometric dates have been obtained from the two sites, a technotypological study by Leder (2018) placed them in the technological groups (Bokerian B/C and Boker Tachtit 4) that are later than Boker Tachtit 1-2.

The increase of later IUP sites in southern Jordan, dated to ca. 45-36 ka according to Wadi Aghar and Tor Fawaz, may have been facilitated by climatic amelioration as the area is currently dominated by semi-arid and arid environments. According to paleoclimatic data from the Dead Sea, a period of 45-40 ka was associated with an increase in lake level, and the lithological facies of sediment cores show a shift towards wetter conditions at least until $35 \mathrm{ka}$ (Torfstein \& Enzel, 2017; Torfstein et al., 2015). A palynological study of the Lake Lisan sediments suggest that the Dead Sea region was climatically stable with constant moisture availability between 62.6 and $15.4 \mathrm{ka}$, as indicated by relatively high percentages of arboreal pollen or high ratios of Artemisia/Amaranthaceae that are linked to moister conditions (Miebach et al., 2019). In addition, a study of marine pollen record in the southeastern Mediterranean suggests a humid interval at 56-44 $\mathrm{ka}$ in the Levant (Langgut et al., 2018). According to this study, the humid interval consists of two phases corresponding to Dansgaard-Oeschger (D-O) interstadials 14 and 12, intervened by a dry spell of Heinrich event 5 (ca. 47-46 ka). The latter humid phase is temporally closer to the beginning of late IUP sites in southern Jordan.

We suggest that a time span estimated for the MP-UP transition at Kebara (49/48 to 47/46 ka: Rebollo et al., 2011) cannot be applied to other areas, where the IUP technology may have lasted until later. An exception is Manot, where the beginning of the Ahmarian was dated to $46 \mathrm{ka}$ cal BP (Alex et al., 2017). Interestingly, neither Kebara nor Manot has yielded IUP assemblages to date, and the assemblages at both sites belong to the northern Ahmarian variant (Abulafia et al., (in press); Kadowaki et al., 2015). In addition, a lithic assemblage from Mughr el-Hamamah (MHM) Layer B, dated to 45-39 ka cal BP (Stutz et al., 2015), has been designated as a variant of the Ahmarian (Shea et al., 2019). Accepting these dates means the contemporaneity of the Ahmarian at Kebara/Manot/MHM and the IUP in other areas in the Levant such as southern Jordan and the Negev. In addition, our age estimate for the IUP at Tor Fawaz (ca. 45-36 ka) overlaps with the age (ca. $38 \mathrm{ka}$ ) of the Ahmarian occupation at Al-Ansab 1 in southern Jordan (Richter et al., 2020). Given the possible contemporaneity of the IUP and Ahmarian, Stutz (2020) proposed that they 
represent two alternative technologies employed by the same forager social networks that spread across areas with variable ecological productivity, population density, and residential mobility.

On the other hand, we suggest it is also important to recognize the geographic differences in the trends of diachronic technological changes. As shown in Fig. 14, the IUP assemblages at Ksar Akil and Boker Tachtit initially showed a similar trend towards an increase in a unidirectional scar pattern. However, the Ksar Akil sequence subsequently shows a decline in the unidirectional pattern from Level XXI (caused by an increase in bidirectional flaking), while at Boker Tachtit unidirectional flaking continued to increase throughout levels 1-4. The increase in bidirectional flaking in the later layers at Ksar Akil is also paralleled by the stratigraphic sequence at Ücağılı, also located in the littoral zone of the northern Levant (Kuhn et al., 2009). This later technological trend in Ksar Akil and Ücağılı continued into their subsequent Ahmarian assemblages, resulting in a prominent trait of the northern Ahmarian variant. In contrast, the successive rise in unidirectional flaking seen in the IUP in the southern Levant continued this progression into the southern variant of the Ahmarian represented by Boker A and BE (Jones et al., 1983), Nahal Nizzana XIII (Davidzon \& Goring-Morris, 2003), the Lagama sites (Bar-Yosef \& Belfer, 1977), Abu Noshra I and II (Phillips, 1988), Tor Sadaf EUP (Fox, 2003), Tor Hamar (Coinman \& Henry, 1995), Tor Aeid (Williams, 1997), Jebel Humeima (Kerry, 1997), Al-Ansab 1 (Hauck, 2015; Hussain, 2015; Richter et al., 2020; Schyle, 2015), and others.

In the northern inland Levant, the IUP variant (Paléolithique intermédiaire) at Umm el-Tlel is characterized the production of elongated convergent blanks through unidirectional core flaking (Boëda \& Bonilauri, 2006; Boëda et al., 2015), and the dominant employment of unidirectional flaking continued to the blade/bladelet production in the overlying UP levels (Ploux \& Soriano, 2003). A similar UP blade/ bladelet assemblage, dominated by unidirectional flaking, has also been found at Wadi Kharar 16R in the same area (Kadowaki, 2018; Kadowaki et al., 2015), while no assemblage similar to the northern Ahmarian has so far been found in the northern inland Levant.

Consequently, we suggest that the geographically variable technological trajectories from the late IUP to the Ahmarian (or other early UP entities) can also serve as robust evidence in discussing cultural/social dynamics at the MP-UP transition. This is because the technological trajectories based on stratigraphic evidence are less vulnerable to chronological uncertainties arising from the difficulty in accurate dating for the period in question. Thus, even if the current chronology for the IUP or the Ahmarian are to be changed or refined in future, the regionally different cultural trajectories from the late IUP to the beginning of the Ahmarian will remain stable evidence for the geographically variable pattern of cultural changes that provide important implications for the forager social networks in the Levant and our understanding in how the MP-UP cultural transition took place (Meignen, 2012; Stutz, 2020). 


\section{Conclusion}

This paper presented lithic technological and chronological analyses of the Tor Fawaz assemblages along with micromorphology, phytolith and dung spherulite examinations to evaluate the formation and postdepositional processes of archaeological remains. As a result, the Tor Fawaz assemblages show general similarity to those of Boker Tachtit Level 4, Tor Sadaf A-B, and Wadi Aghar C-D1 that represent the late phase of the IUP in the southern Levant. Given the extensive redeposition/reworking in the upper layers (Layers A and B), we suggest that the OSL dates of Layer C (particularly Layer C2) as reliable chronological estimates for the IUP occupations at Tor Fawaz (ca. 45-36 ka). This overlaps with the radiocarbon dates of the marine shells (except for a single piece) associated with IUP artifacts.

Thus, Tor Fawaz IUP is temporally close to a nearby IUP occupation at Wadi Aghar C-D1 (ca. 45-40 ka), but the age of Tor Fawaz includes a younger range of post $40 \mathrm{ka}$. This chronological difference may be congruent with sedimentological and lithic technological differences between the two sites. Thus, the IUP occupations at Wadi Aghar and Tor Fawaz in the Jebel Qalkha area may represent slightly different phases that generally parallel the IUP sequence at Tor Sadaf, another IUP site in southern Jordan, and possibly post-date Boker Tachtit Level 4. This is a detailed recognition of lithic and chronological variability within the late IUP.

Based on these observations, we discussed the issue of partial contemporaneity between the Ahmarian and the late IUP assemblages, and more importantly stressed the geographically different trends in cultural changes from the late IUP to the Ahmarian. The latter phenomenon was likely linked to the formation of multiple forager communities that developed over different environmental areas, including the Mediterranean coast, the Jordan Valley, and the inland steppe. The IUP occurrences at Tor Fawaz and Wadi Aghar (and perhaps at Tor Sadaf and AlAnsab 2) represent the exploitation of the inland semi-arid zone that was probably facilitated by humid climatic conditions. Despite the formation of multiple local communities, the boundaries between them were not likely rigid but porous with occasional interactions as there were basic common grounds in the direction of lithic technological changes from the IUP to the Ahmarian, such as the increase in bladelet production with the development of the platform preparation technique (Kadowaki et al., 2021). More accurate chronological and cultural data are required to further our understanding of the MP-UP cultural transition.

Supplementary Information The online version contains supplementary material available at https://doi. org/10.1007/s41982-021-00107-3.

Acknowledgements This research derives from a joint project, entitled "Cultural history of PaleoAsia" directed by Yoshihiro Nishiaki (The University of Tokyo) and was supported by the MEXT KAKENHI (grant numbers 16H06409, 16H06410, 20H00026). We are grateful for a permission of fieldwork in south Jordan and generous supports from Yazid H. Elayan (Director General), Aktham Oweidi, and other staff members of the Department of Antiquities of Jordan. We also thank Manal Basiony and other members of the Aqaba Antiquities. The fieldwork in Jordan was accomplished by diligent work by crew members and local communities in the Humeima area. MP's work has been funded by the European Union's MICROARCHEODUNG project (under the Marie Sklodowska-Curie grant agreement No 
H2020-MSCA-IF-2015-702529) at the University of Reading, UK. The figures in this paper were created with assistance from Ayami Watanabe.

Author contribution Conceptualization and project administration: Seiji Kadowaki. Resources: Sate Massadeh. Investigation: Seiji Kadowaki, Toru Tamura, Risako Kida, Takayuki Omori, Lisa A. Maher, Marta Portillo, Masato Hirose, Eiki Suga. Writing—original draft: Seiji Kadowaki, Toru Tamura, Takayuki Omori, Lisa A. Maher, Marta Portillo. Funding acquisition: Seiji Kadowaki, Marta Portillo. Writing_review and editing and Supervision: Donald O. Henry.

Funding This research was supported by the Grants-in-Aid for Scientific Research from The Ministry of Education, Culture, Sports, Science and Technology, Japan (grant numbers 16H06409, 16H06410, 20H00026). MP's work has been funded by the European Union's MICROARCHEODUNG project (under the Marie Sklodowska-Curie grant agreement No H2020-MSCA-IF-2015-702529) at the University of Reading, UK.

Availability of data and material Not applicable.

Code availability Not applicable.

\section{Declarations}

Conflict of interest The authors declare no competing interests.

Open Access This article is licensed under a Creative Commons Attribution 4.0 International License, which permits use, sharing, adaptation, distribution and reproduction in any medium or format, as long as you give appropriate credit to the original author(s) and the source, provide a link to the Creative Commons licence, and indicate if changes were made. The images or other third party material in this article are included in the article's Creative Commons licence, unless indicated otherwise in a credit line to the material. If material is not included in the article's Creative Commons licence and your intended use is not permitted by statutory regulation or exceeds the permitted use, you will need to obtain permission directly from the copyright holder. To view a copy of this licence, visit http://creativecommons.org/licen ses/by/4.0/.

\section{References}

Abadi, I., Bar-Yosef, O., \& Belfer-Cohen, A. (2020). Kebara V: A contribution for the study of the Middle-Upper Paleolithic transition in the Levant. PaleoAnthropology, 2020, 1-28. https://doi. org/10.4207/PA.2020.ART139

Abulafia, T., Goder-Goldberger, M., Berna, F., Barzilai, O., \& Marder, O. (in press). A technotypological analysis of the Ahmarian and Levantine Aurignacian assemblages from Manot Cave (Area C) and the interrelation with site formation processes. Journal of Human Evolution, https://doi. org/10.1016/j.jhevol.2019.102707

Adamiec, G., \& Aitken, M. (1998). Dose-rate conversion factors: Update. Ancient TL, 16, 37-50.

Albert, R. M., \& Weiner, S. (2001). Study of phytoliths in prehistoric ash layers using a quantitative approach. In J. D. Meunier \& F. Colin (Eds.), Phytoliths, Applications in Earth Sciences and Human History (pp. 251-266). A.A. Balkema Publishers.

Albert, R. M., Shahack-Gross, R., Cabanes, D., Gilboa, A., Lev-Yadun, S., Portillo, M., Sharon, I., Boaretto, E., \& Weiner, S. (2008). Phytolith-rich Layers from the Late Bronze and Iron Ages at Tel Dor (Israel): Mode of formation and archaeological significance. Journal of Archaeological Science, 35, 57-75. https://doi.org/10.1016/j.jas.2007.02.015

Albert, R. M., Ruiz, J. A., \& Sans, A. (2016). PhytCore ODB: A new tool to improve efficiency in the management and exchange of information on phytoliths. Journal of Archaeological Science, 68, 98-105. https://doi.org/10.1016/j.jas.2015.10.014 
Alex, B., Barzilai, O., Hershkovitz, I., Marder, O., Berna, F., Caracuta, V., Abulafia, T., Davis, L., Goder-Goldberger, M., Lavi, R., Mintz, E., Regev, L., Bar-Yosef Mayer, D., Tejero, J.-M., Yeshurun. R., Ayalon, A., Bar-Matthews, M., Yasur, G., Frumkin, A., ... \& Boaretto, E. (2017). Radiocarbon chronology of Manot Cave, Israel and Upper Paleolithic dispersals. Science Advances, 3, e1701450. https://doi.org/10.1126/sciadv.1701450

Auclair, M., Lamothe, M., \& Huot, S. (2003). Measurement of anomalous fading for feldspar IRSL using SAR. Radiation Measurements, 37, 487-492. https://doi.org/10.1016/S1350-4487(03) 00018-0

Azoury, I. (1986). Ksar Akil Lebanon: A technological and typological analysis of the transitional and early Upper Palaeolithic levels of Ksar Akil and Abu Halka. Volume I: Levels XXV-XII. BAR International Series 289. Oxford: B.A.R..

Balescu, S., \& Lamothe, M. (1994). Comparison of TL and IRSL age estimates of feldspar coarse grains from waterlain sediments. Quaternary Science Reviews, 13, 437-444. https://doi.org/10. 1016/0277-3791(94)90056-6

Bar-Yosef, O. (2000). The Middle and Early Upper Paleolithic in southwest Asia and neighboring regions. In O. Bar-Yosef \& D. Pilbeam (Eds.), The geography of Neandertals and modern humans in Europe and the Greater Mediterranean (pp. 107-156). Harvard University.

Bar-Yosef, O. (2007). The archaeological framework of the Upper Paleolithic revolution. Diogenes, 54(3), 3-18. https://doi.org/10.1177/0392192107076869

Bar-Yosef, O., \& Belfer, A. (1977). The Lagaman industry. In O. Bar-Yosef, \& J.L., Phillips (Eds.), Prehistoric investigations in Gebel Maghara, northern Sinai (pp. 42-84). Jerusalem: The Hebrew University of Jerusalem.

Bar-Yosef, O., \& Belfer-Cohen, A. (2010a). The Levantine Upper Palaeolithic and Epipalaeolithic. In E. A. A. Garcea (Ed.), South-eastern Mediterranean peoples between 130,000 and 10,000 years ago (pp. 144-167). Oxbow Books.

Bar-Yosef, O., \& Belfer-Cohen, A. (2010b). The Middle to Upper Palaeolithic transition in western Asia. In K. W. Boyle, C. Gamble, \& O. Bar-Yosef (Eds.), The Upper Palaeolithic revolution in global perspective: Papers in honour of sir Paul Mellars (pp. 85-101). McDonald Institute for Archaeological research.

Belfer-Cohen, A., \& Goring-Morris, N. (2003). Final remarks and epilogue. In A.N. Goring-Morris, \& A. Belfer-Cohen (Eds.), More than meets the eye: Studies on Upper Palaeolithic diversity in the Near East (pp. 274-280). Oxford: Oxbow Books. https://doi.org/10.2307/j.ctvh1dwcq.28

Belfer-Cohen, A., \& Goring-Morris, N. (2014). The Upper Palaeolithic and earlier Epi-Palaeolithic of western Asia. In A. C. Renfrew \& P. G. Bahn (Eds.), The Cambridge World Prehistory (Vol. 3, pp. 1381-1407). Cambridge University Press.

Bell, W. T. (1980). Alpha dose attenuation in quartz grains for thermoluminescence dating. Ancient $T L, 12,4-8$.

Bergman, C. (1981). Point types in the Upper Palaeolithic sequence at Ksar 'Akil, Lebanon. In J. Cauvin \& P. Sanlaville (Eds.), Préhistoire du Levant (pp. 319-330). Centre National de la Recherche Scientifique.

Boaretto, E., Hernandez, M., Goder-Goldberger, M., Aldeias, V., Regev, L., Caracuta, V., McPherron, S. P., Hublin, J.-J., Weiner, S., \& Barzilai, O. (2021). The absolute chronology of Boker Tachtit (Israel) and implications for the Middle to Upper Paleolithic transition in the Levant. Proceedings of the National Academy of Sciences USA, 118, e2014657118. https://doi.org/10.1073/pnas.20146 57118

Boëda, E. (1994). Le Concept Levallois: Variabilité des Méthodes. Paris: Centre de la Recherche Scientifique (CNRS).

Boëda, E., \& Bonilauri, S. (2006). The intermediate Paleolithic: The first bladelet production 40,000 years ago. Anthropologie, XLIV/1, 75-92.

Boëda, E., Bonilauri, S., Kaltnecker, E., Valladas, H., \& Al-Sakhel, H. (2015). Un débitage lamellaire au Proche-Orient vers 40000 ans cal BP. Le site d'Umm el Tlel. Syrie Centrale. L'anthropologie, 119, 141-169. https://doi.org/10.1016/j.anthro.2015.04.001

Bosch, M. D., Mannino, M. A., Prendergast, A. L., O’Connell, T. C., Demarchi, B., Taylor, S. M., Niven, L., van der Plicht, J., \& Hublin, J.-J. (2015a). New chronology for Ksâr 'Akil (Lebanon) supports Levantine route of modern human dispersal into Europe. Proceedings of the National Academy of Sciences USA, 112, 7683-7688. https://doi.org/10.1073/pnas.1501529112 
Bosch, M.D., Mannino, M.A., Prendergast, A.L., O’Connell, T.C., Demarchi, B., Taylor, S.M., Niven, L., van der Plicht, J., \& Hublin, J.-J. (2015b). Reply to Douka et al.: critical evaluation of the Ksâr 'Akil chronologies. Proceedings of the National Academy of Sciences USA, 112, E7035. https://doi. org/10.1073/pnas.1520412112

Bronk Ramsey, C. (2009). Bayesian analysis of radiocarbon dates. Radiocarbon, 51(1), 337-360. https:// doi.org/10.1017/S0033822200033865

Brown, D. A. (1984). Prospects and limits of a phytolith key for grasses in the central United States. Journal of Archaeological Science, 11, 345-368. https://doi.org/10.1016/0305-4403(84)90016-5

Buylaert, J. P., Jain, M., Murray, A. S., Thomsen, K. J., Thiel, C., \& Sohbati, R. (2012). A robust feldspar luminescence dating method for Middle and Late Pleistocene sediments. Boreas, 41, 435-451. https://doi.org/10.1111/j.1502-3885.2012.00248.x

Buylaert, J. P., Murray, A. S., Thomsen, K. J., \& Jain, M. (2009). Testing the potential of an elevated temperature IRSL signal from K-feldspar. Radiation Measurements, 44, 560-565. https://doi.org/ 10.1016/j.radmeas.2009.02.007

Canti, M. G. (1999). The production and preservation of faecal spherulites: Animals, environment and taphonomy. Journal of Archaeological Science, 26, 251-258. https://doi.org/10.1006/jasc.1998. 0322

Coinman, N., \& Henry, D.O. (1995). The Upper Paleolithic sites. In D.O. Henry (Ed.), Prehistoric Cultural Ecology and Evolution: Insights from Southern Jordan (pp. 133-214). New York: Plenum Press. https://doi.org/10.1007/978-1-4757-2397-7_8

Copeland, L. (2000). Forty-six Emireh points from the Lebanon in the context of the Middle to Upper Paleolithic transition in the Levant. Paléorient, 26(1), 73-92.

Davidzon, A., \& Goring-Morris, A. (2003). Sealed in stone: The Upper Palaeolithic Early Ahmarian knapping method in the light of refitting studies at Nahal Nizzana XIII, western Negev, Israel. Journal of Israeli Prehistoric Society, 33, 75-205.

Demidenko, Y.E., Škrdla, P., \& Rychtař́ková, T. (2020). Initial Upper Paleolithic bladelet production: Bladelets in Moravian Bohunician. Přehled výzkumů, 61(1), 21-29. https://doi.org/10.47382/ pv0611-02

Dennell, R. (2020). From Arabia to the Pacific: How our species colonized Asia. Routledge.

Douka, K. (2013). Exploring "the great wilderness of prehistory": The chronology of the Middle to the Upper Paleolithic transition in the northern Levant. Mitteilungen Der Gesellschaft Für Urgeschichte, 22, 11-40.

Douka, K., Bergman, C. A., Hedges, R. E. M., Wesselingh, F. P., \& Higham, T. F. G. (2013). Chronology of Ksar Akil (Lebanon) and implications for the colonization of Europe by anatomically modern humans. PLoS ONE, 8, e72931. https://doi.org/10.1371/journal.pone.0072931

Douka, K., Hedges, R. E. M., \& Higham, T. F. G. (2010). Improved AMS 14C dating of shell carbonates using high-precision X-ray diffraction and a novel density separation protocol (CarDS). Radiocarbon, 52(2), 735-751. https://doi.org/10.1017/S0033822200045756

Durcan, J. A., King, G. E., \& Duller, G. A. (2015). DRAC: Dose rate and age calculator for trapped charge dating. Quaternary Geochronology, 28, 54-61. https://doi.org/10.1016/j.quageo.2015.03. 012

Eren, M. I., \& Lycett, S. J. (2012). Why Levallois? A morphometric comparison of experimental 'preferential' Levallois flakes versus debitage flakes. PLOS ONE, 7(1), e29273. https://doi.org/10.1371/ journal.pone.0029273

Fox, J. (2003). The Tor Sadaf lithic assemblages: A technological study of the Early Upper Palaeolithic in the Wadi al-Hasa. In A.N. Goring-Morris, \& A. Belfer-Cohen (Eds.), More than meets the eye: Studies on Upper Palaeolithic diversity in the Near East (pp. 80-94). Oxford: Oxbow Books. https://doi.org/10.2307/J.CTVH1DWCQ.13

Fox, J., \& Coinman, N. (2004). Emergence of the Levantine Upper Paleolithic. In P. Brantingham, S. Kuhn, \& K. Kerry (Eds.), The Early Upper Paleolithic beyond western Europe (pp. 97-112). Berkley: University of California Press. https://doi.org/10.1525/9780520930094-009

Fu, Q., Li, H., Moorjani, P., Jay, F., Slepchenko, S.M., Bondarev, A.A., Johnson, P.L.F., Aximu-Petri, A., Prüfer, K., de Filippo, C., Meyer, M., Zwyns, N., Salazar-García, D.C., Kuzmin, Y.V., Keates, S.G., Kosintsev, P.A., Razhev, D.I., Richards, M.P., Peristov, N.V., .. \& \& Pääbo, S. (2014). Genome sequence of a 45,000-year-old modern human from western Siberia. Nature, 514, 445-449. 
Fuchs, M. C., Kreutzer, S., Burow, C., Dietze, M., Fischer, M., Schmidt, C., \& Fuchs, M. (2015). Data processing in luminescence dating analysis: An exemplary workflow using the R package 'Luminescence.' Quaternary International, 362, 8-13. https://doi.org/10.1016/j.quaint.2014.06.034

Galbraith, R. F., Roberts, R. G., Laslett, G. M., Yoshida, H., \& Olley, J. M. (1999). Optical dating of single and multiple grains of quartz from jinmium rock shelter, northern Australia: Part 1, experimental design and statistical models. Archaeometry, 41, 339-364. https://doi.org/10.1111/j.1475-4754. 1999.tb00987.x

García-Suárez, A., Matthews, W., \& Portillo, M. (2021a). Micromorphology: Exploring micro-contextual traces of settled life at Çatalhöyük. In I. Hodder (Ed.), Peopling the landscape of Çatalhöyük. Reports from the 2009-2017 seasons, Çatalhöyük Research Project Series Volume 13 (pp. 263279), British Institute at Ankara, Monograph 54.

García-Suárez, A., Matthews, W., \& Portillo, M. (2021b). Micromorphology: Exploring micro-contextual traces of settled life at Çatalhöyük. In I. Hodder (Ed.), The environment and economy of Çatalhöyük East Mound based on the excavations 2009-2017, Çatalhöyük Research Project Volume 16.

Garrod, D. A. E. (1951). A transitional industry from the base of the Upper Palaeolithic in Palestine and Syria. The Journal of the Royal Anthropological Institute of Great Britain and Ireland, 81, 121-130. https://doi.org/10.2307/2844019

Garrod, D. A. E. (1955). The Mugharet el-Emireh in Lower Galilee: Type-station of the Emiran industry. The Journal of the Royal Anthropological Institute of Great Britain and Ireland, 85, 141-162. https://doi.org/10.2307/2844188

Goring-Morris, A.N., \& Belfer-Cohen, A. (2018). The Ahmarian in the context of the earlier Upper Palaeolithic in the Near East. In Y. Nishiaki, \& T. Akazawa (Eds.), The Middle and Upper Paleolithic of the Levant and beyond (pp. 87-104). Singapore: Springer Nature.

Goring-Morris, A. N., \& Belfer-Cohen, A. (2020). Noisy beginnings: The initial Upper Palaeolithic in Southwest Asia. Quaternary International, 551, 40-46. https://doi.org/10.1016/j.quaint.2020.01. 017

Green, R.E., Krause, J., Briggs, A.W., Maricic, T., Stenzel, U., Kircher, M., Patterson, N., Li, H., Zhai, W., Fritz, M.H., Hansen, N.F., Durand, E.Y., Malaspinas, A.S., Jensen, J.D., Marques-Bonet, T., Alkan, C., Prufer, K., Meyer, M., Burbano, H.A., ... \& Paabo, S. (2010). A draft sequence of the Neandertal genome. Science, 328, 710-722. https://doi.org/10.1126/science.1188021

Greenbaum, G., Friesem, D. E., Hovers, E., Feldman, M. W., \& Kolodny, O. (2019). Was inter-population connectivity of Neanderthals and modern humans the driver of the Upper Paleolithic transition rather than its product? Quaternary Science Reviews, 217, 316-329. https://doi.org/10.1016/j. quascirev.2018.12.011

Hauck, T. (2015). Dynamics of culture change at the beginning of the Near Eastern Upper Paleolithic. In D. Schyle \& J. Richter (Eds.), Pleistocene Archaeology of the Petra Area in Jordan (pp. 407-419). Verlag Marie Leidorf GmbH.

Hassan, F.A. (1995). Late Quaternary geology and geomorphology of the area in the vicinity of Ras en Naqb. In D.O. Henry (Ed.), Prehistoric Cultural Ecology and Evolution: Insights from Southern Jordan (pp. 23-31). New York: Plenum Press. https://doi.org/10.1007/978-1-4757-2397-7_2

Heaton, T. J., Köhler, P., Butzin, M., Bard, E., Reimer, R. W., Austin, W. E. N., Ramsey, C. B., Grootes, P. M., Hughen, K. A., Kromer, B., Reimer, P. J., Adkins, J., Burke, A., Cook, M. S., Olsen, J., \& Skinner, L. C. (2020). Marine20-The marine radiocarbon age calibration curve (0-55,000 cal BP). Radiocarbon, 62(4), 779-820. https://doi.org/10.1017/RDC.2020.68

Henry, D. O. (1994). Prehistoric cultural ecology in southern Jordan. Science, 265, 336-341. https://doi. org/10.1126/science.265.5170.336

Henry, D. O. (1995). Prehistoric cultural ecology and evolution. Plenum Press. https://doi.org/10.1007/ 978-1-4757-2397-7

Henry, D. O. (1997). Cultural and geologic successions of Middle and Upper Paleolithic deposits in the Jebel Qalkha area of southern Jordan. In H.-G. Gebel, Z. Kafafi, \& G. Rollefson (Eds.), The Prehistory of Jordan II: Perspectives from 1997 (pp. 69-76). Ex Orient.

Henry, D. O. (Ed.). (2003). Neanderthals in the Levant: Behavioral organization and the beginnings of human modernity. Continuum.

Henry, D.O. (2017a). The Middle Palaeolithic of southern Jordan. In Y. Enzel, \& O. Bar-Yosef (Eds.), Quaternary of the Levant: environments, climate change, and humans (pp. 585-591). Cambridge: Cambridge University Press. https://doi.org/10.1017/9781316106754.064 
Henry, D. O. (2017b). The Upper and Epipalaeolithic of southern Jordan. In Y. Enzel \& O. Bar-Yosef (Eds.), Quaternary of the Levant: Environments, climate change, and humans (pp. 659-667). Cambridge University Press.

Henry, D. O., \& Beaver, J. (Eds.). (2014). The sands of time: The desert Neolithic settlement at Ayn Abū Nukhayla. Ex Oriente.

Hovers, E. (2006). Neanderals and modern humans in the Middle Paleolithic of the Levant: What kind of interaction? In N. J. Conard (Ed.), When Neanderthals and modern humans met (pp. 65-85). Kerns Verlag.

Hovers, E. (2009). The lithic assemblages of Qafzeh Cave. Oxford University Press.

Hovers, E., \& Belfer-Cohen, A. (2013). On variability and complexity: Lessons from the Levantine Middle Paleolithic record. Current Anthropology, 54. Supplement, 8, S337-S357.

Hublin, J.-J. (2015). The modern human colonization of western Eurasia: When and where? Quaternary Science Reviews, 118, 194-210. https://doi.org/10.1016/j.quascirev.2014.08.011

Hublin, J.-J., Sirakov, N., Aldeias, V., Bailey, S., Bard, E., Delvigne, V., Endarova, E., Fagault, Y., Fewlass, H., Hajdinjak, M., Kromer, B., Krumov, I., Marreiros, J., Martisius, N.L., Paskulin, L., SinetMathiot, V., Meyer, M., Pääbo, S., Popov, V., ... \& Tsanova1, T. (2020). Initial Upper Palaeolithic Homo sapiens from Bacho Kiro Cave, Bulgaria. Nature, 581, 299-302. https://doi.org/10.1038/ S41586-020-2259-z

Huntley, D. J., \& Baril, M. R. (1997). The K content of the K-feldspars being measured in optical dating or in thermoluminescence dating. Ancient $T L, 15,11-13$.

Huntley, D. J., \& Lamothe, M. (2001). Ubiquity of anomalous fading in K-feldspars and the measurement and correction for it in optical dating. Canadian Journal of Earth Sciences, 38, 1093-1106. https:// doi.org/10.1139/e01-013

Hussain, S. T. (2015). Technological conduits along the Middle to Upper Palaeolithic transition in the southern Levant: Some conceptual considerations. In D. Schyle \& J. Richter (Eds.), Pleistocene Archaeology of the Petra Area in Jordan (pp. 395-406). Verlag Marie Leidorf GmbH.

Inizan, M.-L., Reduron-Ballinger, M., Roche, H., \& Tixier, J. (1999). Technology and terminology of knapped stone. Nanderre: CREP.

Jones, M., Marks, A. E., \& Kaufman, D. (1983). Boker: The artifacts. The Avdat/Aqev Area, Part 3In A. E. Marks (Ed.), Prehistory and Paleoenvironments in the Central Negev, Israel (Vol. III, pp. 283-329). Southern Methodist University.

Kadowaki, S. (2017). Technology of striking platform preparation on lithic debitage from Wadi Aghar, southern Jordan, and its relevance to the Initial Upper Palaeolithic technology in the Levant. Al-Rāfidān, 38, 23-32.

Kadowaki, S. (2018). Ahmarian or Levantine Aurignacian? Wadi Kharar 16R and new insights into the Upper Palaeolithic lithic technology in the northeastern Levant. In Y. Nishiaki, \& T. Akazawa (Eds.), The Middle and Upper Paleolithic Archeology of the Levant and Beyond (pp. 105-116). Singapore: Springer Nature.

Kadowaki, S., \& Henry, D.O. (2019). Renewed investigation of the Middle and Upper Paleolithic sites in the Jebel Qalkha area, southern Jordan. In S. Nakamura, T. Adachi, \& M. Abe (Eds.), Decades in deserts: essays on western Asian archaeology in honor of Sumio Fujii (pp. 23-41). Japan: Rokuichi Shobo.

Kadowaki, S., Kurozumi, T., \& Henry, D. O. (2019a). Marine shells from Tor Fawaz, southern Jordan, and their implications for behavioral changes from the Middle to Upper Paleolithic in the Levant. In Y. Nishiaki, \& O. Joris (Eds.), Learning among Neanderthals and Palaeolithic modern humans (pp. 161-178). Singapore: Springer Nature.

Kadowaki, S., Omori, T., \& Nishiaki, Y. (2015). Variability in Early Ahmarian lithic technology and its implications for the model of a Levantine origin of the Protoaurignacian. Journal of Human Evolution, 82, 67-87.

Kadowaki, S., Suga, E., \& Henry, D. (2021). Frequency and production technology of bladelets in Late Middle Paleolithic, Initial Upper Paleolithic, and Early Upper Paleolithic (Ahmarian) assemblages in Jebel Qalkha, southern Jordan. Quaternary International, 596, 4-21. https://doi.org/10.1016/j. quaint.2021.03.012

Kadowaki, S., Tamura, T., Sano, K., Kurozumi, T., Maher, L. A., Wakano, J. Y., Omori, T., Kida, R., Hirose, M., Massadeh, S., \& Henry, D. O. (2019b). Lithic technology, chronology, and marine shells from Wadi Aghar, southern Jordan, and Initial Upper Paleolithic behaviors in the southern inland Levant. Journal of Human Evolution, 135, 102646. https://doi.org/10.1016/j.jhevol.2019. 102646 
Katz, O., Cabanes, D., Weiner, S., Maeir, A. M., Boaretto, E., \& Shahack-Gross, R. (2010). Rapid phytolith extraction for analysis of phytolith concentrations and assemblages during an excavation: An application at Tell es-Safi/Gath, Israel. Journal of Archaeological Science, 37, 1557-1563. https:// doi.org/10.1016/j.jas.2010.01.016

Kerry, K.W. (1997). Jebel Humeima: A preliminary lithic analysis of an Ahmarian and Levantine Mousterian site in southwest Jordan. In H.G.K. Gebel, Z. Kafafi, \& G. Rollefson (Eds.), The prehistory of Jordan, II: perspectives from 1997 (pp. 125-136). Berlin: ex oriente.

Kerry, K.W., \& Henry, D.O. (2003). Tor Fawaz (J403): An Upper Paleolithic occupation in the Jebel Qalkha Area, southwest Jordan. In A.N. Goring-Morris, \& A. Belfer-Cohen (Eds), More than meets the eye: studies on Upper Palaeolithic diversity in the Near East (pp. 171-184). Oxford: Oxbow. https://doi.org/10.2307/J.CTVH1DWCQ.19

Kreutzer, S., Schmidt, C., Fuchs, M. C., Dietze, M., Fischer, M., \& Fuchs, M. (2012). Introducing an R package for luminescence dating analysis. Ancient TL, 30, 1-8.

Kuhn, S. L. (2003). In what sense is the Levantine Initial Upper Paleolithic a "transitional" industry? In J. Zilhão \& F. d'Errico (Eds.), The chronology of the Aurignacian and of the transitional technocomplexes: Dating, stratigraphies, cultural implications (pp. 61-70). Instituto Português de Arqueologia.

Kuhn, S., Stiner, M. C., Güleç, E., Özer, I., Yılmaz, H., Baykara, I., Ayşen, A., Goldberg, P., Martínez, M., \& K., Ünay. E., \& Suata-Alpaslan, F. (2009). The early Upper Paleolithic occupations at Ücağılı Cave (Hatay, Turkey). Journal of Human Evolution, 56, 87-113. https://doi.org/10.1016/j. jhevol.2008.07.014

Kuhn, S. L., \& Zwyns, N. (2014). Rethinking the initial Upper Paleolithic. Quaternary International, 347, 29-38. https://doi.org/10.1016/j.quaint.2014.05.040

Langgut, D., Almogi-Labin, A., Bar-Matthews, M., Pickarski, N., \& Weinstein-Evron, M. (2018). Evidence for a humid interval at $\sim 56-44 \mathrm{ka}$ in the Levant and its potential link to modern humans dispersal out of Africa. Journal of Human Evolution, 124, 75-90. https://doi.org/10.1016/j.jhevol. 2018.08.002

Leder, D. (2014). Technological and typological change at the Middle to Upper Palaeolithic boundary in Lebanon. Verlag Dr. Rudolf Habelt GmbH.

Leder, D. (2016). Core reduction strategies at the Initial Upper Palaeolithic sites Ksar Akil and Abou Halka in Lebanon. Lithics, 37, 33-54.

Leder, D. (2018). Lithic variability and techno-economy of the Initial Upper Palaeolithic in the Levant. International Journal of Archaeology, 6(1), 23-36. https://doi.org/10.11648/j.ija.20180601.14

Macphail, R.I., Courty, M.A., Hartner, J., \& Wattez, J. (1997). The soil micromorphological evidence of domestic occupation and stabling activities. In R. Maggi (Ed.), Arene Candide: A functional and environmental assessment of the holocene sequences excavated by Bernardo Brea (1940-1950). Memorie dell Instituto di Paleontologia Umana, vol. V (pp. 53-88). Roma: Il calamo.

Marks, A.E. (1976). Glossary. In A.E. Marks (Ed.), Prehistory and Paleoenvironments in the Central Negev, Israel, Volume I: The Avdat/Aqev Area, Part 1 (pp. 371-383). Dallas: Southern Methodist University.

Marks, A. E. (1983). The Middle to Upper Paleolithic transition in the Levant. In F. Wendorf \& A. E. Close (Eds.), Advances in world archaeology (Vol. 2, pp. 51-98). Academic Press.

Marks, A. E. (1993). The Early Upper Paleolithic: The view from the Levant. In H. Knecht, A. Pike-Tay, \& R. White (Eds.), Before Lascaux: The complex record of the Early Upper Paleolithic (pp. 5-21). CRC Press.

Marks, A. E., \& Ferring, C. R. (1988). The Early Upper Palaeolithic of the Levant. In J. E. Hoffecker \& C. A. Wolf (Eds.), The Early Upper Palaeolithic: Evidence from Europe and the Near East, BAR International Series 437 (pp. 43-72). B.A.R.

Marks, A., \& Kaufman, D. (1983). Boker Tachtit: The artifacts. In A. Marks (Ed.), Prehistory and paleoenvironments in the central Negev, Israel: The Avdat/Aqev area, Part 3 (pp. 69-125). Southern Methodist University.

Marks, A., \& Rose, J. (2012). Through a prism of paradigms: a century of research into the Upper Palaeolithic in the Levant. In M. Otte, \& F. Le Brun-Ricalens (Eds.), Modes of Contact and Mobility during the Eurasian Palaeolithic (pp. 63-93). Liége and Bertrange: ERAUL and ArchéoLogiques.

Meignen, L. (2012). Levantine perspectives on the Middle to Upper Paleolithic "transition." Archaeology Ethnology \& Anthropology of Eurasia, 40(3), 12-21. https://doi.org/10.1016/j.aeae.2012.11.003

Meignen, L. (2019). The Mousterian lithic assemblages from Kebara Cave. In L. Meignen, \& O. BarYosef (Eds.), Kebara Cave, Mt. Carmel, Israel: The Middle and Upper Paleolithic archaeology 
Part II (pp. 1-147). Massachusetts: Peabody Museum of Archaeology and Ethnology, Harvard University.

Mejdahl, V. (1979). Thermoluminescence dating: Beta-dose attenuation in quartz grains. Archaeometry, 21, 61-72. https://doi.org/10.1111/j.1475-4754.1979.tb00241.x

Miebach, A., Stolzenberger, S., Wacker, L., Hense, A., \& Litt, T. (2019). A new Dead Sea pollen record reveals the last glacial paleoenvironment of the southern Levant. Quaternary Science Reviews, 214, 98-116. https://doi.org/10.1016/j.quascirev.2019.04.033

Mulholland, S.C., \& Rapp Jr. G. (1992). A morphological clasification of grass silica-bodies. In G. Rapp Jr., \& S.C. Mulholland (Eds.), Phytolith systematics: Emerging issues, Advances in Archaeological and Museum Science (pp. 65-89). New York: Plenum Press. https://doi.org/10.1007/ 978-1-4899-1155-1_4

Neumann, K., Strömberg, A.E.C., Ball, T., Albert, R.M., Vrydaghs, L., Scott-Cummings, L. (International Committee for Phytolith Taxonomy ICPT). (2019). International code for phytolith nomenclature (ICPN) 2.0. Annals of Botany, 124, 189-199. https://doi.org/10.1093/aob/mcz064

Neuville, R. (1951). Le Paléolithique et le Mésolithique du Désert de Judée. Archives l'Institut de PaléontologieHumaine.

Nishiaki, Y. (1985). Truncated-faceted flakes from Levantine Mousterian assemblages. Bulletin of Department of Archaeology, the University of Tokyo 4, 215-226.

Nishiaki, Y. (2018). Initial Upper Paleolithic elements of the Keoue cave, Lebanon. In Y. Nishiaki, \& T. Akazawa (Eds.), The Middle and Upper Paleolithic of the Levant and beyond (pp. 71-86). Singapore: Springer Nature. https://doi.org/10.1007/978-981-10-6826-3_6

Ohnuma, K. (1988). Ksar 'Akil, Lebanon: A technological study of the earlier Upper Palaeolithic levels of Ksar 'Akil, vol. III. Levels XXV-XIV. BAR International Series 426. Oxford: B.A.R..

Ohnuma, K., \& Bergman, C. A. (1990). A technological analysis of the Upper Palaeolithic levels (XXVVI) of Ksar Akil, Lebanon. In P. Mellars (Ed.), The emergence of modern humans: An archaeological perspective (pp. 91-138). Edinburgh University.

Ohnuma, K., \& Bergman, C. A. (2013). Technological notes concerning "partially faceted butt" on débitage from the Initial and Early Upper Palaeolithic levels of Ksar Akil, Lebanon. Iranian Archaeology, 4, 7-14.

Phillips, J. L. (1988). The Upper Paleolithic of the Wadi Feiran, southern Sinai. Paléorient, 14, 183-200. https://doi.org/10.3406/paleo.1988.4467

Piperno, D. R. (1988). Phytolith analysis: An archaeological and geological perspective. Academic Press. https://doi.org/10.1002/gea.3340050207

Piperno, D. R. (2006). Phytoliths: A comprehensive guide for archaeologists and paleoecologists. AltaMira Press.

Ploux, S., \& Soriano, S. (2003). Umm el Tlel, une séquence du paléolithique supéieur en Syrie central: Industries lithiques et chronologie culturelle. Paléorient, 29(2), 5-34. https://doi.org/10.3406/ paleo.2003.4763

Portillo, M., Belarte, M. C., Ramon, J., Kallala, N., Sanmartí, J., \& Albert, R. M. (2017). An ethnoarchaeological study of livestock dung fuels from cooking installations in northern Tunisia. Quaternary International, 431, 131-144. https://doi.org/10.1016/j.quaint.2015.12.040

Portillo, M., Dudgeon, K., Allistone, G., Raeuf Aziz, K., \& Matthews, W. (2021). The taphonomy of plant and livestock dung microfossils: An ethnoarchaeological and experimental approach. Environmental Archaeology, 24(4), 439-454. https://doi.org/10.1080/14614103.2020.1800344

Portillo, M., García-Suárez, A., Klimowicz, A., Barański, M. Z., \& Matthews, W. (2019). Animal penning and open area activity at Neolithic Çatalhöyük Turkey. Journal of Anthropological Archaeology, 56, 101106. https://doi.org/10.1016/j.jaa.2019.101106

Portillo, M., García-Suárez, A., \& Matthews, W. (2020). Livestock faecal indicators for animal management, penning, foddering and dung use in early agricultural built environments in the Konya Plain Central Anatolia. Archaeological and Anthropological Sciences 12, 40. https://doi.org/10. 1007/s12520-019-00988-0

Portillo, M., Kadowaki, S., Nishiaki, Y., \& Albert, R. M. (2014). Early Neolithic household behavior at Tell Seker al-Aheimar (Upper Khabur, Syria): A comparison to ethnoarchaeological study of phytoliths and dung spherulites. Journal of Archaeological Science, 42, 107-118. https://doi. org/10.1016/j.jas.2013.10.038

Portillo, M., \& Matthews, W. (2020). Investigating use of space and human-animal interactions in agricultural built environments: The geo-ethnoarchaeology of livestock dung. In A. Otto, M. Herles, \& K. Kaniuth (Eds.), Proceedings of the 11th International Congress on the 
Archaeology of the Ancient Near East (pp. 497-508). Wiesbaden: Harrassowitz Verlag. https:// doi.org/10.2307/j.ctv10tq3v9.44

Portillo, M., Valenzuela, S., \& Albert, R. M. (2012). Domestic patterns in the Numidian site of Althiburos (northern Tunisia): The results from a combined study of animal bones, dung and plant remains. Quaternary International, 275, 84-96. https://doi.org/10.1016/j.quaint.2012.01.024

Prescott, J. R., \& Hutton, J. T. (1994). Cosmic ray contributions to dose rates for luminescence and ESR dating: Large depths and long-term time variations. Radiation Measurements, 23, 497500. https://doi.org/10.1016/1350-4487(94)90086-8

Rabb'a, I. (1987). Geological Map Sheet, 1:50000, Al Quwayra (3049 I). Amman: Hashemite Kingdom of Jordan, Ministry of Energy and Mineral Resources, National Resource Authority, Geology Directorate.

Rasmussen, P. (1993). Analysis of sheep/goat faeces from Egolzwil 3, Switzerland: Evidence for branch and twig foddering of livestock in the Neolithic. Journal of Archaeological Science, 20, 479-502.

Rebollo, N. R., Weiner, S., Brock, F., Meignen, L., Goldberg, P., Belfer-Cohen, A., Bar-Yosef, O., $\&$ Boaretto, E. (2011). New radiocarbon dating of the transition from the Middle to the Upper Paleolithic in Kebara Cave, Israel. Journal of Archaeological Science, 38, 2424-2433. https:// doi.org/10.1016/j.jas.2011.05.010

Reich, D. (2018). Who we are and how we got here: Ancient DNA and the new science of the human past. Vintage Books.

Reimer P.J., Austin, W.E.N., Bard, E., Bayliss, A., Blackwell, P.G., Ramsey, C.B., Butzin, M., Cheng, H., Edwards, R.L., Friedrich, M., Grootes, P.M., Guilderson, T.P., Hajdas, I., Heaton, T.J., Hogg, A.G., Hughen, K.A., Kromer, B., Manning, S.W., Muscheler, R., ... \& Talamo S. (2020). The IntCal20 northern hemisphere radiocarbon age calibration curve (0-55 cal k BP). Radiocarbon, 62(4), 725-757. https://doi.org/10.1017/RDC.2020.41

Richter, J., Litt, T., Lehmkuhl, F., Hense, A., Hauck, T. C., Leder, D. F., Miebach, A., Parow-Souchon, H., Sauer, F., Schoenenberg, J., Al-Nahar, M., \& Hussain, S. T. (2020). Al-Ansab and the Dead Sea: Mid-MIS 3 archaeology and environment of the early Ahmarian population of the Levantine corridor. PLoS ONE, 15(10), e0239968. https://doi.org/10.1371/journal.pone.02399 68

Richter, D., Schroeder, H. B., Rink, W. J., Julig, P. J., \& Schwarcz, H. P. (2001). The Middle to Upper Palaeolithic transition in the Levant and new thermoluminescence dates for a late Mousterian assemblage from Jerf al-Ajla Cave (Syria). Paléorient, 27(2), 29-46.

Richter, J., Schyle, D., \& Wolter, T. (2015). The CRC 806 "our way to Europe": Field campaigns into the archaeology of Wadi Sabra from 2008 to 2013. In D. Schyle \& J. Richter (Eds.), Pleistocene archaeology of the Petra area in Jordan (pp. 9-41). Verlag Marie Leidorf GmbH.

Rose, J. I., \& Marks, A. E. (2014). "Out of Arabia" and the Middle-Upper Palaeolithic transition in the southern Levant. Quartär, 61, 49-85. https://doi.org/10.7485/QU61_03

Rosen, A.M. (1992). Preliminary identification of silica skeletons from Near Eastern archaeological sites: An anatomical approach. In G. Rapp Jr., \& S.C. Mulholland (Eds.), Phytolith systematics: Emerging issues, Advances in Archaeological and Museum Science (pp. 129-147). New York: Plenum Press. https://doi.org/10.1007/978-1-4899-1155-1_7

Sánchez-Quinto, F., Botigué, L.R. Civit, S., Arenas, C., Ávila-Arcos, M. C. Bustamante, C. D., Comas, D., \& Lalueza-Fox, C. (2012). North African populations carry the signature of admixture with Neandertals. PLoS ONE, 7(10), e47765. https://doi:https://doi.org/10.1371/journal.pone.0047765

Schyle, D. (2015). The Ahmarian site of al-Ansab 1. In D. Schyle \& J. Richter (Eds.), Pleistocene archaeology of the Petra area in Jordan (pp. 91-129). Verlag Marie Leidorf GmbH.

Shea, J. (2007). Behavioral differences between Middle and Upper Paleolithic Homo sapiens in the East Mediterranean Levant: The roles of intraspecific competition and dispersal from Africa. Journal of Anthropological Research, 63(4), 449-488. https://doi.org/10.3998/jar.0521004.0063.401

Shea, J. (2008). Transitions or turnovers? Climatically-forced extinctions of Homo sapiens and Neanderthals in the east Mediterranean Levant. Quaternary Science Reviews, 27, 2253-2270. https://doi. org/10.1016/j.quascirev.2008.08.015

Shea, J. (2013). Stone tools in the Paleolithic and Neolithic Near East: A guide. Cambridge University Press. https://doi.org/10.1017/S0959774314000134

Shea, J., Stutz, A. J., \& Nilsson-Stutz, L. (2019). An Early Upper Palaeolithic stone tool assemblage from Mughr El-Hamamah, Jordan: An interim report. Journal of Field Archaeology, 44(7), 420-439. https://doi.org/10.1080/00934690.2019.1655519 
Solecki, R. L., \& Solecki, R. S. (1970). A new secondary flaking technique at the Nahr Ibrahim Cave site (Lebanon). Bulletin Musée De Beyrouth, 23, 137-142.

Stoops, G. (2003). Guidelines for analysis and description of soil and regolith thin sections. Soil Science Society of America.

Stutz, A.J. (2020). The Middle-Upper Paleolithic transition: A long-term biocultural effect of anatomically modern human dispersal. In H.S. Groucutt (Ed.), Culture history and convergent evolution: Can we detect populations in prehistory? (pp. 157-186). Cham: Springer Nature Switzerland AG. https://doi.org/10.1007/978-3-030-46126-3_9

Stutz, A. J., Shea, J. J., Rech, J. A., Pigati, J. S., Wilson, J., Belmaker, M., Albert, R. M., Arpin, T., Cabanes, D., Clark, J. L., Hartman, G., Hourani, F., White, C. E., \& Stutz, L. N. (2015). Early Upper Paleolithic chronology in the Levant: New ABOx-SC accelerator mass spectrometry results from the Mughr el-Hamamah Site, Jordan. Journal of Human Evolution, 85, 157-173. https://doi. org/10.1016/j.jhevol.2015.04.008

Thomsen, K. J., Murray, A. S., Jain, M., \& Bøtter-Jensen, L. (2008). Laboratory fading rates of various luminescence signals from feldspar-rich sediment extracts. Radiation Measurements, 43, 1474 1486. https://doi.org/10.1016/j.radmeas.2008.06.002

Tixier, J. (1963). Typologie de I'Epipaléolithique du Maghreb. Mémoires du Centre de Recherches Anthropologiques, Préhistoriques et Ethnographiques 2. Paris: Arts et Métiers Graphiques.

Torfstein, A., \& Enzel, Y. (2017). Dead Sea lake level changes and Levant palaeoclimate. In Y. Enzel, \& O. Bar-Yosef (Eds.), Quaternary of the Levant: environments, climate change, and humans (pp. 115-125). Cambridge: Cambridge University Press. https://doi.org/10.1017/9781316106754.013

Torfstein, A., Goldstein, S. L., Kushnir, Y., Enzel, Y., Haug, G., \& Stein, M. (2015). Dead Sea drawdown and monsoonal impacts in the Levant during the last interglacial. Earth and Planetary Science Letters, 412, 235-244. https://doi.org/10.1016/j.epsl.2014.12.013

Tsartsidou, G., Lev-Yadun, S., Efstratiou, N., \& Weiner, S. (2008). Ethnoarchaeological study of phytolith assemblages from an agro-pastoral village in Northern Greece (Sarakini): Development and application of a Phytolith Difference Index. Journal of Archaeological Science, 35, 600-613. https://doi.org/10.1016/j.jas.2007.05.008

Twiss, P.C. (1992). Predicted world distribution of C3 and C4 grass phytoliths. In G. Rapp Jr., \& S.C. Mulholland (Eds.), Phytolith systematics: Emerging issues, Advances in Archaeological and Museum Science (pp. 113-128). New York: Plenum Press. https://doi.org/10.1007/ 978-1-4899-1155-1_6

Twiss, P. C., Suess, E., \& Smith, R. M. (1969). Morphological classification of grass phytoliths. Soil Science Society of America Proceedings, 33, 109-115. https://doi.org/10.2136/sssaj1969.0361599500 3300010030x

Volkman, P. (1983). Boker Tachtit: Core reconstructions. In A. Marks (Ed.), Prehistory and paleoenvironments in the central Negev, Israel: The Avdat/Aqev area, Part 3 (pp. 127-190). Southern Methodist University.

Williams, J.K. (1997). Tor Aeid: An Upper Paleolithic occupation in southern Jordan. In H.G.K. Gebel, Z. Kafafi, \& G. Rollefson (Eds.), The Prehistory of Jordan, II: Perspectives from 1997 (pp. 137148). Berlin: ex oriente.

Wiseman, M.F. (1993). Lithic blade elements from the southern Levant: A diachronic view of changing technology and design process. Mitekufat Haeven-Journal of the Israel Prehistoric Society, 25, 13-102.

Zwyns, N., Paine, C.H., Tsedendorj, B., Talamo, S., Fitzsimmons, K.E., Gantumur, A., Guunii, L., Davakhuu, O., Flas, D., Dogandžić, T., Doerschner, N., Welker, F., Gillam, J.C., Noyer, J.B., Bakhtiary, R.S., Allshouse, A.F., Smith, K.N., Khatsenovich, A.M., Rybin, E.P., ..., \& Hublin, J.-J. (2019). The northern route for human dispersal in Central and Northeast Asia: New evidence from the site of Tolbor-16, Mongolia. Scientific Reports, 9, 11759. https://doi.org/10.1038/ s41598-019-47972-1

Zwyns, N., Rybin, E. P., Hublin, J.-J., \& Derevianko, A. P. (2012). Burin-core technology and laminar reduction sequences in the initial Upper Paleolithic from Kara-Bom (Gorny-Altai, Siberia). Quaternary International, 259, 33-47. https://doi.org/10.1016/j.quaint.2011.03.036

Publisher's Note Springer Nature remains neutral with regard to jurisdictional claims in published maps and institutional affiliations. 


\section{Authors and Affiliations}

\section{Seiji Kadowaki ${ }^{1}$ (D) Toru Tamura ${ }^{2,9}$ (D) Risako Kida $^{3} \cdot$ Takayuki Omori $^{4}$.} Lisa A. Maher ${ }^{5} \cdot$ Marta Portillo $^{6} \cdot$ Masato Hirose $^{3} \cdot$ Eiki Suga $^{3} \cdot$ Sate Massadeh $^{7}$. Donald O. Henry ${ }^{8}$

1 Nagoya University Museum, Nagoya University, Furo-cho, Chikusa-ku, Nagoya 464-8601, Japan

2 Geological Survey of Japan, AIST, 1-1-1 Higashi, Ibaraki 305-8567 Tsukuba, Japan

3 Graduate School of Environmental Studies, Nagoya University, Furo-cho, Chikusa-ku, Nagoya 464-8601, Japan

4 The University Museum, The University of Tokyo, Hongo 7-3-1, Bunkyo, Tokyo 113-0033, Japan

5 Department of Anthropology, University of California, Berkeley, 232 Anthropology and Art Practice Building, Berkeley, CA 94720-3710, USA

6 Department of Archeology and Anthropology, Archaeology of Social Dynamics (2017SGR 995), Institució Milà i Fontanals, Spanish National Research Council (CSIC), Egipcíaques, 15, 08001 Barcelona, Spain

7 Department of Antiquities of Jordan, Jebal Amman, Third Circle, Abdel Moneim Street, Building No. 21, Amman, Jordan

8 Department of Anthropology, University of Tulsa, Tulsa, OK 74104, USA

9 Graduate School of Frontier Sciences, The University of Tokyo, Chiba 277-8561 Kashiwa, Japan 